\title{
The Brazilian developments on the Regional Atmospheric Modeling System (BRAMS 5.2): an integrated environmental model tuned for tropical areas
}

Saulo R. Freitas ${ }^{1, a}$, Jairo Panetta ${ }^{2}$, Karla M. Longo ${ }^{1, \text { a }}$, Luiz F. Rodrigues ${ }^{1}$, Demerval S. Moreira ${ }^{3,4}$, Nilton E. Rosário ${ }^{5}$, Pedro L. Silva Dias ${ }^{6}$, Maria A. F. Silva Dias ${ }^{6}$, Enio P. Souza ${ }^{7}$, Edmilson D. Freitas ${ }^{6}$, Marcos Longo $^{8}$, Ariane Frassoni $^{1}$, Alvaro L. Fazenda ${ }^{9}$, Cláudio M. Santos e Silva ${ }^{10}$, Cláudio A. B. Pavani ${ }^{1}$, Denis Eiras ${ }^{1}$, Daniela A. França ${ }^{1}$, Daniel Massaru ${ }^{1}$, Fernanda B. Silva ${ }^{1}$, Fernando C. Santos ${ }^{11}$, Gabriel Pereira ${ }^{12}$, Gláuber Camponogara ${ }^{6}$, Gonzalo A. Ferrada ${ }^{1}$, Haroldo F. Campos Velho ${ }^{13}$, Isilda Menezes ${ }^{14,15}$, Julliana L. Freire ${ }^{1}$, Marcelo F. Alonso ${ }^{16}$, Madeleine S. Gácita ${ }^{1}$, Maurício Zarzur ${ }^{13}$, Rafael M. Fonseca ${ }^{1}$, Rafael S. Lima ${ }^{1}$, Ricardo A. Siqueira ${ }^{1}$, Rodrigo Braz ${ }^{1}$, Simone Tomita ${ }^{1}$, Valter Oliveira ${ }^{1}$, and Leila D. Martins ${ }^{17}$

${ }^{1}$ Centro de Previsão de Tempo e Estudos Climáticos, Instituto Nacional de Pesquisas Espaciais, Cachoeira Paulista, SP, Brazil

${ }^{2}$ Divisão de Ciência da Computação, Instituto Tecnológico de Aeronáutica, São José dos Campos, SP, Brazil

${ }^{3}$ Universidade Estadual Paulista (Unesp), Faculdade de Ciências, Bauru, SP, Brazil

${ }^{4}$ Centro de Meteorologia de Bauru (IPMet), Bauru, SP, Brazil

${ }^{5}$ Departamento de Ciências Ambientais, Universidade Federal de São Paulo, Diadema, SP, Brazil

${ }^{6}$ Instituto de Astronomia, Geofísica e Ciências Atmosféricas, Universidade de São Paulo, São Paulo, SP, Brazil

${ }^{7}$ Departamento de Ciências Atmosféricas, Universidade Federal de Campina Grande, Campina Grande, PB, Brazil

${ }^{8}$ Embrapa Informática Agropecuária, Campinas, SP, Brazil

${ }^{9}$ Instituto de Ciência e Tecnologia, Universidade Federal de São Paulo, São José dos Campos, SP, Brazil

${ }^{10}$ Departamento de Ciências Atmosféricas e Climáticas/Programa de Pós graduação em ciências Climáticas, Universidade Federal do Rio Grande do Norte, Natal, RN, Brazil

${ }^{11}$ Centro de Ciências do Sistema Terrestre, Instituto Nacional de Pesquisas Espaciais, São Jose dos Campos, SP, Brazil

${ }^{12}$ Departamento de Geociências, Universidade Federal de São João del-Rei, MG, Brazil

${ }^{13}$ Laboratório Associado de Computação e Matemática Aplicada, Instituto Nacional de Pesquisas Espaciais, São José dos Campos, SP, Brazil

${ }^{14}$ Instituto de Ciências Agrárias e Ambientais Mediterrânicas, Universidade de Évora, Évora, Portugal

${ }^{15}$ Centro Interdisciplinar de Desenvolvimento em Ambiente, Gestão Aplicada e Espaço, Universidade Lusófona de Humanidades e Tecnologia, Campo Grande, Lisbon, Portugal

${ }^{16}$ Faculdade de Meteorologia, Universidade Federal de Pelotas, Pelotas, RS, Brazil

${ }^{17}$ Universidade Tecnológica Federal do Paraná, Londrina, PR, Brazil

anow at: Universities Space Research Association/Goddard Earth Sciences Technology and Research at the Global Modeling and Assimilation Office, NASA Goddard Space Flight Center, Greenbelt, MD, USA

Correspondence to: Saulo R. Freitas (saulo.r.freitas@nasa.gov)

Received: 1 June 2016 - Published in Geosci. Model Dev. Discuss.: 7 June 2016

Revised: 14 December 2016 - Accepted: 20 December 2016 - Published: 13 January 2017 
Abstract. We present a new version of the Brazilian developments on the Regional Atmospheric Modeling System (BRAMS), in which different previous versions for weather, chemistry, and carbon cycle were unified in a single integrated modeling system software. This new version also has a new set of state-of-the-art physical parameterizations and greater computational parallel and memory usage efficiency. The description of the main model features includes several examples illustrating the quality of the transport scheme for scalars, radiative fluxes on surface, and model simulation of rainfall systems over South America at different spatial resolutions using a scale aware convective parameterization. Additionally, the simulation of the diurnal cycle of the convection and carbon dioxide concentration over the Amazon Basin, as well as carbon dioxide fluxes from biogenic processes over a large portion of South America, are shown. Atmospheric chemistry examples show the model performance in simulating near-surface carbon monoxide and ozone in the Amazon Basin and the megacity of Rio de Janeiro. For tracer transport and dispersion, the model capabilities to simulate the volcanic ash 3-D redistribution associated with the eruption of a Chilean volcano are demonstrated. The gain of computational efficiency is described in some detail. BRAMS has been applied for research and operational forecasting mainly in South America. Model results from the operational weather forecast of BRAMS on $5 \mathrm{~km}$ grid spacing in the Center for Weather Forecasting and Climate Studies, INPE/Brazil, since 2013 are used to quantify the model skill of near-surface variables and rainfall. The scores show the reliability of BRAMS for the tropical and subtropical areas of South America. Requirements for keeping this modeling system competitive regarding both its functionalities and skills are discussed. Finally, we highlight the relevant contribution of this work to building a South American community of model developers.

\section{Introduction}

The Brazilian developments on the Regional Atmospheric Modeling System version 5.2 (hereafter, BRAMS 5.2) is derived from the Regional Atmospheric Modeling System (RAMS, Pielke et al., 1992; Cotton et al., 2003) originally developed at Colorado State University in the USA. BRAMS/RAMS are multipurpose numerical weather prediction models designed to simulate atmospheric circulations spanning from planetary-scale waves down to large eddies of the planetary boundary layer. RAMS has progressed with its development, which includes, but is not limited to, its coupling to a biogeochemistry model (Eastman et al., 2001a, b; Lu et al., 2001), air quality applications (Lyons et al., 1995; Pielke and Uliasz, 1998), and, more recently, a climate application over South America (Beltran-Przekurat et al., 2011). On the other side, BRAMS developed its own identity and diverged from RAMS with several new features and modifications that have been included mainly to improve the numerical representation of fundamental physical processes in tropical and subtropical regions (S. R. Freitas et al., 2005, 2009). Additionally, BRAMS includes an urban surface scheme coupled with a photochemical model (E. D. Freitas et al., 2005, 2007), a complete in-line module for atmospheric chemistry and aerosol processes (Longo et al., 2013), as well as a state-of-the-art surface scheme to simulate the energy, water, carbon, and other biogeochemical cycles (Moreira et al., 2013), which extend RAMS original functionalities (as a reference, please see Table B in Pielke, 2013) towards a fully integrated environmental model.

Back in the 1990s, a consortium between the ATMET (Atmospheric, Meteorological, and Environmental Technologies) company from the United States, the Institute of Mathematics and Statistics (IME), the Institute of Astronomy, Geophysics and Atmospheric Sciences (IAG) of the University of São Paulo (USP) and the Center for Weather Forecasting and Climate Studies of the Brazilian National Institute for Space Research (CPTEC/INPE) started the BRAMS project funded by the Brazilian Funding Agency of Studies and Projects (FINEP). Nowadays, BRAMS is one of the models operationally used at CPTEC and in several other regional weather forecast centers in Brazil. At CPTEC, a previous version of BRAMS has been applied since 2003 for air quality forecasting over a domain that encompasses the entire South America with a grid spacing of $25 \mathrm{~km}$. Simultaneous (in-line) predictions of weather and atmospheric composition are available in real time, including smoke from vegetation fires. Since 1 January 2013, BRAMS has been running operationally on the CPTEC's supercomputer, using 9600 cores, to process twice a day regional weather forecasts on $5 \mathrm{~km}$ grid spacing and over a domain covering the entire South America and the neighboring oceans.

BRAMS has also been applied for numerical studies in several universities and research centers addressing local storms, urban heat islands, urban and remote (e.g. fire emissions) air pollution, aerosol-cloud-radiation interactions, carbon and water cycles over the Amazon, volcanic ash dispersion, etc. Numerous $\mathrm{PhD}$ theses and Master dissertations, including at institutions outside Brazil, have been written on BRAMS developments and applications.

From the computational point of view, improved code structure and optimization ensure great scalability in several architectures. BRAMS runs on massively parallel supercomputers, clusters, and personal x86 systems with high efficiency. BRAMS development follows a modular approach to code design, allowing users to write and plug in additional modules as necessary. BRAMS and its components are open source and available under the GNU General Public License at the webpage http://brams.cptec.inpe.br.

As shown in the present paper and references herein, the current BRAMS version has capabilities analogous to the state-of-the-art limited area integrated atmospheric chem- 
istry transport models such as WRF-Chem (Grell et al., 2005) and COSMO-ART (Vogel et al., 2009).

This paper is organized as follows. Section 2 introduces the modeling system focusing on the novelty in comparison with the original RAMS code. In Sect. 3 we highlight the main applications of BRAMS for operational forecast of weather and integrated weather and chemistry in South America. Section 4 summarizes the model accomplishments, and Sect. 5 instructs readers about the code availability and access.

\section{Model system description}

BRAMS solves the compressible non-hydrostatic equations described by Tripoli and Cotton (1982), reproduced here though omitting the horizontal and vertical grid transformations for convenience. The equations of motion are

$$
\begin{aligned}
\frac{\partial u}{\partial t} & =-u \frac{\partial u}{\partial x}-v \frac{\partial u}{\partial y}-w \frac{\partial u}{\partial z}-\theta \frac{\partial \pi^{\prime}}{\partial x}+f v+\frac{\partial}{\partial x}\left(K_{\mathrm{m}} \frac{\partial u}{\partial x}\right) \\
+ & \frac{\partial}{\partial y}\left(K_{\mathrm{m}} \frac{\partial u}{\partial y}\right)+\frac{\partial}{\partial z}\left(K_{\mathrm{m}} \frac{\partial u}{\partial z}\right), \\
\frac{\partial v}{\partial t} & =-u \frac{\partial v}{\partial x}-v \frac{\partial v}{\partial y}-w \frac{\partial v}{\partial z}-\theta \frac{\partial \pi^{\prime}}{\partial y}-f u+\frac{\partial}{\partial x}\left(K_{\mathrm{m}} \frac{\partial v}{\partial x}\right) \\
& +\frac{\partial}{\partial y}\left(K_{\mathrm{m}} \frac{\partial v}{\partial y}\right)+\frac{\partial}{\partial z}\left(K_{\mathrm{m}} \frac{\partial v}{\partial z}\right), \\
\frac{\partial w}{\partial t} & =-u \frac{\partial w}{\partial x}-v \frac{\partial w}{\partial y}-w \frac{\partial w}{\partial z}-\theta \frac{\partial \pi^{\prime}}{\partial z}-\frac{g \theta_{\mathrm{v}}^{\prime}}{\theta_{0}} \\
& +\frac{\partial}{\partial x}\left(K_{\mathrm{m}} \frac{\partial w}{\partial x}\right)+\frac{\partial}{\partial y}\left(K_{\mathrm{m}} \frac{\partial w}{\partial y}\right)+\frac{\partial}{\partial z}\left(K_{\mathrm{m}} \frac{\partial w}{\partial z}\right) .
\end{aligned}
$$

The thermodynamic equation is

$$
\begin{aligned}
& \frac{\partial \theta_{\mathrm{il}}}{\partial t}=-u \frac{\partial \theta_{\mathrm{il}}}{\partial x}-v \frac{\partial \theta_{\mathrm{il}}}{\partial y}-w \frac{\partial \theta_{\mathrm{il}}}{\partial z}+\frac{\partial}{\partial x}\left(K_{\mathrm{h}} \frac{\partial \theta_{\mathrm{il}}}{\partial x}\right) \\
&+ \frac{\partial}{\partial y}\left(K_{\mathrm{h}} \frac{\partial \theta_{\mathrm{il}}}{\partial y}\right)+\frac{\partial}{\partial z}\left(K_{\mathrm{h}} \frac{\partial \theta_{\mathrm{il}}}{\partial z}\right)+\left(\frac{\partial \theta_{\mathrm{il}}}{\partial t}\right)_{\mathrm{rad}} \\
&+\left(\frac{\partial \theta_{\mathrm{il}}}{\partial t}\right)_{\text {mic }}+\left(\frac{\partial \theta_{\mathrm{il}}}{\partial t}\right)_{\mathrm{con}} .
\end{aligned}
$$

The water species mixing ratio continuity equation reads as

$$
\begin{aligned}
\frac{\partial r_{n}}{\partial t} & =-u \frac{\partial r_{n}}{\partial x}-v \frac{\partial r_{n}}{\partial y}-w \frac{\partial r_{n}}{\partial z}+\frac{\partial}{\partial x}\left(K_{\mathrm{h}} \frac{\partial r_{n}}{\partial x}\right) \\
+ & \frac{\partial}{\partial y}\left(K_{\mathrm{h}} \frac{\partial r_{n}}{\partial y}\right)+\frac{\partial}{\partial z}\left(K_{\mathrm{h}} \frac{\partial r_{n}}{\partial z}\right)+\left(\frac{\partial r_{n}}{\partial t}\right)_{\text {mic }} \\
+ & \left(\frac{\partial r_{T}}{\partial t}\right)_{\text {con }} .
\end{aligned}
$$

Finally, for mass continuity, RAMS solves the equation, expressed in terms of the Exner function:

$$
\frac{\partial \pi^{\prime}}{\partial t}=-\frac{R \pi_{0}}{c_{v} \rho_{0} \theta_{0}}\left(\frac{\partial \rho_{0} \theta_{0} u}{\partial x}+\frac{\partial \rho_{0} \theta_{0} v}{\partial y}+\frac{\partial \rho_{0} \theta_{0} w}{\partial z}\right) .
$$

The previous equations are all Reynolds-averaged and the prognostic variables have the usual meaning (see Table 1). BRAMS is equipped with a multiple-grid one-way nesting scheme to perform downscaling on computational meshes of increasing spatial resolution. Original capabilities and physical formulations available within the RAMS model and inherited by BRAMS are described in Cotton et al. (2003), and Table B in Pielke (2013), and references therein, where the readers are asked to search for further information about RAMS, which we shall not discuss here. This paper will mostly concentrate on BRAMS additional features in comparison with the RAMS model. Table 2 summarizes the main options and characteristics present in BRAMS. The following sections introduce some key aspects of BRAMS and exemplify its added capabilities.

\subsection{Aspects of the dynamics}

\subsubsection{Complete, mass conservative formulation for the Exner function prognostic equation}

The BRAMS original prognostic equation for the Exner function was derived by Klemp and Wilhelmson (1978, hereafter KW78). The prognostic equation was obtained by combining the ideal gas equation with the mass continuity equation for compressible fluids. Medvigy et al. (2005, hereafter M05) expanded the original Eq. (6), which now reads as

$$
\begin{aligned}
& \frac{\partial \pi^{\prime}}{\partial t}=\underbrace{-\frac{R \pi_{0}}{c_{v} \rho_{0} \theta_{0}}\left(\frac{\partial \rho_{0} \theta_{0} u}{\partial x}+\frac{\partial \rho_{0} \theta_{0} v}{\partial y}+\frac{\partial \rho_{0} \theta_{0} w}{\partial z}\right)}_{\text {heat flux }} \\
& \underbrace{-u \frac{\partial \pi^{\prime}}{\partial x}-v \frac{\partial \pi^{\prime}}{\partial y}-w \frac{\partial \pi^{\prime}}{\partial z}}_{\text {advection }} \\
& \underbrace{-\frac{R \pi^{\prime}}{c_{v}}\left(\frac{\partial u}{\partial x}+\frac{\partial v}{\partial y}+\frac{\partial w}{\partial z}\right)}_{\text {divregence }}+\underbrace{\frac{R\left(\pi^{\prime}+\pi_{0}\right)}{c_{v} \theta_{\mathrm{v}}} \frac{\mathrm{d} \theta_{\mathrm{v}}}{\mathrm{d} t}}_{\text {heating }} .
\end{aligned}
$$

KW78 pointed out that the first term of the right-hand side of Eq. (7) typically has a higher order of magnitude than the other terms in studies of cloud dynamics, and the simplified version of Eq. (7) became the standard solution in both RAMS and BRAMS. However, KW78 also pointed out that the simplified equation violates mass conservation and deteriorates the accuracy of predicted pressure fields. M05 evaluated the conservation of mass in a regional simulation for New England, found the loss rates to be as large as $3 \%$ day $^{-1}$, and showed a significant improvement when the full equation was included. In this version of BRAMS, both the native and complete forms of the prognostic equation are available, and following M05 implementation, in BRAMS 5.2 we also solved the advection, divergence, and heating terms of Eq. (7) using the main time step, whereas the heat flux term is updated using the acoustic time step. 
Table 1. List of symbols.

\begin{tabular}{ll}
\hline Symbol & Definition \\
\hline$u$ & east-west wind component \\
$v$ & north-south wind component \\
$w$ & vertical wind component \\
$f$ & Coriolis parameter \\
$K_{\mathrm{m}}$ & eddy viscosity coefficient for momentum \\
$K_{\mathrm{h}}$ & eddy viscosity coefficient for heat and moisture \\
$\theta_{\mathrm{il}}$ & ice-liquid water potential temperature \\
$r_{n}$ & water mixing ratio species of total water, rain, pristine crystals, aggregates, and snow \\
$\rho_{0}$ & reference state for air density \\
con & subscript denoting tendency from convective parameterization \\
$R$ & dry air gas constant \\
rad & subscript denoting tendency from radiation parameterization \\
mic & subscript denoting tendency from resolvable-scale microphysical parameterization \\
$g$ & gravity \\
$r_{\mathrm{t}}$ & total water mixing ratio \\
$r_{\mathrm{V}}$ & water vapor mixing ratio \\
$\pi_{0}$ & reference state for Exner function \\
$\pi^{\prime}$ & perturbation Exner function \\
$\theta_{\mathrm{V}}$ & virtual potential temperature \\
$\theta_{0}$ & reference state for potential temperature \\
$c_{\mathrm{V}}$ & specific heat of air at constant volume \\
\hline
\end{tabular}

\subsubsection{Time integration schemes}

RAMS employs a hybrid time integration scheme combining a leapfrog scheme for the wind components and an Exner function with forward-in-time for scalars. The computational mode produced by the leapfrog scheme is damped with the application of the Robert-Asselin time filter (Asselin, 1972), which makes the overall accuracy first order. Williams (2009) proposed a simple modification to this time filter with a few extra lines of coding but increasing the accuracy of the scheme to third order. This improved time filter is available in BRAMS by appropriate setting of a flag in the namelist input file (RAMSIN).

A third option for time integration in BRAMS was based on the work of Wicker and Skamarock (2002, hereafter WS2002). This scheme has proven to be very robust and efficient, being applied in several state-of-the-art nonhydrostatic atmospheric models (e.g. Skamarock and Klemp, 2008; Baldauf, 2008, 2010; Skamarock et al., 2012). The WS2002 scheme is of a low-storage Runge-Kutta type with three stages and a third order for linear problems (hereafter RK3). The three stages require three evaluations of the slow mode tendencies (e.g. the advection term); however, this cost is offset by the larger time step allowed by the scheme when allied with a high-order advection scheme (see the discussion in Sect. 2.1.3).

The last option for a time integration scheme was described by Wicker (2009). This technique consists of a combination of two different schemes applied in two steps. A predictor step is performed by applying Adams-Bashforth of a second-order scheme and then a corrector step is completed by applying Adams-Moulton of a third-order scheme (hereafter ABM3). ABM3 is of third order and requires only two evaluations of the slow mode tendencies, demanding, however, a larger memory footprint than RK3 and a shorter time step. The advantage of using ABM3 over RK3 might arise when the length of the time step required by model stability is not dictated by the advective transport but by other physical processes (e.g. cloud microphysics).

\subsubsection{Additional advection schemes}

\section{Monotonic scheme for advection of scalars}

An additional advection scheme, which preserves the initial monotonic characteristics of a scalar field being transported with simultaneously levying low numerical diffusion, is available in BRAMS. The method developed by Walcek (2000) is highly accurate and absolutely monotonic. Freitas et al. (2012) reported its implementation in BRAMS and related impacts on the accuracy of the transport of relatively inert tracers as well as on the formation of secondary species from nonlinear chemical reactions of precursors. The results revealed that the new scheme produces much more realistic transport patterns, without generating spurious oscillations and undershoots and overshoots or diffusing mass away from the local peaks. Besides these features, the scheme also presents good performance in retaining nonlinear tracer correlations and conserving the mass of multi-component chemical species. The latter feature is not evident since mono- 
tonic preserving filters typically make the numerical advection scheme non-strictly linear.

As an example of the application of this scheme within BRAMS, the advection of a hypothetical rectangular parallelepiped tracer field by a realistic 3-D wind flow is discussed as follows. The model was configured with one grid with $10 \mathrm{~km}$ horizontal grid spacing covering the southeastern part of Brazil and with a time step of $15 \mathrm{~s}$. The total length of the time integration was $24 \mathrm{~h}$. The tracer mass mixing ratio is initiated with $100 \mathrm{au}$ and the background is set to zero. The horizontal domain initially occupied by the tracer is shown in panel a of Fig. 1, while in the vertical the tracer was initially localized between 1.7 and $4.1 \mathrm{~km}$ in height (not shown). The tracer mass mixing ratio distribution $12 \mathrm{~h}$ after and simulated by the original and monotonic advection schemes is shown in panels $b$ and $c$ of Fig. 1, respectively. In this study, the original advection scheme of BRAMS noticeably introduced spurious oscillations, overshoots, and undershoots (panel b), the latter with negative values of the mass mixing ratio (see Freitas et al., 2012, for further details). On the other hand, the simulation produced by the new scheme is much better at keeping the monotonicity of the distribution without spurious oscillations and negative mass mixing ratios (panel c), even for a real strongly divergent and deformational wind, as in this case.

\section{High-order advection schemes}

Following WS2002, BRAMS also has a new set of advection schemes to be applied in conjunction with RK3 or ABM3 time schemes. The set is comprised of first- to sixth-order spatial approximations for the fluxes at the edge of the grid cells. Also, exactly the same flux approximation can be applied for advection of scalars and momentum. The positivity constraint for scalars can be applied following Skamarock (2006).

Future versions of BRAMS will also include monotonicity constraints for scalars and an option for the WENO (weighted essentially non-oscillatory) third- and fifth-order formulations (Baba and Takahashi, 2013) for the advection operators.

\subsection{Physical parameterizations}

\subsubsection{Microphysics}

\section{Two-moment parameterization from RAMS/CSU}

The current version of the two-moment (2M) microphysical parameterization used in RAMS, version 6, has been implemented in BRAMS. This scheme has prognostic equations for number concentration and mixing ratio for eight hydrometeor categories (cloud, drizzle, rain, pristine, snow, aggregates, graupel, and hail). Each hydrometeor size spectrum is described by a generalized gamma distribution with a user- specified shape parameter (Meyers et al., 1997; Saleeby and Cotton, 2004, 2008).

According to Cotton et al. (2003), the 2M microphysical scheme comes with an efficient and stable algorithm for heat and vapor diffusion without requiring numerical iteration (Walko et al., 2000), sea salt and dust treatment, and a bin sedimentation scheme. Lately, Saleeby and Cotton (2008) developed a binned approach to cloud-droplet rimming, which computes the collision-coalescence process between ice and cloud particles in a more realistic way.

Cloud and drizzle number concentrations are computed from cloud condensation nuclei $(\mathrm{CCN})$ and giant $\mathrm{CCN}$ (GCCN) concentrations, respectively. A lookup table (LUT) is used to obtain the $\mathrm{CCN}$ concentration that is activated as a function of aerosol size, concentration, and composition via hygroscopicity parameter (Petters and Kreidenweis, 2007), as well as updraft velocities, pressure, and temperature. On the other hand, GCCN activation does not depend on the environmental conditions, being completely used in the drizzle nucleation process. Both aerosol categories may be advected, diffused, depleted, and restored (by droplet evaporation) as well as have their initial concentrations specified by the user as either homogeneous or heterogeneous fields (Saleeby and Cotton, 2004, 2008).

\section{Thompson cloud microphysics}

The aerosol aware bulk microphysics scheme described in Thompson et al. (2008) and Thompson and Eidhammer (2014), hereafter GT, was also implemented in BRAMS. The GT scheme treats five separate water species, mixing single- and double-moment treatment for different cloud species to minimize computational cost. It also includes the activation of aerosols as cloud condensation (CCN) and ice nuclei (IN) and, therefore, explicitly predicts the droplet number concentration of cloud water as well as the number concentrations of the two new aerosol variables, one each for $\mathrm{CCN}$ and IN. The aerosol species are lumped into two different groups according to their hygroscopicity. Hygroscopic aerosols are in the general category of "water friendly" (Nwfa), and the non-hygroscopic ice-nucleating aerosols are in the group "ice friendly" (Nifa). As a first approximation, Nifa is assumed to be only mineral dust in the accumulation mode, and all the other species (sulfates, sea salts, organic matter, and black carbon) are assumed to be a mixture of the species in each population and allocated to the hygroscopic mode Nwfa.

Aerosol activation also uses a LUT of activated fraction determined by temperature, vertical velocity, aerosol number concentration, and hygroscopicity parameter determined by the model. The LUT was built following Köhler activation theory within a parcel model from Feingold and Heymsfield (1992) with additional changes by Eidhammer et al. (2009) to use the hygroscopicity parameter (Petters and Kreidenweis, 2007). This approach is similar to the one used by RAMS 

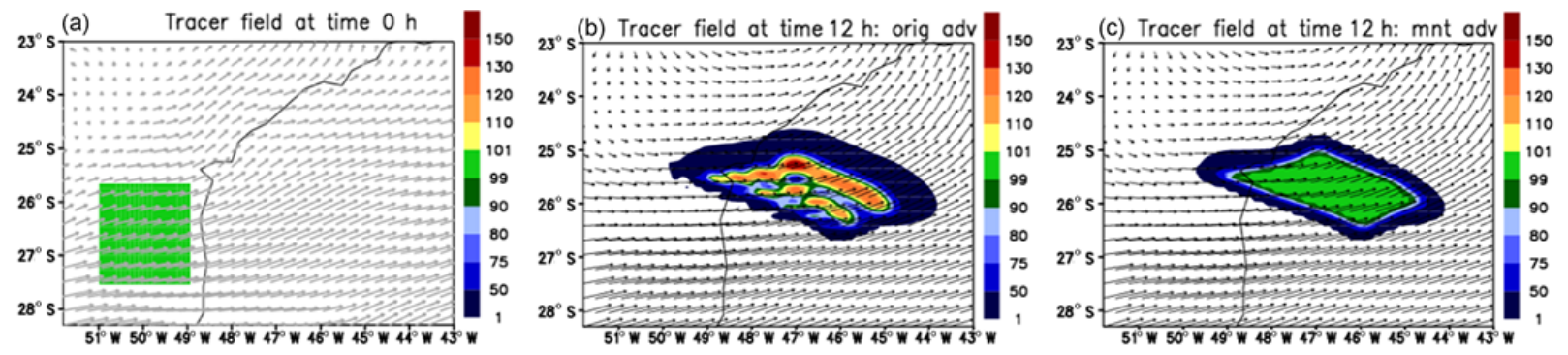

Figure 1. A 3-D hypothetical case study: transport of a rectangular parallelepiped by a realistic divergent flow over the southeastern part of Brazil. (a) The tracer concentration field expressed in terms of the mass mixing ratio at initial time and $1900 \mathrm{~m}$ height; the horizontal wind flow is also depicted. $(\mathbf{b}, \mathbf{c})$ The correspondent mass mixing ratio after $12 \mathrm{~h}$ as simulated by the original and monotonic advection schemes, respectively.

CSU microphysics previously described (Saleeby and Cotton, 2004, 2008). However, the LUT of GT has a coarser variation in terms of hygroscopicity parameters compared to RAMS CSU. The coarse resolution of the LUT in terms of aerosol hygroscopicity contributes to the GT scheme's low cost, but also represents a limitation for the ambient with high loads of very low hygroscopic aerosols, such as biomass burning affected areas (Sánchez Gácita et al., 2016).

\section{Abdul-Rassack parameterization}

As a low-cost option for the explicit aerosol aware microphysics schemes described above, the parameterization of aerosol particle activation as $\mathrm{CCN}$ was also implemented following the approach of Abdul-Razzak and Ghan (2000, 2002). This scheme, in its form for multiple log-normal distributions, assumes that the particles are in equilibrium with the environment, and the terms of curvature and the solute in the particle growth after activation can be neglected. As a first approach, for applications in a black-carbon rich atmosphere, the aerosol activation can be done via Abdul-Rassack parameterization and feed either the GT or RAMS CSU microphysics directly with the $\mathrm{CCN}$ number concentration.

\subsubsection{Radiation}

\section{CARMA and RRTMG schemes}

The BRAMS radiation module includes two additional schemes to treat atmospheric radiative transfer consistently for both longwave and shortwave spectra. The first scheme is a modified version of the Community Aerosol and Radiation Model for Atmospheres (CARMA) (Toon et al., 1989), and the second one is the Rapid Radiation Transfer Model (RRTM) version for GCMs (RRTMG, Mlawer et al., 1997; Iacono et al., 2008). RRTMG shares the same basic physics as RRTM, though it incorporates several modifications (Iacono et al., 2008) in order to improve computational efficiency. The CARMA and RRTMG schemes both solve the radiative transfer using the two-stream method and include all the major molecular absorbers (water vapor, car- bon monoxide, ozone, oxygen) and aerosol extinction. The RRTMG implementation preserved all the absorption coefficients for molecular species used in the correlated $k$ distribution method, which were based on a line-by-line model (Iacono et al., 2008). CARMA treats gaseous absorption coefficients using an exponential sum formulation (Toon et al., 1989).

Radiation schemes in BRAMS are both in-line coupled with the aerosol and cloud microphysics modules to provide online simulations of aerosol-cloud-radiation interactions. The CARMA and RRTMG radiative schemes are both fed with aerosol optical depth (AOD) profiles calculated from simulated aerosol mass loading and prescribed aerosol intensive optical properties, specifically the extinction efficiency, single scattering albedo, and asymmetry parameter taken from a LUT. Aerosol intensive optical parameters' prescription is regionally dependent. For South America, the parameters present in the LUT (Procopio et al., 2001; Rosário et al., 2013) are obtained from offline Mie calculations using as input climatological particle size distribution and the complex refractive index from sites of the AErosol RObotic NETwork (AERONET, Holben et al., 1998) distributed across South America. As an example, Figs. 2 and 3 present comparisons between BRAMS 5.2 simulation with the CARMA scheme for a set of diurnal cycles of downward shortwave and longwave irradiance, respectively, at the surface, with measurements at a pasture site (Abracos Hill $-10.760^{\circ} \mathrm{S}, 62.358^{\circ} \mathrm{W}$ ) in the southern portion of the Amazon Basin. For both radiation spectrums, the model reproduced consistently the diurnal cycle of the surface downward radiative energy. In the case of the shortwave radiation, the inclusion of the aerosol radiative effect proves to be fundamental to modeling its diurnal cycle.

Cloud physical (ice and liquid water path and particle sizes) and optical properties (optical depth) in the CARMA radiative scheme have been parameterized according to Sun and Shine (1994), Savijärvi (1997), and Savijärvi et al. (1997, 1998) using liquid and ice water content profiles provided by the BRAMS cloud microphysical module. In this case, subgrid-scale cloud variability is not taken into account. 


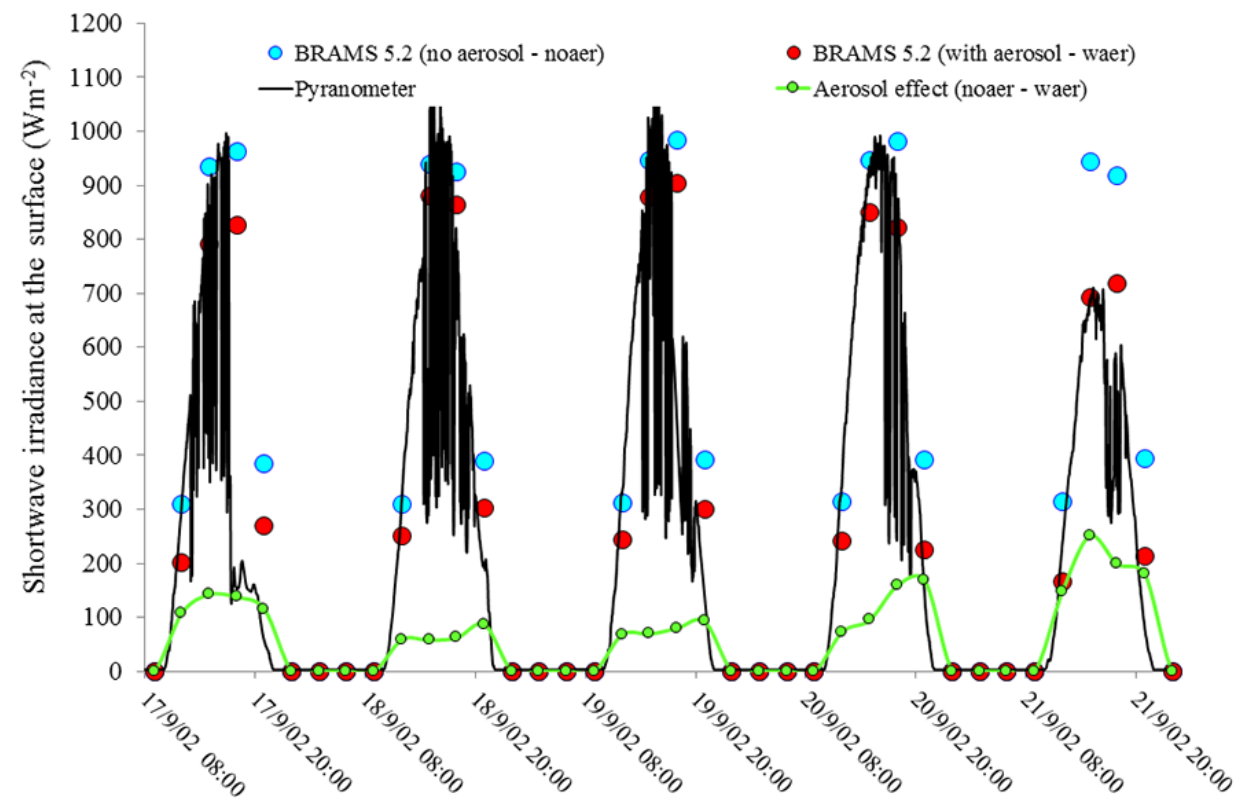

Figure 2. Time series of downwelling shortwave irradiance $\left(\mathrm{W} \mathrm{m}^{-2}\right)$ at the Abracos Hill AERONET site during a cloudy period from 17 to 21 September 2002 from BRAMS 5.2 results with (in red) and without (in blue) aerosol effects. The black line refers to measurement data in the same periods, and the green (line and marks) is the attenuation due to the aerosol effect.

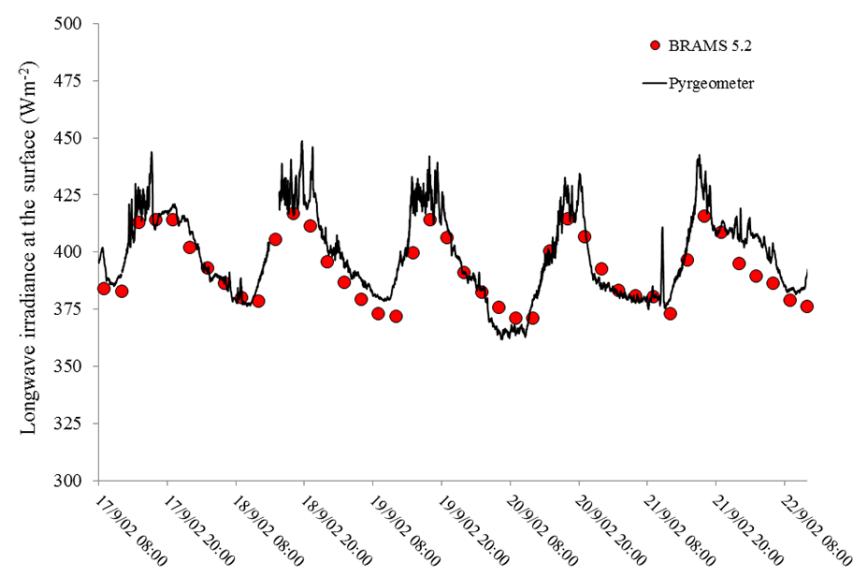

Figure 3. Time series of downwelling longwave irradiance $\left(\mathrm{W} \mathrm{m}^{-2}\right)$ at the Abracos Hill AERONET site during a cloudy period from 17 to 21 September 2002 from BRAMS 5.2 results. The black line refers to measurement data in the same period.

For the RRTMG scheme, the optical properties of liquid and ice water are from Hu and Stamnes (1993) and Ebert and Curry (1992), respectively, and sub-grid-scale cloud variability including cloud overlap is statistically addressed with MCICA (Iacono et al., 2008), the Monte Carlo independent column approximation (Barker et al., 2008; Pincus et al., 2003). The MCICA approach presupposes that cloud liquid water and ice, and cloud fraction, are prognostic variables. As such, the cloud liquid water effective radius was parame- terized in BRAMS following the generalized power-law expression of Liu et al. (2008):

$r_{\mathrm{el}}=\left(\frac{3}{4 \pi \rho_{w}}\right)^{1 / 3} \beta\left(\frac{\mathrm{LWC}}{N}\right)^{1 / 3}$

where LWC is the liquid water content, and is the water density, and $N$ is the cloud droplet number concentration. $L$ and $N$ are in CGS units. $\beta$ is a dimensionless parameter that depends on the spectral shape of the cloud droplet distribution, set based on observation as

$\beta=a_{\beta}\left(\frac{\mathrm{LWC}}{N}\right)^{-b_{\beta}}$,

with $a_{\beta}$ and $b_{\beta}$ equal to 0.07 and 0.14 , respectively.

The cloud radiative forcing is very sensitive to the determination of $\beta$. According to Liu et al. (2008), $\beta$ increases with aerosol loading and leads to a warming effect that acts to substantially offset the cooling of the Twomey effect by a factor of 10 to $80 \%$. A $b_{\beta}>0$ leads to a weaker dependence of $r_{\mathrm{el}}$ on LWC / $N$ and a smaller indirect aerosol effect, with a better agreement with observation. In principle, this generalized power-law expression for $r_{\mathrm{e}}$ effectively accounts for the increase in droplet concentration and the decrease in droplet size due to aerosol (Twomey, 1974), as well as the reduction in precipitation efficiency, which increases the liquid water content, the cloud lifetime (Albrecht, 1989), and the cloud thickness (Pincus and Baker, 1994).

The ice effective radius was parameterized in BRAMS following Wyser and Yang (1998), with an explicit dependence 
on both ice water content and temperature:

$r_{\mathrm{ei}}=377.4+203.3 B+37.91 B^{2}+2.3696 B^{3}$,

$B=-2+10^{-3}(273-T)^{1.5} \log _{10}\left(\frac{\mathrm{IWC}}{\mathrm{IWC}_{0}}\right)$,

where $T$ is the temperature in Kelvin, IWC is the ice water content in $\mathrm{gm}^{-3}$, and $\mathrm{IWC}_{0}=50 \mathrm{gm}^{-3}$.

This parameterization assumes the ice crystals consisting of hexagonal columns, and so is compatible with the ice optical properties from Ebert and Curry (1992) assumed in RRTMG.

In addition, to fulfill MCICA requirements, a cloud fraction representation was also implemented in BRAMS, based on the parameterization originally from the Community Atmosphere Model (CAM, http://www.cesm.ucar.edu/models/ cesm1.2/cam/), which is a generalization of the scheme introduced by Slingo (1987), with variations described in Kiehl et al. (1998), Hack et al. (1993), and Rasch and Kristjansson (1998). In this representation, three types of cloud are diagnosed, depending on relative humidity, atmospheric stability, and convective mass fluxes: low-level marine stratus, shallow and deep convective clouds, and layered cloud.

The marine stratus clouds are located according to the identification of stable layers between the surface and $700 \mathrm{mb}$ $\left(>0.125 \mathrm{~K} \mathrm{mb}^{-1}\right.$ ) and using the following empirical relationship from Klein and Hartmann (1993):

$$
\begin{aligned}
C_{\mathrm{st}}= & \min \left\{1.0, \max \left[0.0,\left(\theta_{700}-\theta_{\mathrm{s}}\right)\right.\right. \\
& 0.0057-0.5573]\},
\end{aligned}
$$

where $\theta_{700}$ and $\theta_{\mathrm{s}}$ are the potential temperatures at the $700 \mathrm{mb}$ and surface levels, respectively. The stratus clouds are located just below the strongest stability jump between these two levels.

The convective cloud fraction follows a formulation based on the updraft mass flux, both for shallow and deep (Xu and Krueger, 1991; Xu and Randall, 1996):

$$
\begin{aligned}
& C_{\text {shallow }}=k_{1, \text { shallow }} \ln \left(1.0+k_{2} M_{\mathrm{c}, \text { shallow }}\right), \\
& C_{\text {deep }}=k_{1, \text { deep }} \ln \left(1.0+k_{2} M_{\mathrm{c}, \text { deep }}\right),
\end{aligned}
$$

with $k_{1 \text {,shallow }}=0.07, k_{1, \text { deep }}=0.14$, and $k_{2}=500$, and $M_{\mathrm{c}}$ is the convective mass flux at the given level.

Any other clouds are diagnosed according to the relative humidity:

$$
\begin{gathered}
C_{\mathrm{c}}=\min \left[0.999,\left(\max \frac{\mathrm{Rh}-\mathrm{RH}_{\min }}{1-\mathrm{RH}_{\min }}\right)^{2}\right], \\
\mathrm{RH}_{\min }=\left\{\begin{array}{l}
\mathrm{RH}_{\text {min }}^{\text {low }}, p \geq 750 \mathrm{mb}, \\
\mathrm{RH}_{\text {min }}^{\text {high }}, p<750 \mathrm{mb},
\end{array}\right.
\end{gathered}
$$

with $\mathrm{RH}_{\min }^{\text {low }}=0.90$ and 0.80 , over water and land, respectively, and $\mathrm{RH}_{\min }^{\text {high }}=0.80$.

$C_{\mathrm{c}}=\min \left[0.999,\left(\max \frac{\mathrm{Rh}-\mathrm{RH}_{\min }}{1-\mathrm{RH}_{\min }}\right)^{2}\right]$
The total cloud fraction in the grid cell is

$C_{\text {tot }}=\min \left[1, \max \left(C_{\mathrm{st}}, C_{\text {deep }}, C_{\text {shallow }}, C_{\mathrm{s}}\right)\right]$.

The total cloud optical depth is given by the contribution from liquid and ice water contents, and accounts for the cloud fraction.

\subsubsection{Turbulence parameterizations}

\section{Nakanishi and Niino TKE based formulation}

In BRAMS, as in the original RAMS formulation, the local changes in momentum and scalars due to turbulent transport depend on the divergence of turbulent fluxes (RAMS, 2003). When the grid resolution is coarser than the size of the largest eddies (typically coarser than $100 \mathrm{~m}-1 \mathrm{~km}$ ), the eddy covariance fields needed to determine the turbulent fluxes are determined through K-theory (Stull, 1988), which requires the determination of eddy diffusivities for momentum and scalar quantities

$$
\begin{aligned}
\overline{u^{\prime} v^{\prime}} & =\overline{v^{\prime} u^{\prime}}=-K_{\mathrm{m} h}\left(\frac{\partial u}{\partial y}+\frac{\partial v}{\partial x}\right), \\
\overline{u_{h}^{\prime} w^{\prime}} & =-K_{\mathrm{m} z} \frac{\partial u_{h}}{\partial z} \\
\overline{w^{\prime} u_{h}^{\prime}} & =-K_{\mathrm{m} z} \frac{\partial w}{\partial x_{h}} \\
\overline{u_{h}^{\prime} \varepsilon^{\prime}} & =-K_{h h} \frac{\partial \varepsilon}{\partial x_{h}} \\
\overline{w^{\prime} \varepsilon^{\prime}} & =-K_{h z} \frac{\partial \varepsilon}{\partial z}
\end{aligned}
$$

where $(x, y)$ are the horizontal directions ( $x_{h}$ is either $x$ or $\left.y\right)$, $z$ is the vertical direction, $(u, v)$ are the horizontal wind directions ( $u_{h}$ is either $u$ or $v$ ), $w$ is the vertical velocity and $\varepsilon$ is any scalar, $K_{\mathrm{m} h}$ and $K_{\mathrm{m} z}$ are the horizontal and vertical diffusivity coefficients for momentum, and $K_{h h}$ and $K_{h z}$ are the horizontal and vertical diffusivity coefficients for scalars. It is important to note that Eqs. (3)-(4) are only to be used when the grid horizontal resolution is much coarser than the vertical resolution because they violate vorticity conservation; however, different scales are needed when the horizontal and vertical grid resolutions are different to avoid numerical instabilities (RAMS, 2003).

The horizontal diffusivities are determined using the same algorithm implemented in RAMS, which is based on Smagorinsky (1963), with the inclusion of the Brunt-Väisäla correction by Hill (1974). For the vertical diffusivity coefficients, we use a vertical parameterization based on the level2.5 model by Mellor and Yamada (1982), further modified by Nakanishi and Niino (2004). In this model, the diffusivity coefficients depend on turbulent kinetic energy per unit mass (TKE), which also becomes a prognostic variable:

$$
\begin{aligned}
& K_{\mathrm{m} z}=L q S_{\mathrm{m}}, \\
& K_{h z}=L q S_{h}, \\
& q=\sqrt{2 \mathrm{TKE}}=\sqrt{\overline{u^{\prime} u^{\prime}}+\overline{v^{\prime} v^{\prime}}+\overline{w^{\prime} w^{\prime}},}
\end{aligned}
$$


where $L$ is the master length scale and $S_{\mathrm{m}}$ and $S_{h}$ are nondimensional stability functions for momentum and buoyancy. Both $L$ and the stability functions are determined following Nakanishi and Niino (2004), which allows for stronger turbulence and deeper boundary layers compared to the original formulation. The non-dimensional stability functions also include a correction factor to avoid numerical instabilities under growing turbulence (see Helfand and Labraga, 1988) and an upper limit on $L$ under very stable conditions to avoid TKE becoming negative, following the implementation by Janjić (2001) and Nakanishi and Niino (2006). Although Nakanishi and Niino (2004) also described a higher-order, level-3 parameterization, this would require including prognostic equations for the variance of every scalar and the covariance between pairs of scalars, which would rapidly become unmanageable due to high computational load (Mellor and Yamada, 1982).

\subsubsection{Surface interactions}

\section{Town Energy Budget (TEB) scheme to simulate urban areas}

BRAMS also offers the possibility of using a combination of the LEAF surface scheme (Walko et al., 2000) and the Town Energy Budget (TEB) (Masson, 2000; Freitas et al., 2007). Use of the bare soil formulation or the adjustment in the surface-vegetation-atmosphere transfer (SVAT) scheme parameters is very frequent. However, as stressed by Masson (2000), such an approximation is satisfactory only for large temporal or spatial averages, and it is necessary to incorporate a more detailed scheme when smaller scales are considered. Therefore, the simulation of several mesoscale and local processes that simultaneously occur in an urban atmosphere and its surroundings requires a more detailed urban surface parameterization. Such processes include the circulations generated by an urban heat island (UHI) and its interaction with other atmospheric phenomena (Freitas et al., 2007; Nair et al., 2004), air pollution (Andrade et al., 2004; E. D. Freitas et al., 2005), and human comfort conditions (Johansson et al., 2013), among others. In BRAMS 5.2, the TEB and LEAF schemes are activated simultaneously, and the surface fluxes of momentum and moisture, temperature, surface albedo, and emissivity are calculated by TEB wherever an urban grid point is identified, while LEAF is applied elsewhere (e.g. bare soil, water bodies, grass, forest, or any vegetation). TEB considers the interaction of shortwave and longwave radiation with the urban structure, allowing multiple reflections with walls and roads. In addition to the 3-D urban structure in the TEB formulation, another advantage is the possibility of simulating anthropogenic heat and moisture fluxes emitted both by mobile sources, such as heavy and light duty vehicles, and fixed sources, such as industries, commerce, and domestic activities in general. For large cities, such as São Paulo and Rio de Janeiro, the anthropogenic heat sources are key features, not only for meteorological reasons, but also for health and public policy management. As anthropogenic contributions can vary strongly depending on the urban area, the implementation of TEB in BRAMS allows the user to define those contributions in the model configuration file. Following the work of Khan and Simpson (2001), anthropogenic contributions can be estimated based on fuel and electricity consumption, as well as the population and their related activities in the area of interest. For example, maximum values of 30 and $20 \mathrm{~W} \mathrm{~m}^{-2}$ of the sensible heat flux emission in the peak hours for vehicular and industrial contributions, respectively, were considered for the metropolitan area of São Paulo, Brazil, with more than 20 million inhabitants, and more than 7 million vehicles (Freitas et al., 2007). Such fluxes properly represent most of the urban heat island features for São Paulo, including the interaction between the UHI and the sea breeze. However, the fluxes must be adjusted on a case-by-case basis, and, therefore, urban structure and anthropogenic contributions are user-specified in the model namelist (Table 3) to limber model application for different urban areas. Additionally, the diurnal cycle of vehicle activities and other related features (pollutant emission, for example) are dependent on local time. Therefore, there is an input file describing local time as a function of the latitude and longitude of each grid point. Vehicular activity is defined in the model using a double normal distribution centered on two values of the time of rush hours, which are also userdefinable (E. D. Freitas et al., 2005, 2007).

\section{Joint UK Land Environment Simulator (JULES) model}

In this section, the coupling between the Joint UK Land Environment Simulator (JULES) surface-atmosphere interaction model (Best et al., 2011; Clark et al., 2011) and the BRAMS model is concisely described (for further details, readers are referred to Moreira et al., 2013). JULES contains the state-ofthe-art numerical representation of surface processes and is able to simulate a number of soil-vegetation processes such as vegetation dynamics, photosynthesis, and plant respiration, and also transport of energy and mass in soils and plants, including a representation of urban elements. The coupling of JULES and BRAMS is fully two-way, with BRAMS providing atmospheric dynamics, thermodynamics, and chemical constituent information to JULES, which in turn responds with fluxes of horizontal momentum, water, energy, carbon, and other tracers exchanged between the atmosphere and the surface beneath. In JULES, the land surface is divided in subgrid boxes, which can be occupied by a number of plant functional types (PFTs) and non-functional plant types (NPFTs). Up to five PFTs are allowed in each sub-grid box: broadleaf trees (BT), needleleaf trees (NT), C3 grass type (C3G), C4 grass type (C4G), and shrubs (Sh). A sub-grid box can also be occupied by up to four NPFTs: urban, inland water, soil, and ice. JULES adopts a tiled structure, in which the surface processes are calculated separately for each surface type. Its 
Table 2. Main configuration options in BRAMS 5.2.

\begin{tabular}{|c|c|}
\hline Basic equations & $\begin{array}{l}\text { - Non-hydrostatic time-split compressible } \\
\text { - Option for a complete, mass conservative formulation for the Exner function prognostic equation }\end{array}$ \\
\hline Coordinates & $\begin{array}{l}\text { - Vertical coordinate: } \\
\text { - Standard Cartesian coordinate } \\
\text { - Terrain-following height coordinate } \\
\text { - Horizontal coordinate: } \\
\text { - Standard Cartesian coordinate } \\
\text { - Rotated polar-stereographic transformation }\end{array}$ \\
\hline Computational grid & $\begin{array}{l}\text { - Arakawa-C grid staggering on horizontal, Lorenz grid on vertical } \\
\text { - Vertical grid spacing can vary with height } \\
\text { - One-way nesting only }\end{array}$ \\
\hline Time integration & $\begin{array}{l}\text { - Time differencing: } \\
\text { - Hybrid combination of leapfrog and forward-in-time, with an option for Robert-Asselin-Williams time } \\
\text { filter (Williams, 2009) } \\
\text { - Runge-Kutta second- and third-order (Wicker and Skamarock, 1998, 2002) } \\
\text { - Adams-Bashforth-Moulton third order (Wicker, 2009) } \\
\text { - Time-split small step for acoustic and gravity-wave modes: } \\
\text { - Small step horizontally explicit, vertically implicit } \\
\text { - Divergence damping option }\end{array}$ \\
\hline Advection schemes & $\begin{array}{l}\text { - Forward upstream of second order (Tremback et al., 1987) } \\
\text { - Monotonic advection scheme for scalars (Walcek, 2000) } \\
\text { - first- to sixth-order advection options (horizontal and vertical, Wicker and Skamarock, 1998, 2002) with } \\
\text { positivity constraint (Skamarock, 2006). }\end{array}$ \\
\hline Turbulence closure & $\begin{array}{l}\text { - Smagorinsky (1963), Lilly (1962), and Hill (1974) closure formulation } \\
\text { - Deardorff (1980) level-2.5 scheme } \\
\text { - Mellor-Yamada level-2.5 scheme (Mellor and Yamada, 1982) } \\
\text { - Nakanishi and Niino (2004) TKE based formulation } \\
\text { - Taylor's theory based formulation (Degrazia et al., 1998) }\end{array}$ \\
\hline Cloud microphysics & $\begin{array}{l}\text { - Single-moment bulk scheme (Walko et al., 1995a) } \\
\text { - Double-moment bulk scheme (Meyers et al., 1997) } \\
\text { - Thompson double-moment and aerosol aware scheme (Thompson and Eidhammer, 2014) }\end{array}$ \\
\hline Radiation & $\begin{array}{l}\text { - CARMA (Toon et al., 1989) schemes for longwave and shortwave radiation } \\
\text { - RRTMG (Iacono et al., 2008) schemes for longwave and shortwave radiation }\end{array}$ \\
\hline Convective parameterization & $\begin{array}{l}\text { - Modified Kuo for deep convection (Tremback, 1990) } \\
\text { - For shallow convection based on the heat engine approach (Souza, 1999) } \\
\text { - Grell and Deveny (2002) ensemble version for deep convection } \\
\text { - Grell and Freitas (2014) ensemble version, scale and aerosol aware for deep and shallow convection }\end{array}$ \\
\hline Surface processes and lower boundary & $\begin{array}{l}\text { - LEAF-3 soil-vegetation-snow parameterization (Walko et al., 2000) } \\
\text { - Town Energy Budget (TEB) scheme for urban areas (Freitas et al., 2007) } \\
\text { - Joint UK Land Environment Simulator scheme (Moreira et al., 2013) } \\
\text { - Fire spread model (Mandel et al., 2011; Menezes, 2015)* }\end{array}$ \\
\hline Chemical processes & $\begin{array}{l}\text { - Gas-/aqueous-phase chemistry with CCATT (Longo et al., 2013) and SPM (E. D. Freitas et al., 2005) } \\
\text { modules. } \\
\text { - Photochemistry with LUT, FAST-TUV and FAST-J photolysis calculation } \\
\text { - SPACK chemical mechanism pre-processor } \\
\text { - PREP-CHEM-SRC pre-processor emission fields (Freitas et al., 2011) } \\
\text { - Rosenbrock second- and third-order solvers } \\
\text { - Dry and wet deposition }\end{array}$ \\
\hline Aerosol processes & $\begin{array}{l}\text { - Simple aerosol model for volcanic ash, biomass burning, sea salt and urban aerosols (Longo et al., 2013) } \\
\text { - MATRIX aerosol model (Bauer et al., 2008)* } \\
\text { - Aerosol direct effect included in CARMA radiation scheme }\end{array}$ \\
\hline Upper boundary condition & $\begin{array}{l}\text { - Rigid lid } \\
\text { - Rigid lid with a high-viscosity layer aloft }\end{array}$ \\
\hline Lateral boundary condition & $\begin{array}{l}\text { - Klemp and Wilhelmson (1978) radiative condition } \\
\text { - Large-scale nudging boundary conditions (Davies, 1983) }\end{array}$ \\
\hline Initialization and data assimilation & $\begin{array}{l}\text { - Horizontally homogeneous from a single sounding } \\
\text { - RAMS-ISAN analysis package (Tremback, 1990) with inclusion of tracers } \\
\text { - 4-D nudging (Newtonian relaxation) to data analyses with inclusion of tracers } \\
\text { - Digital filter } \\
\text { - Soil moisture initialization using real-time cycling estimation from an offline hydrological model (Gevaerd } \\
\text { and Freitas, 2006) }\end{array}$ \\
\hline
\end{tabular}

* Under development and/or evaluation 
Table 3. List of parameters that can be modified by the user when using TEB in the model.

\begin{tabular}{ll}
\hline Variable & Meaning and units \\
\hline RUSHH1 & Morning rush hour (local time in hours) \\
RUSHH2 & Afternoon/evening rush hour (local time in hours) \\
HC_ROOF, HC_ROAD, HC_WALL & Heat capacity for roof, road, and wall layers $\left(\mathrm{J} \mathrm{m}^{-3} \mathrm{~K}^{-1}\right)$ \\
TC_ROOF, TC_ROAD, TC_WALL & Thermal conductivity for roof, road, and wall layers $\left(\mathrm{Wm}^{-1} \mathrm{~K}^{-1}\right)$ \\
D_ROOF, D_ROAD, D_WALL & Depth for roof, road, and wall layers (m) \\
Z0_TOWN & Urban type roughness length (m) \\
BLD & Fraction occupied by buildings in the grid cell (\%) \\
BLD_HEIGHT & Building height (m) \\
BLD_HL_RATIO & Vertical/horizontal rate (N/D) \\
AROOF, AROAD, AWALL & Roof, road, and wall albedo (N/D) \\
EROOF, EROAD, EWALL & Roof, road, and wall emissivity (N/D) \\
HTRAF & Maximum value of sensible heat released by traffic $\left(\mathrm{W} \mathrm{m}^{-2}\right)$ \\
HINDU & Maximum value of sensible heat released by industry $\left(\mathrm{W} \mathrm{m}^{-2}\right)$ \\
PLETRAF & Maximum value of latent heat released by traffic $\left(\mathrm{W} \mathrm{m} \mathrm{m}^{-2}\right)$ \\
PLEINDU & Maximum value of latent heat released by industry $\left(\mathrm{W} \mathrm{m}{ }^{-2}\right)$ \\
\hline
\end{tabular}

initialization requires land cover and soil type classifications, the normalized difference vegetative index (NDVI), sea surface temperature, carbon and soil moisture contents, and soil temperature.

Moreira et al. (2013) indicated that the application of JULES to simulations over South America implied a significant gain of skill compared to the original surface scheme in RAMS (LEAF3). As an example, Fig. 4 shows the model root-mean-square error (RMSE) of $2 \mathrm{~m}$ temperature, which was calculated using observations from ground stations distributed all over a large part of this continent. RMSE corresponds to the first $24 \mathrm{~h}$ forecast averaged over 30 runs in the wet (March, panel a) and dry seasons (September, panel b) of 2010. During the night, both surface schemes present similar skills, with LEAF3 being slightly better in the dry season. However, during daytime JULES notably improves model skills in both seasons. As a daily average, RMSE decreases by approximately $10 \%$ with the latter surface scheme.

\subsubsection{Parameterizations of moist convection}

\section{Shallow convection}

The shallow cumulus parameterization scheme in BRAMS is a mass flux type described in detail in Souza (1999). The cloud model follows the version of Albrecht et al. (1986) for a single-cloud formulation of the Arakawa and Schubert (1974) ensemble scheme. The shallow cumulus characteristic in the cloud model is obtained through an entraining function that gives more weight to the side entrainment as air parcels approach the cloud top. Therefore, a lifted air parcel from near the surface starts with a small entrainment of $\lambda=10^{-6} \mathrm{~m}^{-1}$, and this value increases by an order of magnitude each time the parcel reaches a 10 -fold height $z_{\mathrm{f}}$, which is the only adjustable parameter of the scheme. The entrain- ment rate is about $10^{-3} \mathrm{~m}^{-1}$ at the $2.1 \mathrm{~km}$ height for a $z_{\mathrm{f}}$ of $0.7 \mathrm{~km}$. The cloud top is reached when the total buoyancy of the parcel, integrated from the surface to the top, becomes zero. The mass-flux formulation is based on the heat engine framework proposed by Rennó and Ingersoll (1996). The derivation of the convective mass flux follows the rationale that the convective heat engine, which is driven by surface heat flux, forces the upward motion of air masses. The convective flux is then a result of the total forcing at the surface, namely the sum of the fluxes of sensible and latent heat, which are converted into kinetic energy according to the second law of thermodynamics. Once surface fluxes start forcing the heat engine, upward convecting air parcels might reach levels where water vapor saturation takes place. The triggering function follows the work of Wilde et al. (1985), which showed that moist parcels could give origin to shallow cumuli only when the entrainment zone, located on top of the mixing layer, is above the lifting-condensation-level zone.

This shallow convective scheme is suitable for studying the interaction between shallow convection and surface processes and its use in BRAMS improved the representation of the diurnal cycle of temperature and moisture over land.

\section{Grell and Deveny for deep convection}

The Grell and Deveny (2002, hereafter GD) deep convection scheme was included in BRAMS in 2002 and its implementation is described in S. R. Freitas et al. (2005). One of the reasons for the GD inclusion in BRAMS was the need for a mass flux scheme for consistent convective transport of tracers. GD expanded the original formulation based on Grell (1993) by including stochastic capability by permitting a series of different assumptions that are widely used in convective parameterizations. The GD scheme can use a very large number of ensemble members based on five dif- 

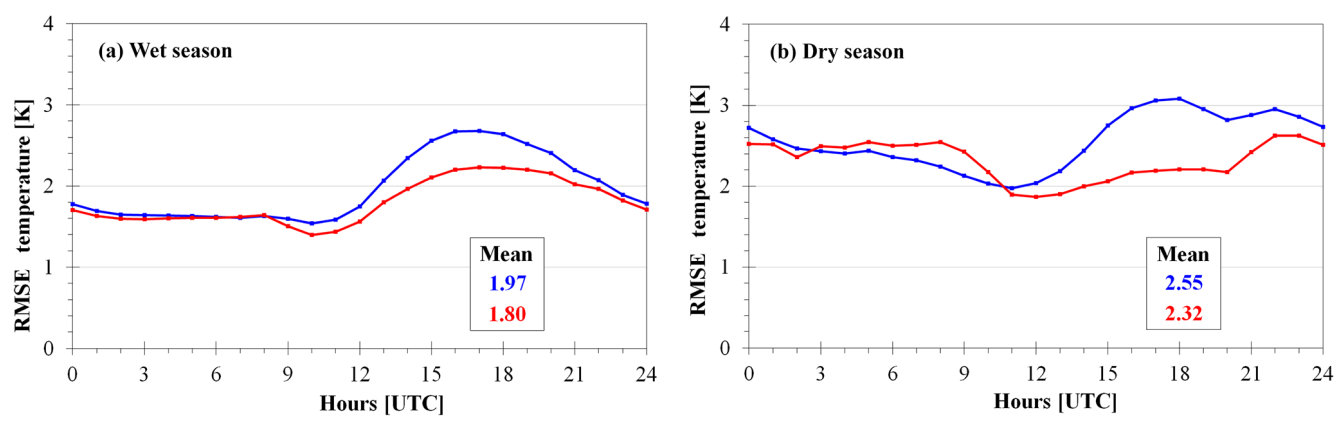

Figure 4. RMSE of air temperature at $2 \mathrm{~m}$ using the JULES (in red) and LEAF3 (in blue) surface schemes with BRAMS over South America during (a) the wet season in March 2010 and (b) the dry season in September 2010.

ferent types of closure formulations, precipitation efficiency, and the ability of the source air parcels to overcome the convective inhibition energy.

Dos Santos el at. (2013) developed a method to generate a set of weights related to the closure members of the GD ensemble to optimize the combination of them. As an inverse problem of parameter estimation, the optimization problem for retrieving the weights applied a metaheuristic optimization method called the Firefly algorithm (FY, Yang, 2008). The method consists of minimizing an objective function computed with the quadratic difference between BRAMS precipitation forecasts and observation, a measure of the distance between the observational data and model results. Six different model simulations were performed to produce a five-member ensemble of precipitation forecasts, each one using a single closure option, and one of the runs was performed using the ensemble simple mean option. The single closure options used were Arakawa and Schubert (1974), moisture convergence (Krishnamurti et al., 1983), low-level Omega (Frank and Cohen, 1987), Kain and Fritsch (1992), and Grell (1993). The method proved able to produce an ensemble with improved statistical scores compared with the original ensemble mean calculation (Dos Santos et al., 2013; Santos, 2014). As an example, the categorical verification bias score computed for South America is depicted in Fig. 5. The mean of a set of 30 forecasts of $24 \mathrm{~h}$ accumulated precipitation for $120 \mathrm{~h}$ in advance of precipitation for January 2008 (panel a) and 2010 (panel b) was carried out using both the GD ensemble arithmetic mean (EN) and the ensemble mean using the FY method. The model setup included a grid with $25 \mathrm{~km}$ horizontal resolution covering South America and a $100 \mathrm{~m}$ vertical resolution in the first level; then, the vertical resolution varied telescopically with a ratio of 1.1 up to a maximum vertical resolution of $950 \mathrm{~m}$, with the top of the model at approximately $19 \mathrm{~km}$ (a total of 40 vertical levels). As initial and boundary conditions, we used the CPTEC/INPE Atmospheric General Circulation Model (AGCM) analysis with T126L28 resolution, where T126 is the rhomboidal truncation at wave number 126 and L28 is the number of model vertical levels.
The vertical bars in Fig. 5 refer to a significance test from the bootstrap method (Hamill, 1999). These results indicate a reduction of bias at the low thresholds of precipitation, as well as an increase in the model skills for higher thresholds, in agreement with the increase in equitable threat score (not shown) for higher thresholds, both with statistical significance, which demonstrates that FY is a robust method for training the GD ensemble of closures.

In addition, the GD scheme in BRAMS contains an alternative option for the convective trigger function (CTF), which was originally developed by Jakob and Siebesma (2003) and implemented by Santos e Silva et al. (2012). In this formulation, the CTF is linked with the sensible and latent surface fluxes. Previous results, within both a global model (Betchold et al., 2004) and BRAMS (Santos e Silva et al., 2012), showed improvements in simulating the diurnal cycle of precipitation over continental areas, especially in tropical South America.

\section{A scale and aerosol aware convective parameterization for deep and shallow cumulus}

The Grell and Freitas (2014, hereafter GF) scheme is based on the stochastic approach originally implemented by GD, with several additional features. One new feature is scaledependence formulations for high-resolution runs (or a gray zone for deep convection model configurations) and interaction with aerosols. The scale dependence was introduced by two approaches. One is based on spreading subsidence to neighboring grid points instead of in the same model convective column, as is usually done by classical convective parameterizations. The second approach applies methods devised by Arakawa et al. (2011). This work reformulated the eddy fluxes associated with the convective transports as a function of the updraft area fraction and the eddy fluxes given by a closure of a conventional convective parameterization. The idea is readily applied to the conventional parameterizations provided that a reliable formulation for the updraft area fraction is achieved. Because of its simplicity and its capability for an automatic smooth transition as the resolu- 

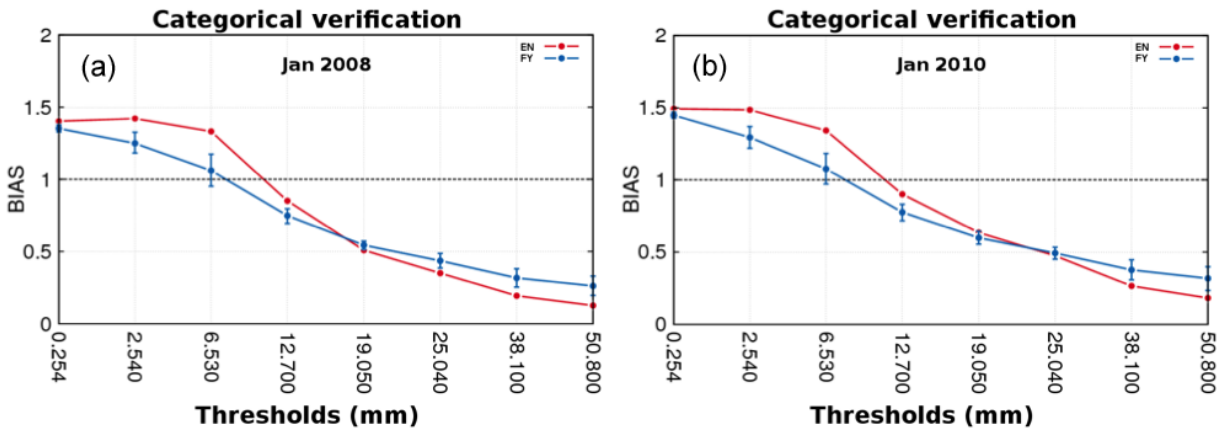

Figure 5. Mean bias score versus precipitation thresholds for South America for a set of 30 forecasts of $24 \mathrm{~h}$ accumulated precipitation for $120 \mathrm{~h}$ in advance for (a) January 2008 and (b) January 2010. Blue lines represent simulations using the FY weight method and red lines the original EN. The blue bars indicate the significance test from the bootstrap method (Hamill, 1999).

tion is increased, Arakawa's approach is recommended to the BRAMS users.

A second new feature present in GF is an aerosol awareness capability through a $\mathrm{CCN}$ (cloud condensation nuclei number concentration) dependent autoconversion of cloud water to rain, as well as an aerosol dependent evaporation of cloud drops. However, this feature is still in the experimental stage, so caution when using it is advised.

Recently, the GF ensemble of closures has been extended to include a new closure inspired by ideas developed by Bechtold et al. (2008, 2014 - hereafter B2014). In the B2014 paper, the authors derive a diagnostic CAPE based closure where selective boundary layer timescales over land and water are applied. As a consequence, their convective parameterization improved its capability in the representation of non-equilibrium convection forced by boundary layer processes, with a more realistic phase of the associated diurnal cycle over land. In the GF scheme, 2015 version, a corresponding closure, although built on the cloud work function concept, was included. Additionally, GF, 2015 version, contains a variant scheme for shallow convection (nonprecipitating) with three options for the closure of mass flux at the cloud base.

Several experiments with BRAMS, with the GF 2015 version, including Arakawa's approach (GF-A), using horizontal grid sizes of 5,10 , and $20 \mathrm{~km}$, were carried out to evaluate the performance of the GF scheme as well as its behavior on different scales. For the $5 \mathrm{~km}$ model run we also described the performance of the scheme without applying any scale correction (GF-NS). Each experiment comprised 15 runs from 1 to 15 January for $36 \mathrm{~h}$ forecasts, all starting at 00:00 UTC; $24 \mathrm{~h}$ precipitation accumulation used for verification was taken from 12 to $36 \mathrm{~h}$. Also, all experiments covered the same region and used the same initial and boundary conditions, which were taken from NCEP/USA Global Forecast System (GFS) analysis and forecast fields. Physical parameterizations included CARMA radiation, the JULES surface scheme, the Mellor-Yamada 2.5 turbulence scheme, and the single-moment bulk microphysics parameterization from Walko et al. (1995a). Model results are presented in Fig. 6. Decreasing the grid spacing from 20 to $5 \mathrm{~km}$ (panels a, b, and c), detailed precipitation structures show up, while the broad precipitation distribution is preserved with the domainaveraged precipitation, exhibiting deviation in a $10 \%$ range (between 4.1 and $4.5 \mathrm{~mm} \mathrm{day}^{-1}$ ). On the other hand, the precipitation produced by $\mathrm{CP}$ only (lower row, panels e, $\mathrm{f}$, and g) presents a consistent decrease, becoming less significant, from 3.5 to $1.0 \mathrm{~mm} \mathrm{day}^{-1}$, allowing the dynamics and cloud microphysics to be responsible for a much larger fraction of the total precipitation. Instead of a GF-A $5 \mathrm{~km}$ run, GF-NS (panel d) resulted in about $20 \%$ larger domain average precipitation with a much smoother spatial distribution. In panel $\mathrm{h}$ is shown that, even on $5 \mathrm{~km}$ grid spacing, most of the precipitation $(\sim 75 \%)$ is generated by the convection scheme. These results demonstrate the ability of the GF-A scheme to produce a smooth transition across scales within the BRAMS modeling system.

Figure 7 introduces an exploratory study on the impacts of the B2014 closure (here called the "diurnal cycle" closure) on BRAMS results with respect to the diurnal cycle of precipitation over the Amazon Basin. The model configuration for this study comprised a grid with spacing of $27 \mathrm{~km}$ on the horizontal and 80 to $850 \mathrm{~m}$ on the vertical. The physical parameterizations and the initial and boundary conditions were the same as the preceding scale-dependence experiment, but GF applied the B2014 approach. Again, the model was set up to perform several runs resembling the operational mode, comprising 15 runs (from 1 to 15 February 2011) with $120 \mathrm{~h}$ forecast each.

Santos e Silva et al. $(2009,2012)$ discussed in detail the diurnal cycle of precipitation over the Amazon Basin using the TRMM rainfall product (Huffman et al., 2007) and observational data from an $\mathrm{S}$ band polarimetric radar (S-POL) and rain gauges obtained in a field experiment during the wet season of 1999. Their analysis indicated that a peak in rainfall is common late in the afternoon (between 17:00 and 

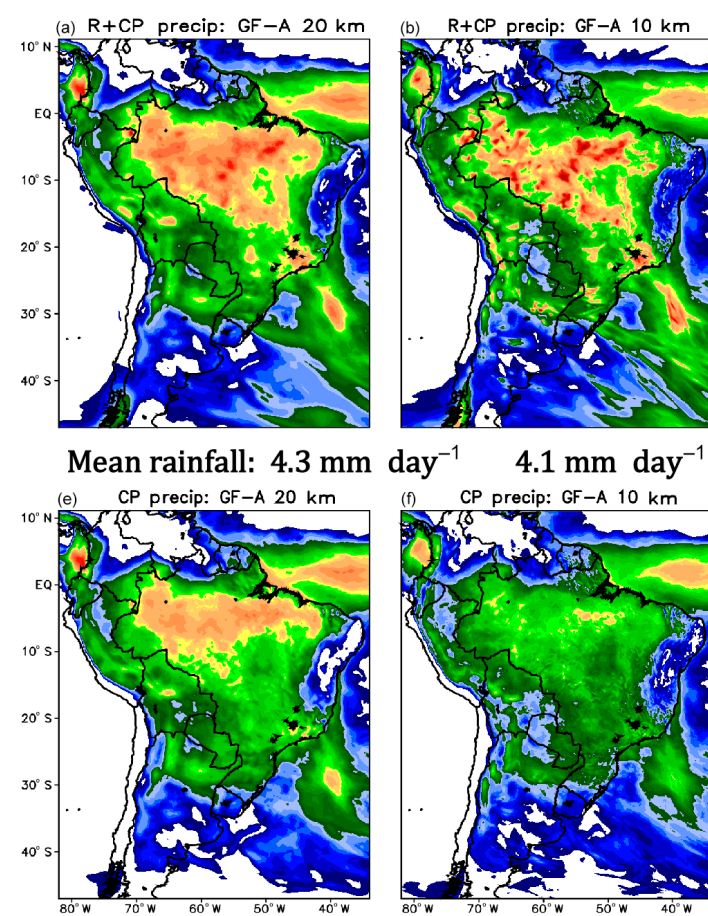

Mean rainfall: $3.5 \mathrm{~mm}$ day

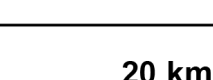

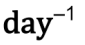

$4.1 \mathrm{~mm} \mathrm{day}{ }^{-1}$

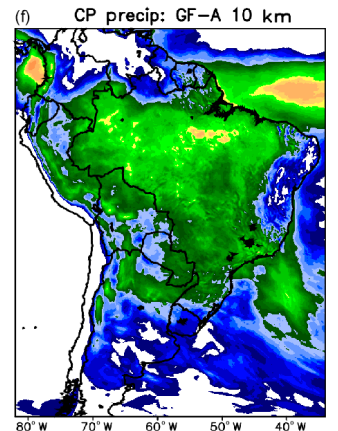

$2.5 \mathrm{~mm} \mathrm{day}^{-1}$

$10 \mathrm{~km}$

With scale dependence

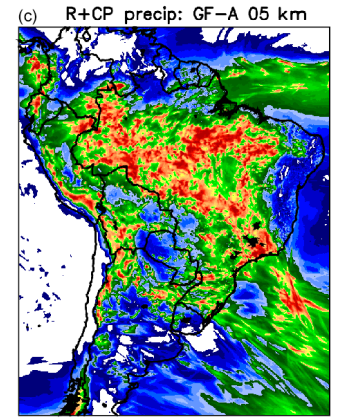

$4.5 \mathrm{~mm} \mathrm{day}{ }^{-1}$

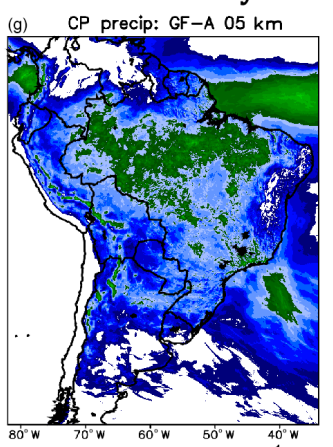

$1.0 \mathrm{~mm} \mathrm{day}^{-}$

$05 \mathrm{~km}$

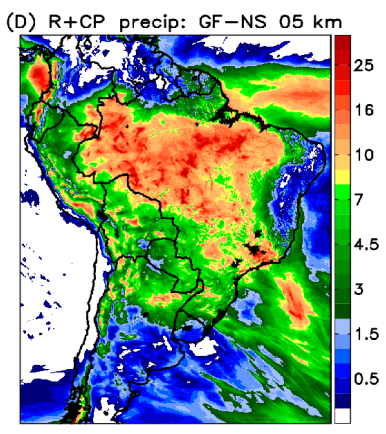

$5.3 \mathrm{~mm} \mathrm{day}{ }^{-1}$

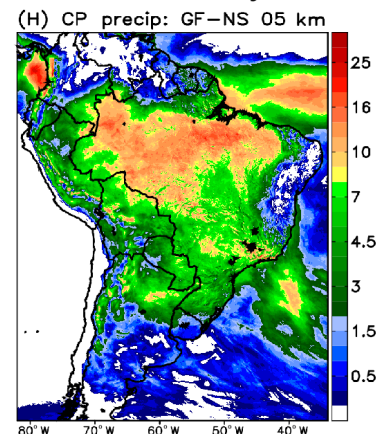

$4.1 \mathrm{~mm} \mathrm{day}^{-1}$

$05 \mathrm{~km}$

No scale dependence

Figure 6. Averaged precipitation rates over 15 runs for total precipitation $(\mathbf{a}, \mathbf{b}, \mathbf{c})$ and convective (non-resolved) precipitation (e, $\mathbf{f}, \mathbf{g})$, using the scale-dependence formulation (GF-A) and horizontal resolutions of $20 \mathrm{~km}(\mathbf{a}, \mathbf{e}), 10 \mathrm{~km}(\mathbf{b}, \mathbf{f})$, and $5 \mathrm{~km}(\mathbf{c}, \mathbf{g})$. The column on the right $(\mathbf{d}, \mathbf{h})$ depicts results on $5 \mathrm{~km}$ without the scale-dependence formulation (GF-NS). Units are mm day ${ }^{-2}$.
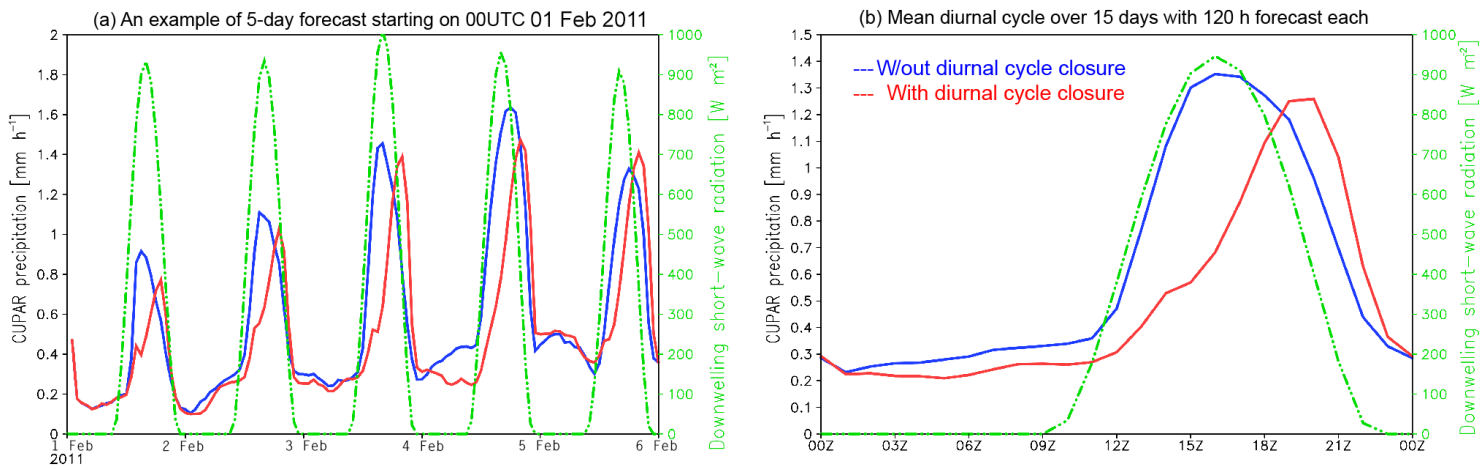

Figure 7. Simulation of the diurnal cycle of precipitation over the Amazon Basin with the GF scheme and the diurnal cycle closure. (a) An example of a 5-day forecast of the convective parameterization precipitation rate $\left(\mathrm{mm} \mathrm{h}^{-1}\right.$, averaged over the model domain). (b) The same as (a) but with daily averaging also over 15 runs with $120 \mathrm{~h}$ forecast each. The green line shows the diurnal cycle of the downwelling shortwave radiation $\left(\mathrm{W} \mathrm{m}^{-2}\right)$ to spot the local time.

21:00 UTC), in spite of variations existent associated with wind regimes. Figure 7 shows model results with and without the diurnal cycle closure; both panels depict area average precipitation from the GF scheme $\left(\mathrm{mm} \mathrm{h}^{-1}\right)$ as well as downwelling shortwave radiation ( $\mathrm{W} \mathrm{m}^{-2}$, DSWR). A sample of a 5-day forecast starting at 00:00 UTC, 1 February 2011, is presented in panel a. The simulated precipitation from the GF scheme not applying the diurnal cycle closure shows a premature peak, with both precipitation and DSWR closely in phase. The introduction of the B2014 closure causes a shift between the two curves, delaying the peak of precipitation by about $3 \mathrm{~h}$, in better agreement with the observation. 
The diurnal cycle averaged over the 15 runs with $120 \mathrm{~h}$ forecasts each is presented in panel $\mathrm{b}$, clearly showing the rainfall shift, which demonstrates the robustness of the B2014 closure. One potential drawback of this closure is the systematic reduction of the total amount of precipitation evidenced in panel b. Future work will focus on this issue.

An example of real-time rainfall forecast over South America with BRAMS using a different set of physical parameterizations is discussed as follows. The case is associated with a mid-latitude cold front approach together with tropical daytime convection over the northwestern part of the Amazonia Basin and a weak band of convection in the Inter-Tropical Convergence Zone (ITCZ) over the Atlantic Ocean. Figure 8 shows an estimate of the $24 \mathrm{~h}$ accumulated rainfall given by the TRMM product for the day of 12 October 2015 and depicts location and rainfall intensities of the cloud systems discussed above. This rainfall estimate is produced on a grid with $0.25^{\circ}$ resolution. Model forecast was done on $5 \mathrm{~km}$ horizontal grid spacing with the vertical resolution varying from $50 \mathrm{~m}$ up to a maximum value of $850 \mathrm{~m}$, with the top of the model at $19 \mathrm{~km}$. The soil model was composed of seven layers distributed within the first $12 \mathrm{~m}$ of the soil depth. Again, GFS analysis and forecast fields were used for initial and boundary conditions, while initial soil moisture was supplied following Gevaerd and Freitas (2006), and the sea surface temperature was prescribed using data from Reynolds et al. (2002). The physical parameterizations included RRTMG shortwave and longwave radiation schemes, the GF 2015 version for deep and shallow convection with the diurnal cycle closure, Thompson single moment on cloud liquid water (no aerosol aware option) cloud microphysics, and the MYNN turbulence parameterization. The model run was completed on a CRAY XE-6 supercomputer using 2400 cores. This configuration took $1.6 \mathrm{~h}$ to complete a $24 \mathrm{~h}$ forecast with $1360 \times 1480$ on horizontal and 45 on vertical grid points, and $12 \mathrm{~s}$ for the time step. The simulation applied the hybrid time integration scheme with the RA time filter.

Figure 9 presents the $24 \mathrm{~h}$ accumulated rainfall model forecast for this day. The total (resolved plus from convection scheme) rainfall is shown in panel a. Visual comparison with TRMM rainfall (Fig. 8) shows that the model properly reproduces the main rainfall patterns over different parts of South America, despite the extreme amount of concentrated rainfall estimated by TRMM on the Amazon Basin (around $5^{\circ} \mathrm{S}$ and $65^{\circ} \mathrm{W}$ ) being underestimated by the model. Similar model behavior is spotted in the Atlantic Ocean, close to the border between Brazil and Uruguay. However, in general, the model is able to capture consistently the rainfall intensity as well. Figure $9 \mathrm{~b}$ shows the separated contribution of the cumulus convection scheme to the total rainfall (panel a). Noticeable is the fact that, on $5 \mathrm{~km}$ grid spacing, the scale awareness capability of the convection scheme allows the rainfall associated with the mid-latitude cold front to be almost entirely explicitly resolved. On the other hand, over tropical areas a significant part of the total rainfall is rather gener-

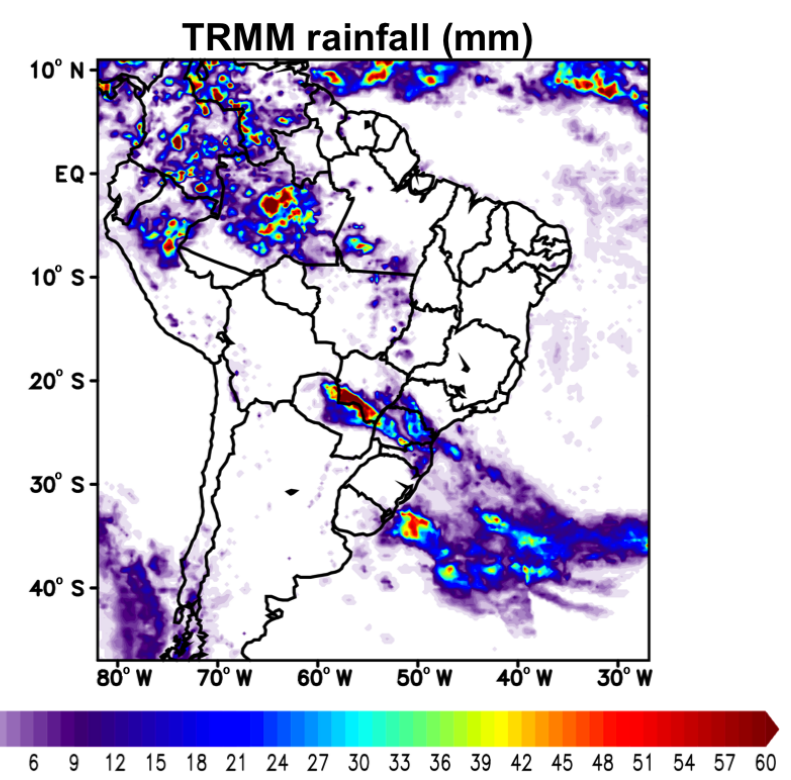

Figure 8. TRMM $24 \mathrm{~h}$ accumulated rainfall for the day of $12 \mathrm{Oc}-$ tober 2015 . The data are produced at $0.25^{\circ}$ grid resolution and the unit is $\mathrm{mm}$.

ated by the convection scheme, suggesting the existence of much smaller-scale rainfall systems, which is not explicitly captured at this model resolution.

\subsection{Atmospheric composition related processes and tracer transport}

\subsubsection{The CCATT in-line emission, deposition, transport, and chemical reactivity model}

The Coupled Chemistry-Aerosol-Tracer Transport model (Longo et al., 2013, hereafter CCATT) is an Eulerian transport model coupled with BRAMS and developed to simulate the transport, dispersion, chemical transformation, and removal processes of gases and aerosols for atmospheric composition and air pollution studies. CCATT computes the tracer transport in line with the simulation of the atmospheric state by BRAMS, using the same dynamical core, transport scheme, and physical parameterizations. The prognostic of the tracer mass mixing ratio includes the effects of sub-gridscale turbulence in the planetary boundary layer and convective transports by shallow and deep moist convection, in addition to grid-scale advective transport. The model also includes gaseous/aqueous chemistry, scavenging and dry depositions, and aerosol sedimentation. 
(a) Total rainfall $(\mathrm{mm})$

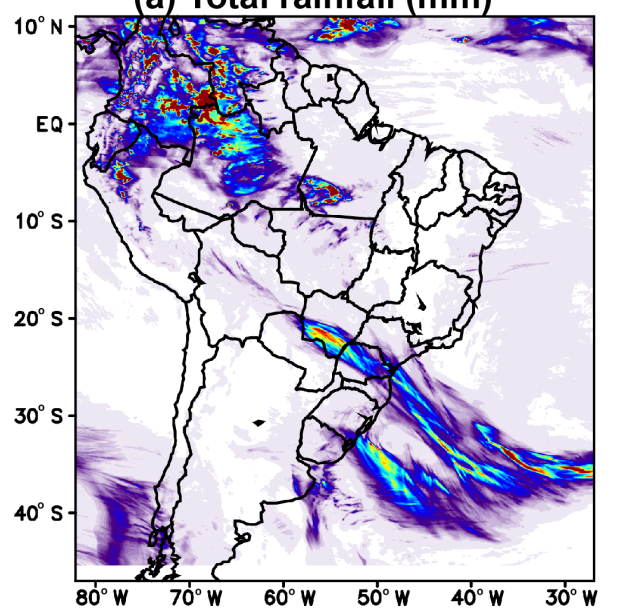

(b) CUPAR rainfall $(\mathrm{mm})$

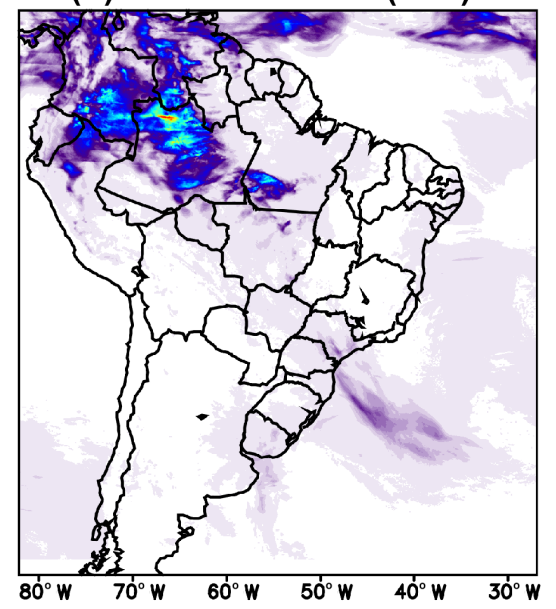

$\begin{array}{lllllllllllllllllllll}0 & 3 & 6 & 9 & 12 & 15 & 18 & 21 & 24 & 27 & 30 & 33 & 36 & 39 & 42 & 45 & 48 & 51 & 54 & 57 & 60\end{array}$

Figure 9. BRAMS model forecast of $24 \mathrm{~h}$ accumulated (a) total precipitation and (b) from convective parameterization for 12 October 2015 and on $5 \mathrm{~km}$ grid spacing. The unit is $\mathrm{mm}$.

In a form of tendency, the general mass continuity equation for gas-phase tracers solved in the CCATT model is

$$
\begin{aligned}
\frac{\partial \bar{s}}{\partial t}= & \left(\frac{\partial \bar{s}}{\partial t}\right)_{\mathrm{adv}}+\left(\frac{\partial \bar{s}}{\partial t}\right)_{\substack{\mathrm{BSL} \\
\text { diff }}}+\left(\frac{\partial \bar{s}}{\partial t}\right)_{\substack{\text { deep } \\
\text { conv }}} \\
& +\left(\frac{\partial \bar{s}}{\partial t}\right)_{\substack{\text { shallow } \\
\text { conv }}}+\left(\frac{\partial \bar{s}}{\partial t}\right)_{\text {chem }}+W+R+Q,
\end{aligned}
$$

where $\bar{s}$ is the grid box mean tracer mixing ratio, the term adv represents the 3-D resolved transport (advection by the mean wind) and the terms PBL diff, deep conv, and shallow conv stand for the sub-grid-scale turbulence in the planetary boundary layer (PBL) and deep and shallow convection, respectively. The chem term refers either to the simple passive tracers' lifetime (Freitas at al., 2009) or to the calculation of chemical loss and production (Longo et al., 2013). $W$ is the term for wet removal applied only to aerosols, and $R$ is the term for the dry deposition applied to both gases and aerosol particles. Finally, $Q$ is the emission source term, which for biomass burning emissions also solves the plume rise mechanism associated with vegetation fires (Freitas et al., 2006, 2007, 2010).

In addition to CCATT-BRAMS code itself, the modeling system also includes three pre-processing software tools for user-defined chemical mechanisms (M-SPACK, Longo et al., 2013), aerosol and trace gas emissions fields (PREP-CHEMSRC, Freitas et al., 2011), and the interpolation of initial and boundary conditions for meteorology and chemistry (BCPREP) (see Fig. 10).

The choice of different chemistry mechanisms in CCATTBRAMS is possible using a modified version of the SPACK pre-processing tool (Simplified Pre-processor for Atmo- spheric Chemical Kinetics, Damian-Iordache and Sandu, 1995; Djouad et al., 2002). The modified-SPACK (hereafter called M-SPACK) basically allows the passage of a list of species and chemical reactions from symbolic notation (text file) to a mathematical one (ODEs), automatically preprocesses chemical species aggregation, and creates Fortran 90 routines files directly compatible to be compiled within the main CCATT-BRAMS code. The M-SPACK output also feeds the codes of pre-processor tools PREP-CHEM-SRC and BC-PREP for emissions and the initial and boundary fields for the chemical species, respectively, in order to ensure consistency between the several input databases to be used in CCATT-BRAMS and the list of species treated in chemical mechanisms.

In principle, M-SPACK allows the use of any chemical mechanism in CCATT-BRAMS, though it requires building of the emissions interface. The current version of M-SPACK includes three widely used tropospheric chemistry mechanisms: RACM, the Regional Atmospheric Chemistry Mechanism (Stockwell et al., 1997), Carbon Bond (Yarwood et al., 2005), and RELACS, the Regional Lumped Atmospheric Chemical Scheme (Crassier et al., 2000), which consider, respectively, 77, 36, and 37 chemical species. Photolysis calculations are possible via LUTs of pre-calculated photolysis rates as well as through Fast-J (Wild et al., 2000; Brian and Prather, 2002) and Fast-TUV (Madronich, 1989; Tie et al., 2003) radiative codes. The latter approach provides online calculation of photolysis rates, including interaction of radiation with aerosols and clouds.

CCATT-BRAMS performance has been extensively evaluated for both urban and biomass burning areas (Freitas et al., 2009; Longo et al., 2010, 2013; Alonso et al., 2010; Bela 


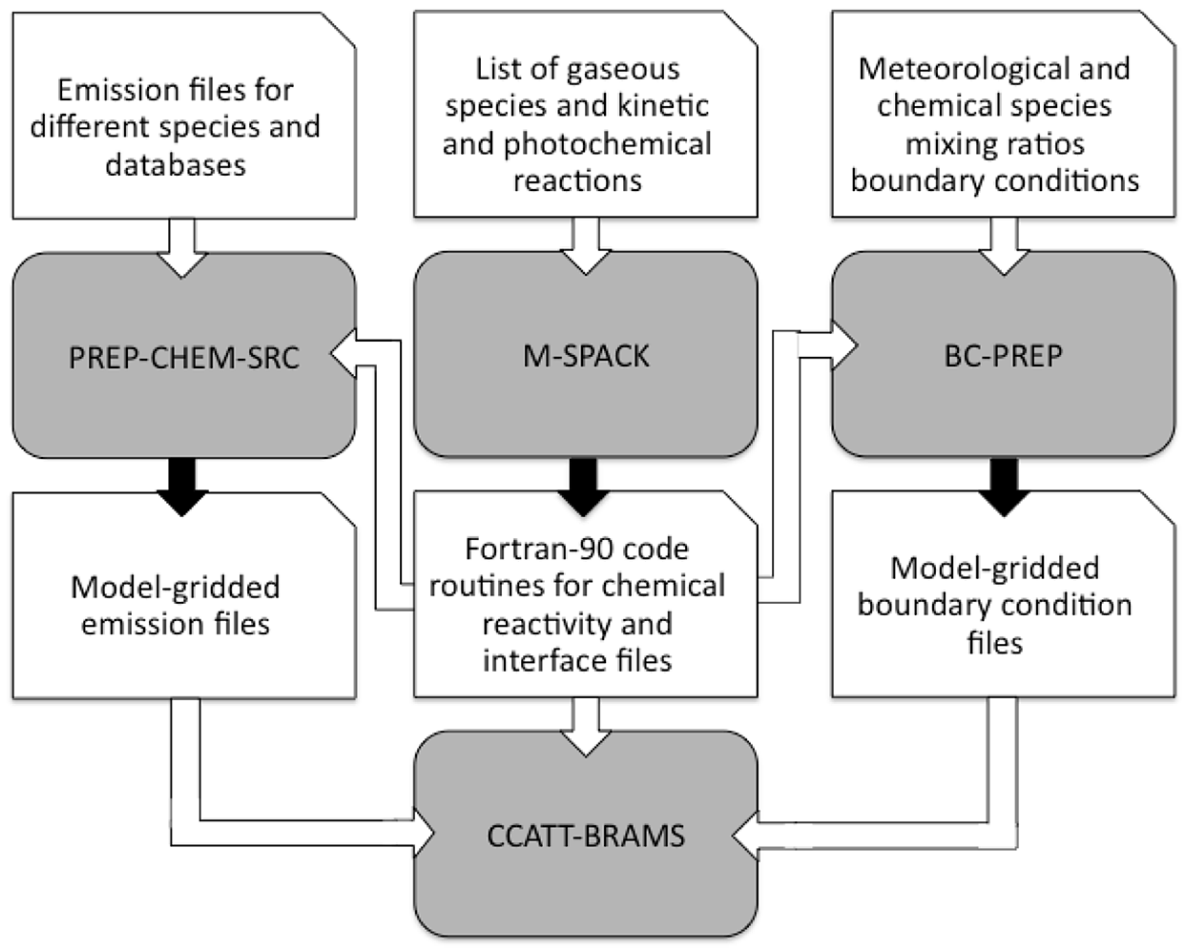

Figure 10. A chart of the BRAMS system with the CCATT chemistry model component. The gray blocks and the black arrows indicate the codes that make up the CCATT-BRAMS system and their outputs, respectively. The white blocks indicate either the input files for the pre-processing (first line) as the pre-processing outputs (third line), which are also input files for pre-processing emissions and boundary conditions and routines for composing the BRAMS model (adapted from Longo et al., 2013).

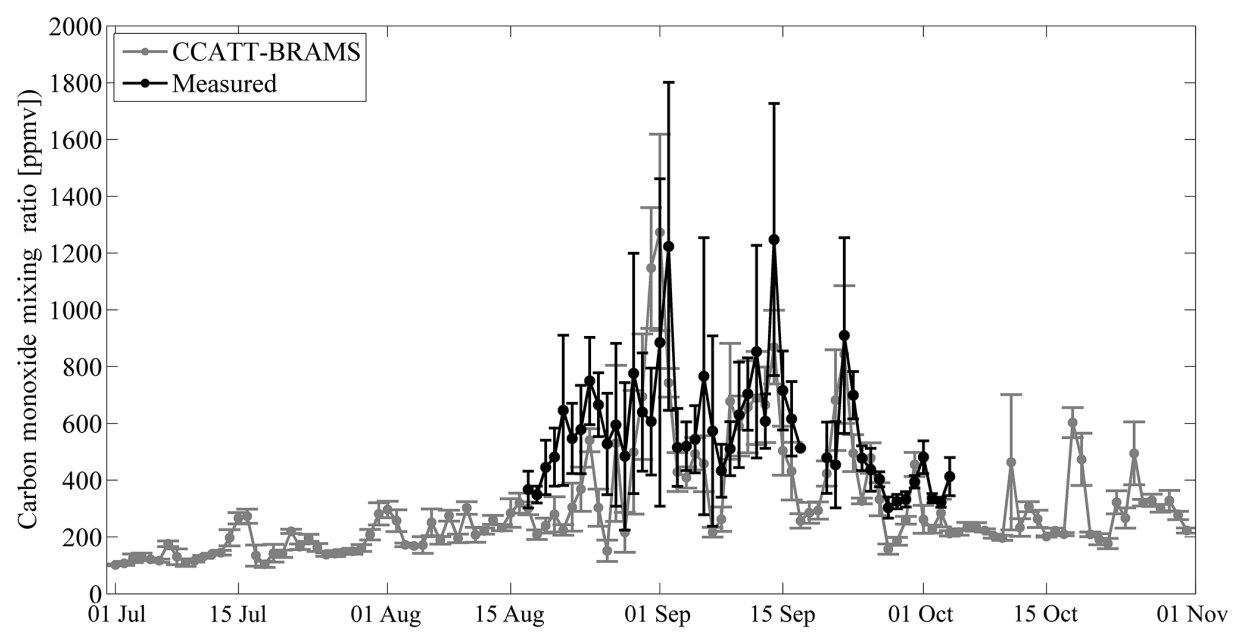

Figure 11. Time series of mean daily values of the mixing ratio of carbon monoxide measured at an Amazonian ground station (Porto Velho) and from CCATT-BRAMS simulations.

et al., 2015). Figures 11 and 12 depict examples of model comparison results with mean daily values of carbon monoxide and ozone mixing ratio measured near the surface level in Porto Velho, Brazil, from 14 August to 8 October 2012. For this specific experiment, the model was configured to simulate smoke emission, transport, and its effects during the 2012 dry season in South America. The applied domain covered the whole of South America with a horizontal resolution of $25 \mathrm{~km}$ and 42 vertical levels. Atmospheric initial and boundary conditions were assimilated from analysis of the Brazilian Center for Weather Forecasting and Climate Studies global circulation model. The tropospheric chemistry 


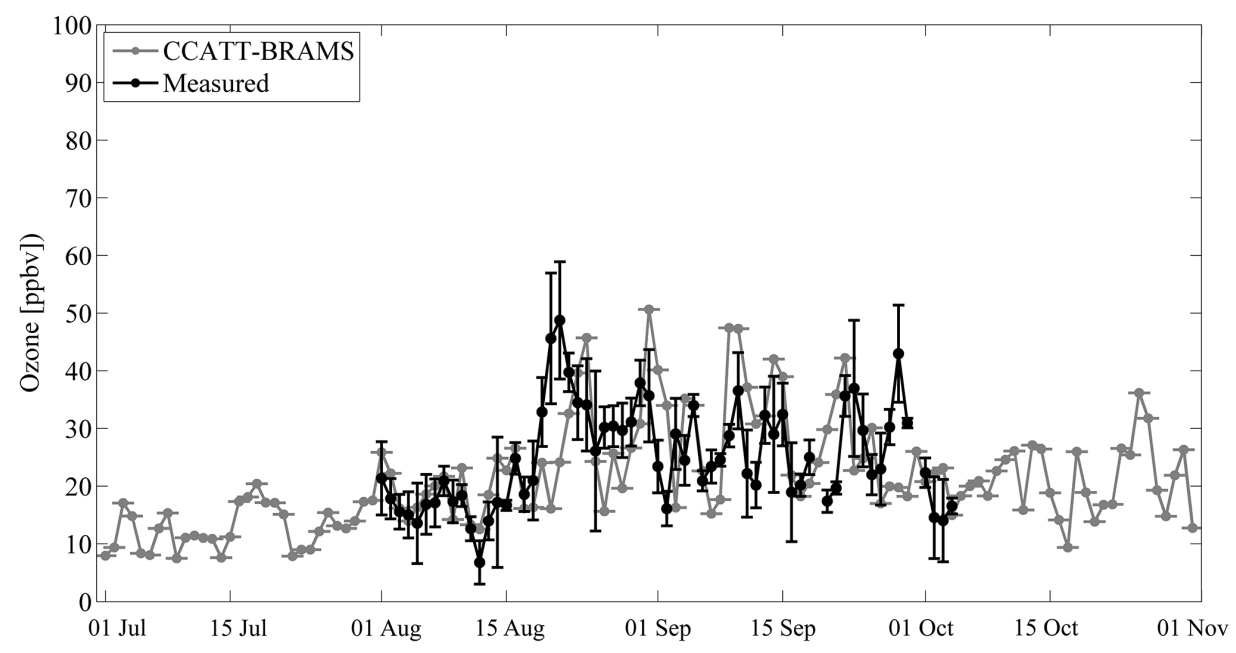

Figure 12. Time series of the ozone mixing ratio measured at an Amazonian ground station and from CCATT-BRAMS simulations.

mechanism used was RACM and biomass burning emissions for carbon monoxide and ozone precursors were estimated by the Brazilian Biomass Burning Emission Model (3BEM, Longo et al., 2010) in PREP-CHEM-SRC based on satellite remote sensing fire detections (Freitas et al., 2011).

\subsubsection{Simple Photochemical Model with TEB}

BRAMS also has a simpler option for ozone forecasting suitable for urban areas. The Simple Photochemical Model (SPM) is available in the model together with the TEB scheme (E. D. Freitas et al., 2005). The model is composed of 15 reactions related to ozone formation and consumption. This small number of reactions was possible through the lamping of a large number of hydrocarbons, allowing a simplified way to deal with the photochemical process in the model, which is very convenient to be used in the operational mode. TEB-SPM considers industrial and vehicular emissions of carbon monoxide, volatile organic compounds (VOC), nitrogen oxides $\left(\mathrm{NO}_{x}\right)$, sulfur dioxide $\left(\mathrm{SO}_{2}\right)$, and particulate matter $\left(\mathrm{PM}_{2.5}\right)$. In spite of its very simple formulation, the model has been used with relative success to simulate ozone concentrations in the São Paulo (E. D. Freitas et al., 2005) and Rio de Janeiro metropolitan areas in Brazil. Figure 13, adapted from Carvalho (2010), shows a comparison between model results and ozone observational data in two ground stations (Duque de Caxias and Jardim Primavera) of an automated network maintained by Rio de Janeiro's Environmental Agency (INEA). As one can see, the agreement is relatively high for a period over 7 days. For the simulations, the author used the Global Forecast System (GFS) analysis for the initial and boundary conditions. The model was set up with two nested grids of 16 and $4 \mathrm{~km}$ horizontal grid spacing, respectively, with 33 vertical sigma- $z$ type levels. Both grids were centered at $22.80^{\circ} \mathrm{S}$ and $43.25^{\circ} \mathrm{W}$. The coarser domain covered an area of $61440 \mathrm{~km}^{2}(60 \times 30$ grid points), while the inner domain covered a $22464 \mathrm{~km}^{2}$ area (54 $\times 26$ grid points). The primary pollutant emissions were based on the inventories provided by INEA and considered both vehicular and industrial emissions for the five elements previously mentioned (CO, VOC, $\mathrm{NO}_{x}, \mathrm{SO}_{2}$, and $\left.\mathrm{PM}\right)$.

\subsubsection{Carbon cycle}

This section introduces the capability of BRAMS composed with JULES in simulating $\mathrm{CO}_{2}$ fluxes associated with biogenic activities. Here we discuss an example of model simulation for September 2010 over the Amazon Basin. For this case, the BRAMS model was set with $20 \mathrm{~km}$ horizontal resolution covering the northern part of South America. The simulation was carried out for 45 days, starting on $15 \mathrm{Au}-$ gust 2010 at 00:00 UTC, with the first 15 days discarded due to model spinup. The NCEP Global Forecast System analysis (http://rda.ucar.edu/datasets/ds083.2/), with $1^{\circ} \times 1^{\circ}$ spatial resolution, provided initial and boundary conditions for the meteorological fields. The carbon data assimilation system, Carbon Tracker 2015 (Krol et al., 2005), with $3^{\circ} \times 2^{\circ}$ horizontal resolution, provided the $\mathrm{CO}_{2}$ initial and boundary conditions. Biomass burning emissions of trace gases and aerosols were from 3BEM (Longo et al., 2010). The land use map, with $1 \mathrm{~km}$ spatial resolution, was provided by the USGS (United States Geological Survey), merged with a land cover map for the Brazilian legal Amazon region (Sestini et al., 2003). Figure 14 presents the gross primary productivity (GPP, panel a), plant respiration (PR, panel b), soil respiration (SR, panel c), and the net ecosystem exchange $(\mathrm{NEE}=\mathrm{PR}+\mathrm{SR}-\mathrm{GPP}$, panel d), all as a monthly average. September corresponds to the last month of the austral winter, with typically a very low amount of rainfall over a large part of Brazil. In this month, the ITCZ stays over positive latitudes, inducing rainfall only in the northwestern part of South America, with warm temperatures (maximum around $33^{\circ} \mathrm{C}$ ), 

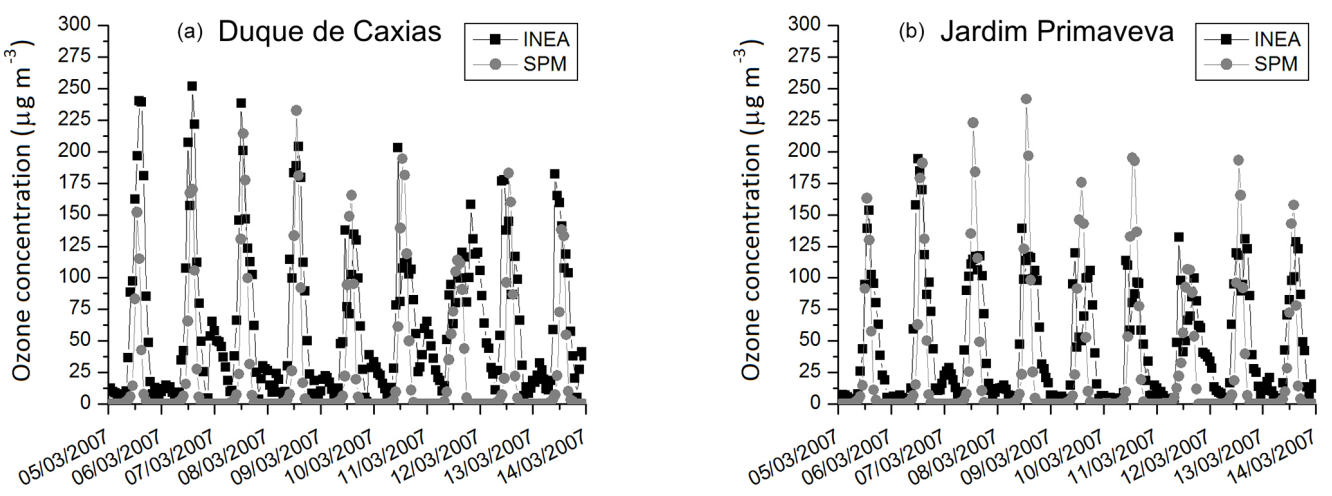

Figure 13. Comparisons between model results for ozone concentrations and observed values provided by INEA in Rio de Janeiro (adapted from Carvalho, 2010).
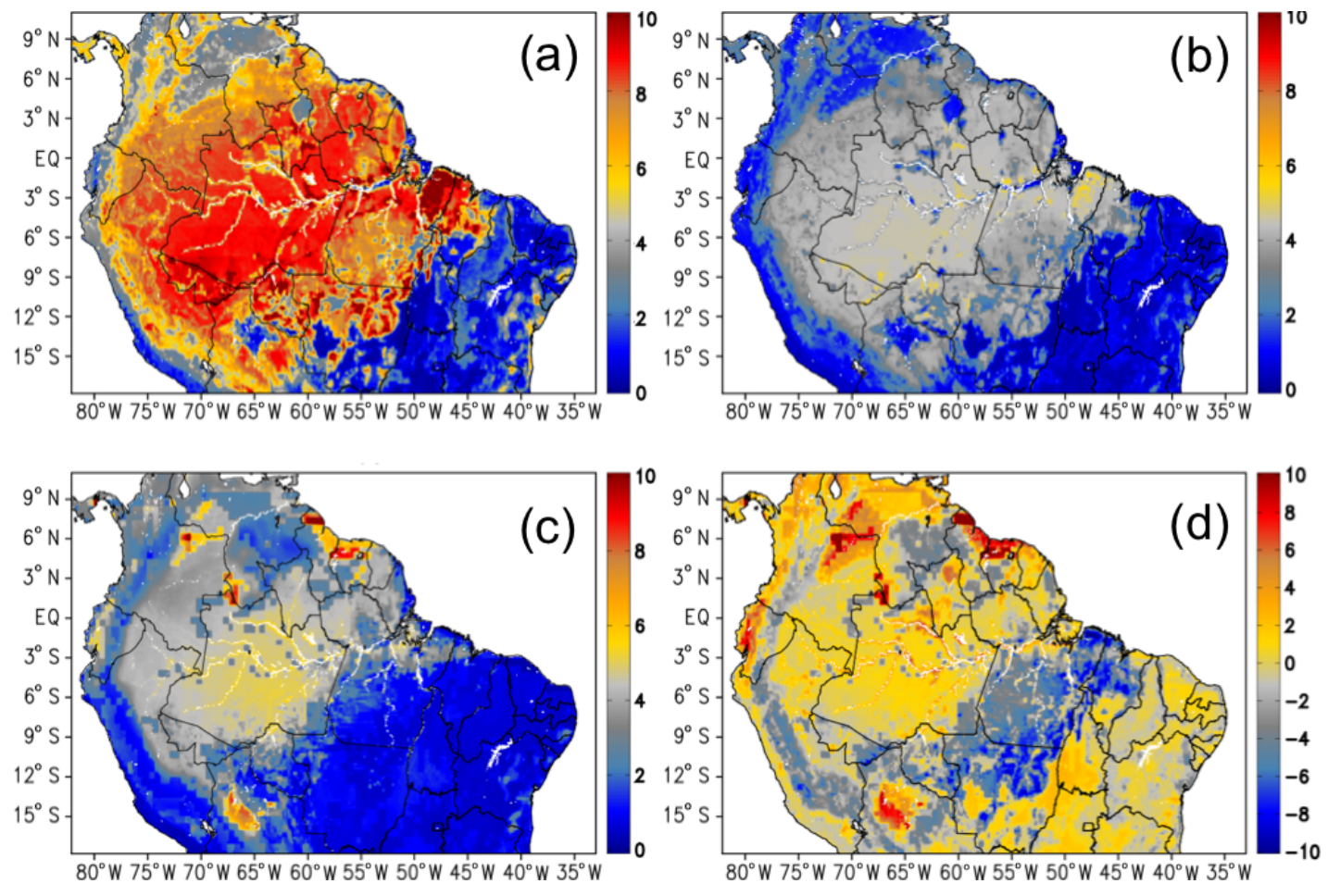

Figure 14. $\mathrm{CO}_{2}$ fluxes as simulated by BRAMS ( $\mu$ molC m $\mathrm{m}^{-2} \mathrm{~s}^{-1}$ ), average for September 2010. (a) Gross primary production, (b) plant respiration, (c) soil respiration, and (d) net ecosystem exchange. A positive value means $\mathrm{CO}_{2}$ flux from the atmosphere to the land surface.

low moisture, and clear skies. The abundance of photosynthetic active radiation and water availability in root zones of the tropical forest implies a large GPP over the region dominated by this land cover. As SR is mostly controlled by the soil humidity, the larger values are present in the region with higher rainfall amounts, which are in the northwestern part of the domain shown. At the same time, over areas dominated by Cerrado and Caatinga biomes, dry soil conditions dictate the response of the plants, with very low values of GPP and SR. However, the simulated NEE presents a more complex spatial distribution, with values oscillating from around zero and extreme around $\pm 10 \mu \mathrm{mol} \mathrm{C} \mathrm{m}{ }^{-2} \mathrm{~s}^{-1}$, meaning $\mathrm{CO}_{2}$ in/out atmospheric fluxes (panel d).

BRAMS simulation of the diurnal cycle of $\mathrm{CO}_{2}$ in the low troposphere over the Amazon Basin is discussed as follows. Figure 15 shows 1-day simulation of the $\mathrm{CO}_{2}$ mixing ratio and the turbulent kinetic energy (TKE) in the low troposphere and DSWR at the surface. In this figure, TKE is used as a proxy for the depth of the atmospheric boundary layer, which evolves from a stable layer with less than $200 \mathrm{~m}$ depth during the nighttime and early morning towards a convective and well-mixed boundary layer with maximum heights of 1.2 to $1.5 \mathrm{~km}$ in the late afternoon. The results show a real- 
istic nighttime near-surface accumulation of $\mathrm{CO}_{2}$ associated with the surface (soil and vegetation) respiration and a shallow stable boundary layer. After sunrise, with the increasing DSWR, the photosynthesis starts to dominate the net flux of $\mathrm{CO}_{2}$, which becomes more negative and subtracts this gas from the atmosphere. At the same time, the heating of the surface produces buoyant air parcels, which generates TKE deepening of the mixing layer. As a result, $\mathrm{CO}_{2}$ is mixed up and depleted inside of this layer, with its mixing ratio ending smaller than the one of the free atmosphere late in the afternoon.

\subsubsection{Volcanic ash transport and dispersion}

The BRAMS tracer transport capability also incorporates emission, transport, dispersion, settling, and dry deposition of volcanic emissions, both for ash and a set of related gases. This capacity represents a critical step towards a numerical tool suitable not only for research, but also for an emergency, on-demand system for ash dispersion forecast after a volcanic eruption event, which is required for the safety of the air traffic around disturbed areas. The volcanic ash module follows closely the system described in Stuefer et al. (2013), and more details of its implementation in BRAMS are provided in Pavani (2014) and Pavani et al. (2016). The input needed to set up BRAMS for volcanic ash is produced using the PREP-CHEM-SRC (Freitas et al., 2011) emissions preprocessing tool, which contains a comprehensive database developed by Mastin et al. (2009). This database has information about 1535 volcanoes, including location (geographical position and height above sea level of the vent) and a set of historical parameters (e.g. initial plume height, mass eruption rate, volume rate, duration of eruption, and size distribution of the ash particle), which can be used as a first guess for a potentially recurring volcanic eruption. However, by default, whenever available, observed real-time information overwrites the historical ones. In BRAMS simulations, a vertical profile of the ash emission distribution is defined by a linear detraining of $25 \%$ of the total ash mass below the injection height and $75 \%$ around it, obeying a parabola shape. Pavani et al. (2016) adjusted an exponential curve between the rate of ash mass produced during the eruption and the injection height, which is expressed as follows:

$H=0.34 M^{0.24}$,

where $H$ is the plume height in $\mathrm{km}$ (height above the vent) and $M$ is the emission rate in $\mathrm{kg} \mathrm{s}^{-1}$. This fitting formula is an additional method to make a first guess of the erupted mass of ash when the injection height is known.

The model functionality for volcanic ash dispersion has been applied to real cases. One example is the eruption of the Puyehue volcano in Chile, which occurred around 20:15 UTC on 4 June 2011, expelling a huge mass of ash and gases up to $13 \mathrm{~km}$ in height above sea level. This eruptive event caused the closure of numerous airports for many

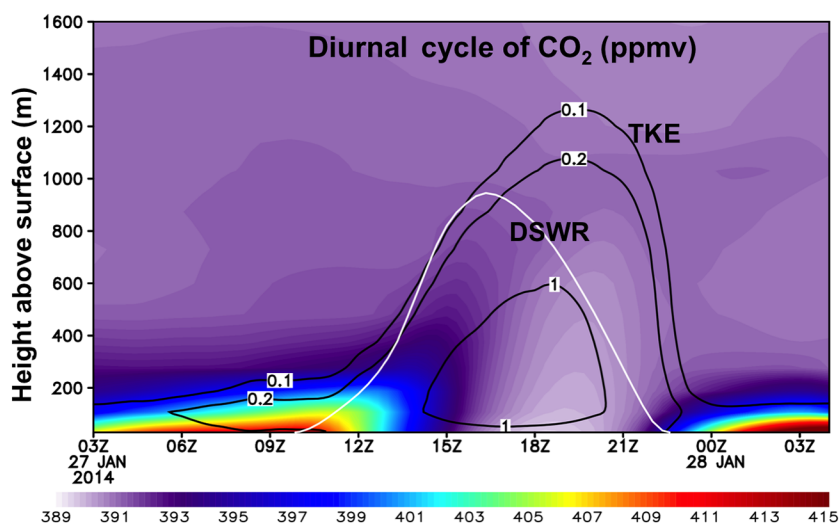

Figure 15. The diurnal cycle of the $\mathrm{CO}_{2}$ mixing ratio (ppmv, shaded colors), the turbulent kinetic energy (TKE, $\mathrm{m}^{2} \mathrm{~s}^{-2}$, black contours), and the downwelling shortwave radiation at the surface (DSWR, $\mathrm{W} \mathrm{m}^{-2}$, in white line and using the same scale as the height above the surface on the left) as simulated by BRAMS with the JULES surface scheme in the low troposphere. All quantities are area averaged over a portion of the Amazon Basin with tropical forest as the dominant vegetation type, and correspond to an example for 27 January 2014.

days and transport disruption in several countries in South America, South Africa, and even Australia and New Zealand. Additionally, ash scavenging caused harm to agriculture and livestock, besides other economical and public health related issues. Costa et al. (2012) described the development and application of a remote sensing technique for traces of ash retrieval based on METEOSAT-8 satellite data.

The BRAMS simulation to study the transport of the Puyehue volcano ash was carried out for 40 days starting on 4 June 2011, 00:00 UTC, with $30 \mathrm{~km}$ horizontal resolution and a vertical resolution starting at $100 \mathrm{~m}$ at the surface, stretching with a ratio of 1.1 up to $500 \mathrm{~m}$ at the model top. Figure 16 shows the location of ash as determined by this technique on 6 June 2011, 15:00 UTC, approximately $44 \mathrm{~h}$ after the first eruption event. The eruption introduced material into the jet stream region which was rapidly transported eastward following the Rossby wave circulation. BRAMS results for this case study showed significant improvement with the use of the monotonic advection scheme described in Sect. "Monotonic scheme for advection of scalars", since monotonicity is required to properly model the long distance transport of tracers associated with sharp, small-scale emission sources within low-resolution atmospheric models. Figure 17 depicts the regional distribution of the ashes, as an example of the model performance in simulating the longrange transport of volcanic emissions. Panel a shows the simulated vertically integrated total mass of ash $\left(\mathrm{mg} \mathrm{m}^{-2}\right)$ for the same time of the remote sensing imagery (Fig. 16). Panel b shows the ash total mass concentration $\left(\mu \mathrm{g} \mathrm{m}^{-3}\right)$ at approximately $9500 \mathrm{~m}$ above the surface. At the beginning of the eruption, the ash was transported eastward for about $20^{\circ}$, 


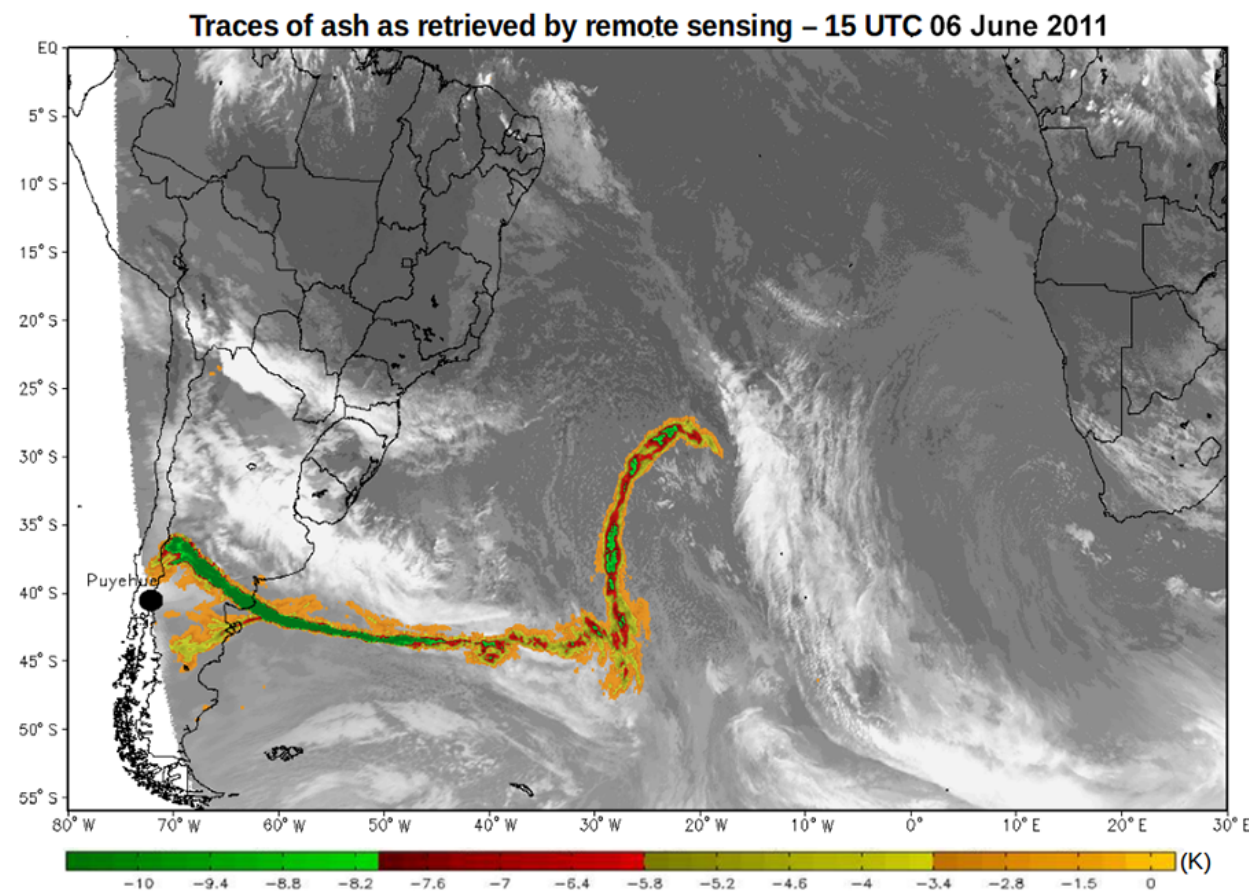

Figure 16. Traces of volcanic ash associated with the eruption of the Puyehue volcano as retrieved from METEOSAT- 8 satellite data. The image corresponds to 6 June 2011 at 15:00 UTC. The color scale refers to the temperature difference between the infrared 10 and 11 channels (Costa et al., 1012), the contrast allowing one to identify the ashes.

and then assumed an undulating shape associated with the Rossby waves. The ash layer at $9500 \mathrm{~m}$ is constituted primarily of small-sized particles, since the larger and heavier ones quickly fall vertically due to the gravitational force. The higher sensitivity of the ash retrieval in the upper levels explains the better agreement between the ash distribution presented in this panel and the traces of ash retrieved by remote sensing (Fig. 16). The wider ash distribution close to the volcanic vent in panel a is associated mainly with the vertical settling of the large, heavy ash particles that end by getting different wind circulations and/or are quickly deposited over land. A more comprehensive analysis of this case study is discussed in Pavani et al. (2016).

\subsection{Additional features, miscellaneous aspects}

\subsubsection{Coupling with STILT Lagrangian particle dispersion modeling}

The Stochastic Time-Inverted Lagrangian Transport model (STILT, Lin et al., 2003) is a Lagrangian model framework coupled with surface emission models, and has been used to identify sources and their influence on receptors in studies with a multitude of scales and chemical components (see Gerbig et al., 2003; Miller et al., 2008, 2013; Xiang et al., 2013; McKain et al., 2015). The core component of STILT is a Lagrangian particle dispersion model that has two key features that allow for a realistic representation of disper- sion: (1) STILT accounts for sub-grid-scale transport and dispersion by incorporating an stochastic component associated with small-scale turbulence (Lin et al., 2003); (2) STILT also accounts for vertical transport due to parameterized convective clouds (Nehrkorn et al., 2010). However, in order to take full advantage of BRAMS turbulent and convective models, additional turbulence and convection related quantities are included in BRAMS output so that they can be directly used by STILT.

Following Lin et al. (2003), in STILT each wind component $u_{i}$ can be decomposed following a Markov assumption, i.e. the grid volume average component $u_{i}^{\prime}$ and a turbulent component $u_{i}^{\prime}$. The turbulent component is modeled after Hanna (1982), who defines the autocorrelation coefficient in terms of the Lagrangian timescale $T_{\mathrm{Li}}$ and the standard deviation of wind $\sigma_{u i}$ in the mixing layer:

$$
\begin{gathered}
u_{i}^{\prime}(t+\Delta t)=\alpha_{i}(\Delta t) u_{i}^{\prime}(t)+N\left(0, \sigma_{u_{i}}(t)\right) \sqrt{1-\left(\sigma_{i}(\Delta t)\right)^{2}}, \\
\alpha_{i}(\Delta t)=\exp \left(\frac{-\Delta t}{T_{L_{i}}}\right),
\end{gathered}
$$

where $t$ is the previous time, $\Delta t$ is the time step, and $N$ is a random number following the normal distribution with mean 0 and standard deviation given by $\sigma_{u i}$. For consistency with the turbulence scheme, the standard deviation is computed following Nakanishi and Niino (2004). The Lagrangian timescale is determined following the parameterization by Hanna (1982), which also depends on the boundary 


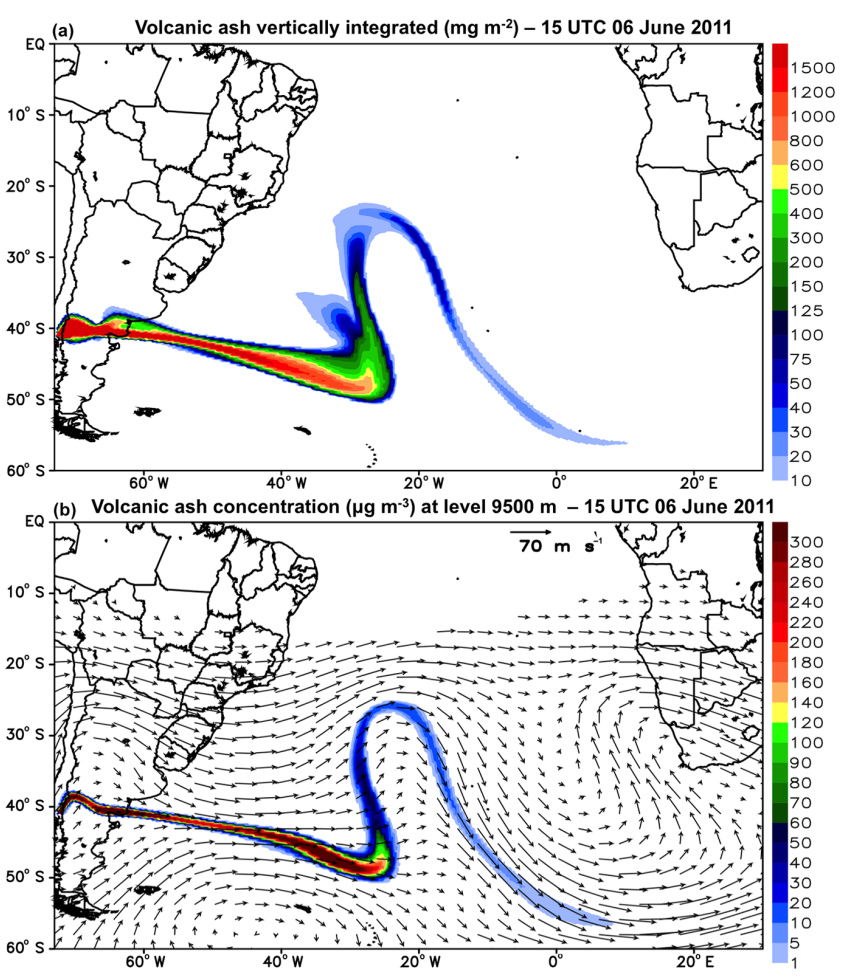

Figure 17. (a) Vertically integrated total mass of ash $\left(\mathrm{mg} \mathrm{m}^{-2}\right)$. (b) Total ash mass concentration $\left(\mu \mathrm{g} \mathrm{m}^{-3}\right)$ at the level of approximately $9500 \mathrm{~m}$ above the surface and the associated horizontal wind. Both panels show results for 6 June 2011 at 15:00 UTC as simulated by the BRAMS model.

layer depth. Hanna (1982) parameterization of the boundary layer depth depends on the reciprocal of the vertical component of Coriolis vorticity, which would cause singularities at the Equator. Therefore, we implemented an alternative parameterization by Vogelezang and Holtslag (1996).

When BRAMS simulations are carried out using the Grell and Dévényi (2002) cumulus parameterizations, all mass fluxes associated with updrafts and downdrafts (entrainment, detrainment, and vertical motion) are also saved to the output, and can be used to assign both the probability of any particle being in the environment or in the cloud (either at the updraft or downdraft), as well as the vertical displacement of particles in case they are in the updrafts or downdrafts, using the same method described by Nehrkorn et al. (2010). Besides, the inclusion of mass flux and turbulence related variables in the output also allows a seamless integration with different Lagrangian particle dispersion models.

\subsubsection{Coupling with an air parcel trajectories model}

BRAMS simulated fields can readily be applied as input data to a 3-D air parcel kinematic trajectory model described in Freitas et al. (1996, 2000). Forward and backward time integrations are allowed using a second order in time accurate scheme. The trajectories are computed using the same map projection and the vertical coordinate of BRAMS and also include a sub-grid-scale vertical velocity enhancement associated with sub-grid-scale convection not explicitly solved by model dynamics.

\subsubsection{Digital filter}

A digital filter for model initialization has been implemented in BRAMS and demonstrated the ability to reduce high-order imbalances and inconsistencies among model variables, with the potential to improve deterministic forecasts.

\subsubsection{Model output for GrADS visualization}

A new feature present in BRAMS is the possibility of the model output being produced in GrADS (http://iges.org/ grads) format during the runtime, simultaneously with the model integration. This feature is especially important for operational centers by allowing faster generation of operational products.

\subsection{Model data structure and code aspects}

BRAMS version 5.2 is mostly written in Fortran 95, with a few modules written in C. BRAMS has had a pure MPI parallelism since its first version. Only the horizontal domain is decomposed over MPI ranks. This parallelism has been incrementally enhanced over time in a cumulative fashion; that is, enhancements made to previous versions are present in version 5.2. The following paragraphs summarize the development history of BRAMS parallelism.

BRAMS versions 1 to 4 were run on machines with less than 100 computing cores. Parallel scalability of BRAMS on machines with higher core counts was unknown. In 2007 CPTEC acquired SUN-NEC cluster "UNA" with 275 nodes, each node with two dual-core AMD Opteron 2218, with a total of 1100 cores. Each node addresses 8 GB of central memory and the nodes are connected to a 70 TB Lustre parallel file system. UNA was used to enhance the parallel scalability of BRAMS version 4.2 from about 100 cores to about 1000 cores. In 2011 CPTEC acquired a Cray XE6 named "TUPA" with 1304 computing nodes, each node with two 12-core AMD Opteron Magny Cours with a total of 31296 cores. Each node addresses 32 GB of central memory and the nodes are connected to a $866 \mathrm{~TB}$ Lustre parallel file system. TUPA was used to enhance parallel scalability of BRAMS version 5.2 from about 1000 cores to about 10000 cores.

Core count increase was used to enhance resolution. CPTEC's operational domain covers most of South America and parts of the surrounding oceans, spanning an area of approximately $6800 \times 7400 \mathrm{~km}$. UNA was used to enhance horizontal resolution from the previous operational resolution of $20 \mathrm{~km}$ to the new $10 \mathrm{~km}$ resolution, keeping 38 vertical levels on both grids. TUPA was used to enhance horizontal reso- 


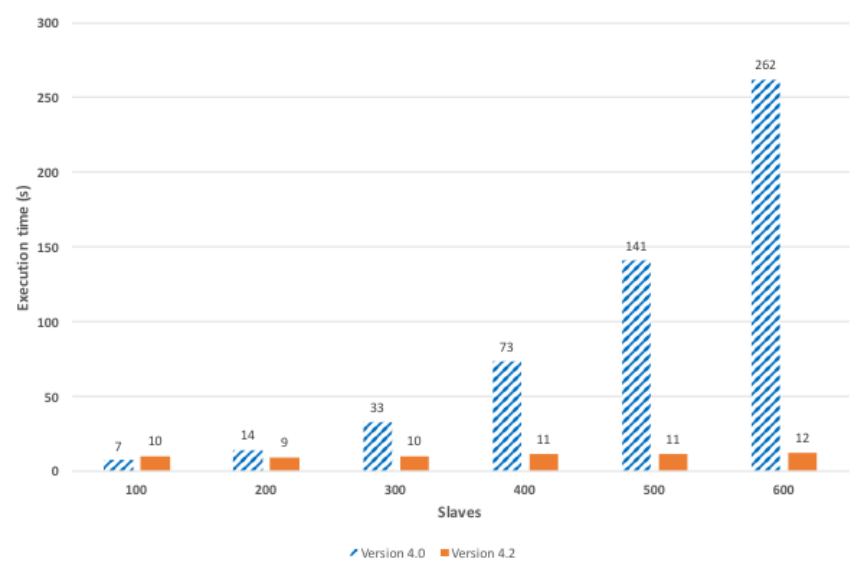

Figure 18. Execution time of the input phase at UNA for $24 \mathrm{~h}$ forecasting over the $20 \mathrm{~km}$ grid.

lution to $5 \mathrm{~km}$ and increase the number of vertical levels to 45. The $5 \mathrm{~km}$ grid has about 90 million grid points, about 19 times the number of grid points of the $20 \mathrm{~km}$ grid. To keep numerical stability according to the CFL condition, the timestep integration has to be decreased according to horizontal grid resolution, increasing the total amount of computing from the $20 \mathrm{~km}$ grid to the $5 \mathrm{~km}$ grid by a factor of about 76 times per forecasting day. This increase in computing has to be achieved by enhancing parallel scalability by a factor of 100 , from about 100 cores to about 10000 cores.

Parallel scalability of BRAMS versions 4.2 to 5.2 was enhanced by working on four unglamorous computing phases. Input and output algorithms were sequential. Master-slave parallelism wasted computational resources and created unnecessary synchronization points. Old coding practices used too much memory. The work on each of these directions is summarized herein.

In BRAMS version 4, input was performed by the master process. The master process input new boundary conditions every $3 \mathrm{~h}$ of forecast time, performed domain decomposition, and sent the sub-domains to slaves. This was a sequential algorithm since a single process (master) computed the decomposition and sent the data. Consequently, runtime increased with the number of slaves since the number of data partitions (and messages) increased with the number of slaves. BRAMS intermediate version 4.2 moved the domain decomposition to the slaves (Fazenda et al., 2011). The master process read each input data field and broadcasted the full field to the slaves. Each slave extracted their own sub-domain from the broadcasted field, parallelizing domain decomposition. Figure 18 contains the impressive execution time reduction from the original version 4.0 sequential algorithm to the version 4.2 parallel algorithm as a function of slave processes count. Data of Fig. 18 were collected at UNA on a $24 \mathrm{~h}$ forecast over the $20 \mathrm{~km}$ resolution CPTEC operational grid.

On BRAMS version 4, output was performed by the master process. Each slave process sends its sub-domain to the

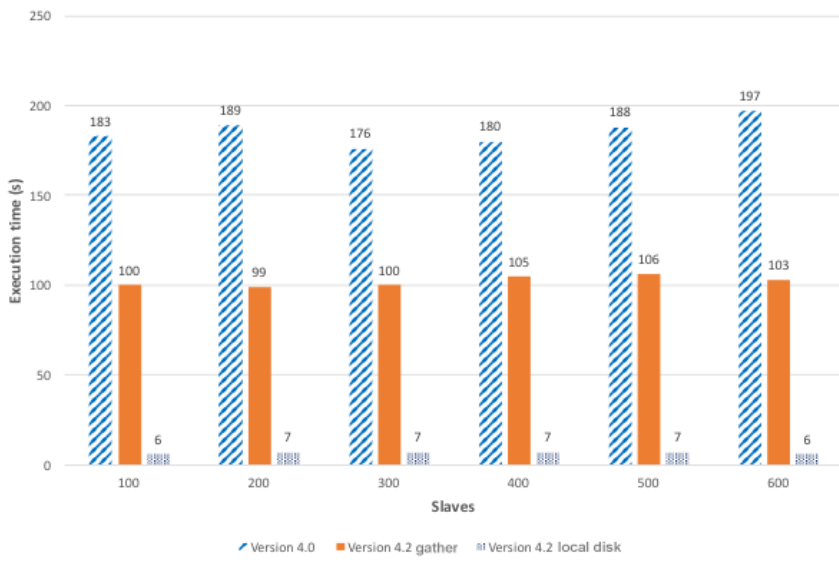

Figure 19. Execution time of the output phase at the UNA machine for $24 \mathrm{~h}$ forecasting with the $20 \mathrm{~km}$ grid spacing model configuration.

master process, that collected the slave partitions through MPI point to point communications, composed the full field and outputs each field. Again, this was a sequential algorithm since its execution time increases with the number of slaves. Two solutions were implemented at UNA and incorporated at BRAMS version 4.2. The first solution was to use a collective MPI operation to gather all sub-domains of each field at the master process prior to output. The second solution was to use UNA's local disk at each node for output: each slave wrote data on its own sub-domain to the local disk, moving the gather phase to post-processing. Since execution time of MPI_Gather depends on the inter-node network speed, both solutions were kept as user-selected options at run-time (Fazenda et al., 2011). Figure 19 compares the execution time of the output phase of the original version 4 sequential algorithm with version 4.2 parallel algorithms as a function of slave processes count. Data of Fig. 19 was collected at UNA on a $24 \mathrm{~h}$ forecast over the $20 \mathrm{~km}$ resolution CPTEC's operational grid.

Replacing BRAMS version 4 input and output sequential algorithms by version 4.2 parallel algorithms substantially reduced the workload of the old master process. Thus, there is no reason to distinguish the master process from slave processes, and all processes can perform the same computation (computing the time-step phase), although only one of them (the old master, now MPI rank zero) performs I/O operations.

Elimination of the master process had a profound impact on code structure, since from the original version on, BRAMS always had one set of procedures for the master process and a distinct set of procedures for slave processes. It also contained a third set of procedures to connect master and slave codes just for sequential (non-MPI) runs. BRAMS version 4.2 collapsed these three distinct source codes into a single code, since the master-slave distinction occurred only at $\mathrm{I} / \mathrm{O}$, and a sequential computation can be performed on a single MPI process. 
Figure 20 shows the execution time reduction at UNA on 20 and $10 \mathrm{~km}$ grids due to the input, output, and code structure optimizations just summarized (Fazenda et al., 2011). These optimizations increased parallel scalability, allowing execution time reduction by increasing core count.

The availability of TUPA allowed experimentation with the $5 \mathrm{~km}$ grid. The first experiments could not use all cores in each node, due to the high memory requirement per MPI process. Only 8 of the 24 cores per node could be used at preliminary executions. A detailed analysis showed that the higher memory usage was due to an old coding practice, from the times when dynamic memory allocation in Fortran was expensive: allocate large scratch arrays at the beginning of the computation, keep these scratch arrays allocated throughout the computation, and use them whenever scratch areas are required. It turns out that there were just too many and overly large scratch areas. Long and tedious work replaced the largest scratch areas by dynamically allocated and deallocated areas that exist only in required code sections. This procedure reduced the memory requirement per process from the original 3.84 to $1.08 \mathrm{~GB}$, allowing the use of all 24 cores per node (Fazenda et al., 2012).

The left side of Fig. 21 contains the execution time of the reduced memory BRAMS version 4.2 on the $5 \mathrm{~km}$ grid at TUPA with 400 fixed nodes and an increasing core count per node from 1 to 24 . It shows execution time stagnation around 4800 cores. The right side of the same figure shows an execution time explosion in the input, time-step, and output phases as a percentage of the total execution time. It is clear that the output-phase responsibility increases with core count, up to a point where output dominates the computation.

The output phase of BRAMS reduced memory version 4.2 at TUPA used the MPI_GATHER solution described above. The local disk output solution, used at UNA, could not be used at TUPA, since TUPA computational nodes are diskless. A new form of output had to be devised. MPI-IO and parallel HDF-5 were implemented as code options, selected at runtime. Both forms of parallel I/O scaled correctly. BRAMS version 4.2 with the reduced memory and new I/O modifications was named BRAMS version 5. Figure 22 contains the execution time and the parallel efficiency of BRAMS version 5 on the $5 \mathrm{~km}$ resolution grid at TUPA up to 9600 cores. Execution time with 9600 cores has been low enough to allow daily operational runs at CPTEC at the $5 \mathrm{~km}$ resolution since the end of 2011.

A few years later, an independent work (Souto et al., 2015) obtained even better scalability of BRAMS version 5.2 on the $5 \mathrm{~km}$ grid on the Santos Dumont cluster. This is an ATOS/BULL machine with 786 nodes, each node containing two Intel Xeon E5-2695s with 12 cores each, totalling 18144 cores. The same grid in the same domain was run from 1024 cores to 13400 cores, achieving a parallel efficiency of $78 \%$ on 13400 cores with respect to the 1024-core execution.

\subsection{Ongoing work features}

\subsubsection{Spread Fire model}

Spread Fire (SFIRE) is a semi-empirical fire propagation model developed by Coen (2005), Clark et al. (2004), and Mandel et al. $(2009,2011)$ that was coupled to the BRAMS model and is currently under evaluation. SFIRE simulates a fire propagation based on a spread rate $S=S(x, y, t)$ in an orthogonal direction to the fire boundary and expressed as a function of the wind $\boldsymbol{v}=\boldsymbol{v}(x, y, z, t)$ and terrain gradient $\nabla z$. The model provides the sensible and latent heat fluxes associated with the fire propagation (the second terms of the RHS of Eqs. 23 and 24, respectively), allowing feedbacks between the combustion processes and the surrounding atmosphere. The total sensible $Q_{H}$ and $Q_{E}$ latent heat fluxes are given by

$$
\begin{aligned}
Q_{H} & =-c_{p} \rho_{\mathrm{a}} T_{*} u_{*}+\frac{F(T)-F(t+\Delta t)}{\Delta t} \frac{1}{1+M_{\mathrm{f}}} w h, \\
Q_{E} & =-\chi_{*} \rho_{\mathrm{a}} u_{*}+\frac{F(T)-F(t+\Delta t)}{\Delta t} \frac{M_{\mathrm{f}}+0.56}{1+M_{\mathrm{f}}} w L .
\end{aligned}
$$

Here the fluxes depend on properties of forestry fuel models, following Anderson (1982) categories, and on an exponential decay function of total fuel fraction, $F$ (see Table 4 for a detailed description of the symbols). The fuel fraction decreases exponentially from the initial ignition time $t_{i}$ (Albini, 1994) and is given by

$F(x, y, t)=\left\{\begin{array}{l}\frac{1}{\operatorname{area}} \iint_{\begin{array}{c}(x, y) \in \Omega(t) \\ 1 \\ \text { otherwise. }\end{array}} e^{-\frac{0,8514\left(t-t_{i}(x, y)\right)}{w(x, y)}} \mathrm{d} x \mathrm{~d} y, \\ \end{array}\right.$

An interface code was built to implement a link between SFIRE and BRAMS, which includes new modules for memory allocation, initialization, and a new namelist (sfire.in). Currently, the fire spread model runs only in a serial mode inside of a BRAMS parallel simulation. Full parallelization of the SFIRE model will be available in future BRAMS versions.

The user needs to produce fuel model classes map and topography defined on the refined surface meshes used by SFIRE; to do so, the user must download any necessary highresolution fields (topography raster and FNNL fuel models; Anderson, 1982) and convert them into a geographic information system (GIS) for ASCII (American Standard Code for Information Interchange) format, through a Euclidean allocation interpolation. Instead the user can use topography from BRAMS, although it is highly smoothed for the needs of SFIRE, and the code cannot benefit for more accurate fire spread computations, because it required a high-resolution grid. These high-resolution data are interpolated and assimilated by BRAMS-SFIRE in fire mesh simulations. 

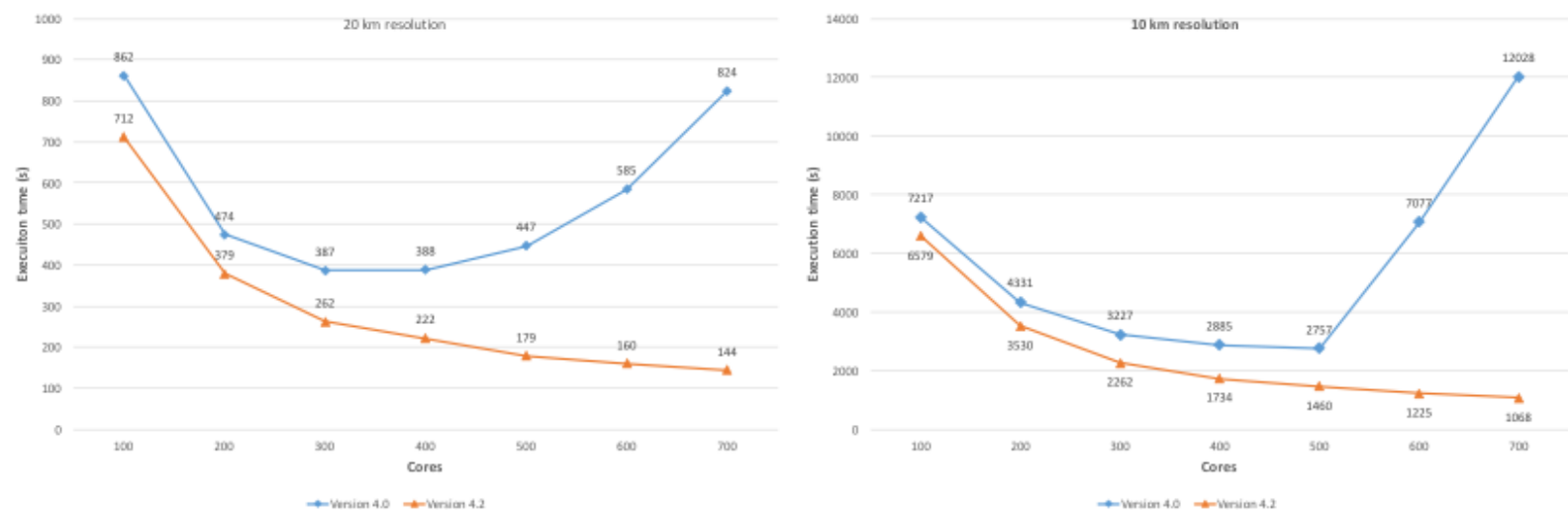

Figure 20. Execution time reduction at the UNA machine on 20 and $10 \mathrm{~km}$ grid spacing model configurations.
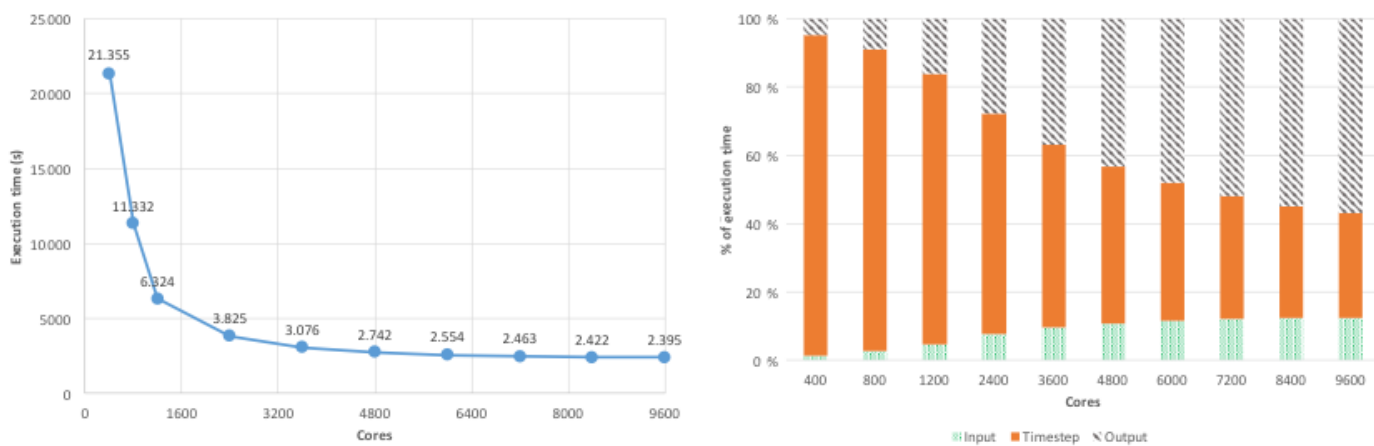

Figure 21. Execution time at TUPA of the $5 \mathrm{~km}$ grid and processes responsibility.

Table 4. List of symbols in the SFIRE model.

\begin{tabular}{ll}
\hline$u_{*}$ & scale friction velocity \\
$\rho_{\mathrm{a}}$ & air density \\
$T_{*}$ & scale of temperature \\
$\chi_{*}$ & scale of specific moisture \\
$c_{p}$ & specific heat at constant pressure \\
$M_{\mathrm{f}}$ & moisture content of the fuel particle \\
$w$ & total fuel load per unit area \\
$h$ & low heat value \\
$L$ & specific latent heat of water condensation \\
$t$ & time \\
$Q_{H}$ & sensible heat flux \\
$Q_{E}$ & latent heat flux \\
\hline
\end{tabular}

The atmospheric data available to BRAMS are limited to around $111 \mathrm{~km}$ resolution and should be simulated in downscaling grids, each with a 4-to-5 refinement ratio, and can incorporate weather sounding data. The BRAMS model was simulated on a 3-D grid covering the Earth's surface, and only the downscaling refined atmospheric domain can be activated with the SFIRE model. BRAMS-SFIRE was applied to the region of Alentejo in Portugal, but can be applied to any other region of the world. The coupled model has an input file named "namelist.fire" where the user is able to intro- duce the properties of fuel models of the region of interest (Menezes, 2015).

The average sensible and latent heat fluxes released in the time interval $(t, t+\Delta t)$, Eqs. (23) and (24), from SFIRE are passed into the atmospheric model through fluxes coming from boundary conditions and mixed in the boundary layer by the PBL scheme.

The BRAMS-SFIRE simulations were performed using the downscaling procedure (one-way interaction), which started from a model grid of $64 \mathrm{~km}$ resolution (with the model domain covering Europe). The data from this simulation are then applied to feed another model run with a grid of $16 \mathrm{~km}$ resolution (covering continental Portugal), which in turn feed another grid of $4 \mathrm{~km}$ resolution (covering the Alentejo), which feed another grid of $1 \mathrm{~km}$ resolution (which covers the area under study). Finally, the $200 \mathrm{~m}$ grid resolution simulation (in the area of forest fire) applied the SFIRE model with atmospheric fields provided by the $1 \mathrm{~km}$ resolution grid model run.

The BRAMS physical parameterizations were configured with silhouette orography to a topography scheme, KlempWilhelmson, to lateral boundary conditions, CARMA to shortwave and longwave radiation schemes, with a $900 \mathrm{~s}$ frequency update of the radiation trend, microphysics complexity level 3 (Flatau et al., 1989), Grell 3-D formulation con- 

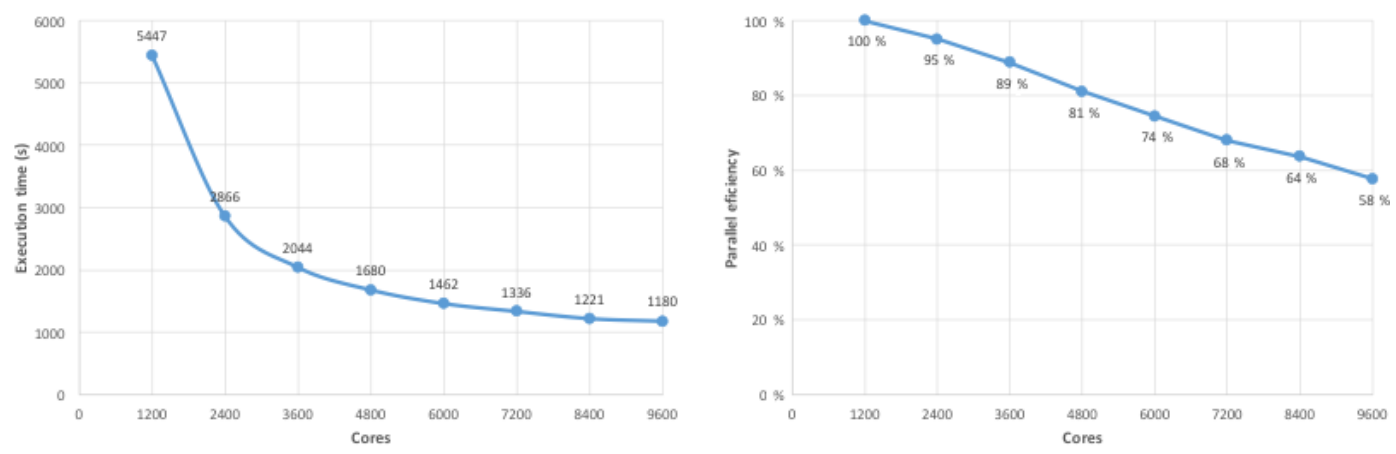

Figure 22. On the left, the execution time of BRAMS on $5 \mathrm{~km}$ grid spacing covering South America and the adjacent oceans as a function of the number of computing cores. On the right appears the corresponding parallel efficiency.

vective parameters with a convection 900 s frequency, and Grell-Deveny parameters of shallow cumulus with a $1200 \mathrm{~s}$ frequency. For $1 \mathrm{~km}$ and $200 \mathrm{~m}$ grid resolutions, cumulus parameterization was not used. The JULES surface scheme (Moreira et al., 2013) was used for downscaling until $4 \mathrm{~km}$ resolution, and LEAF (Walko et al., 2000) was used in the $1 \mathrm{~km}$ and $200 \mathrm{~m}$ resolution grids. The turbulent diffusion coefficient parameter of Mellor and Yamada (Mellor and Yamada, 1982) was used in all grids until $1 \mathrm{~km}$ resolution, and an isotropic deformation was used for the $200 \mathrm{~m}$ resolution grid.

The simulations were carried out with the non-hydrostatic equations on a vertical grid with 55 levels. SFIRE was configured with $200 \mathrm{~m}$ horizontal grid resolution and by updating the fuel moisture calculation every $30 \mathrm{~s}$, with a reaction velocity of $7 \mathrm{~m} \mathrm{~s}^{-1}$, with a $15 \mathrm{~km}$ radius prescription fire, and with a fire initiation time of $180 \mathrm{~s}$ after the start of the atmospheric simulation.

One of the results from the BRAMS-SFIRE simulation showed that, over the three regions, of flat land and low hills, the propagation of the fire line originated sensible heat fluxes of approximately $28 \mathrm{kWm}^{-2}$. During its spread over fuel models 1 and 2, the fire burned them quickly, compared to fuel model 4, which degraded fuel and released fluxes of about $2.5 \mathrm{kWm}^{-2}$ during combustion. Fuel models 8 and 9 combustion-liberated fluxes of between 1.4 and $1.6 \mathrm{kWm}^{-2}$, and over fuel model 9 liberated fluxes on the order of $1.2 \mathrm{kWm}^{-2}$, which glowed until its extinction at approximately $0.75 \mathrm{kWm}^{-2}$. The fire spread was influenced by the topography gradient, following dispersion over valleys or down the mountain (Ossa mountain range, Fig. 23) or simply propagating into plain zones. In all three regions, propagation occurred in an elliptical pattern. In the Ossa mountain range region, the wind is anabatic with intensity $4.5 \mathrm{~ms}^{-1}$, and changes its pattern with fire outbreak, becoming disordered with vortices on the fire which increased the intensity of the wind to $7.5 \mathrm{~ms}^{-1}$; this pattern extends to the entire region as the fire develops and the fire line spreads (Fig. 23).

\section{Applications for weather and air quality forecasting}

\subsection{Regional air quality forecast}

Since March 2003, previous versions of BRAMS have been applied operationally at CPTE/INPE for integrated weather and air quality forecasts over South America. Besides the traditional meteorological fields, forecasts of biomass burning related aerosols and the main trace gases harmful to public health such as carbon monoxide and ozone are generated once a day with a 3-day ahead time window. The forecast is routinely available at the webpage http://meioambiente. cptec.inpe.br/. For the next months, CPTEC/INPE plans to implement BRAMS version 5.0 in the operational forecast system, running on $20 \mathrm{~km}$ grid spacing.

\subsection{Regional- and local-scale weather forecast}

Since January 2013, BRAMS has been applied operationally at CPTEC/INPE to provide an up to 3.5-day weather forecast. The system ran twice a day on $5 \mathrm{~km}$ horizontal grid spacing with the grid domain encompassing the South American continent and part of the neighboring oceans. On the vertical, model grid spacing starts at $50 \mathrm{~m}$, increasing to $800 \mathrm{~m}$ at the upper levels. The number of grid points is $1360 \times 1489 \times 55(\sim 100$ million grid cells $)$ and the model runs over 9600 cores to process the forecast, with initial and boundary conditions taken from the GFS/NCEP global model, which are pre-processed using the RAMS ISAN analysis software package. The forecast is available online at the webpage http://previsaonumerica.cptec.inpe.br/ golMapWeb/DadosPages?id=Brams5. Robust evaluations of BRAMS $5 \mathrm{~km}$ forecasts are provided by Figs. 24 and 25 . The former one shows BIAS and RMSE of five near-surface quantities ( $2 \mathrm{~m}$ temperature and dew-point temperature, $10 \mathrm{~m}$ wind speed, $24 \mathrm{~h}$ accumulated precipitation, and the mean sea level pressure). The evaluation was performed using observations from approximately 1000 surface stations distributed all along South America and for the time period comprising 15 January 2013 to 15 January 2015 . The evaluated quanti- 

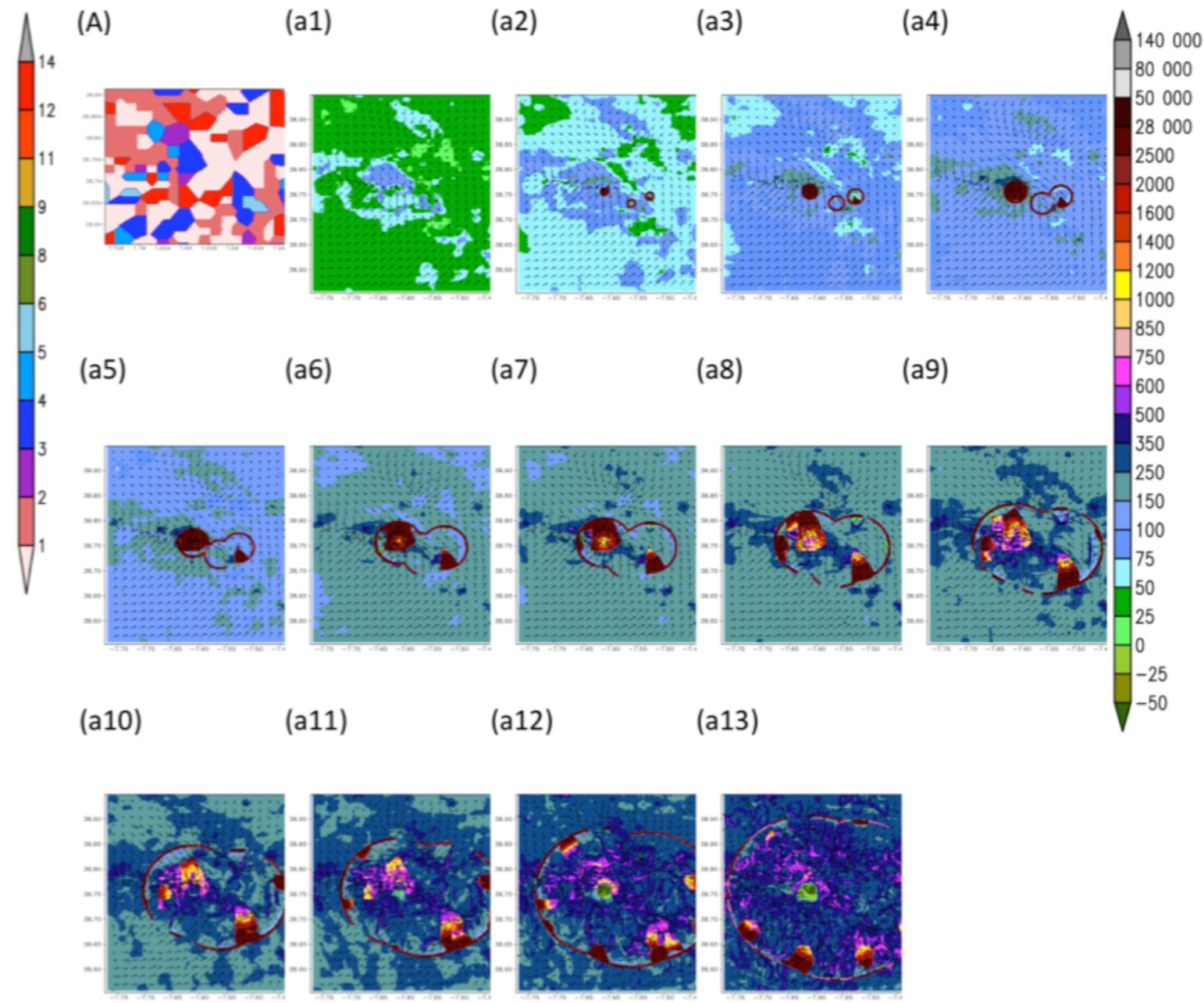

Figure 23. (a) Fuel models of the Ossa mountain range region. The panels from a1 to a13 show sensible heat fluxes $\left(\mathrm{W} \mathrm{m}^{-2}\right.$ ) during the fire-line spread and behavior of horizontal atmospheric wind $\left(\mathrm{m} \mathrm{s}^{-1}\right)$ at the surface under the influence of the fire in different moments of forest fire that occurred on 7 August 2006 in the Ossa mountain range in Alentejo in Portugal, simulated by BRAMS-SFIRE. The fuel model range is expressed in the left-side bar color and sensible flux range in the right-side bar color.

ties have a BIAS in a numerical range of $\sim-1.0$ to $\sim+1.0$, which are consistent with most state-of-the-art NWP models with forecast available for South America. For RMSE, the $24 \mathrm{~h}$ accumulated precipitation shows the lower range of values $(\sim 1.75)$, with wind speed, dew-point temperature, and pressure oscillating around $\sim 2.0$. The temperature has the larger RMSE $(\sim 2.25 \mathrm{~K})$, with higher values during the dry season (austral winter). Sensitivity studies (not shown) have demonstrated that the initial soil moisture field, provided by the Gevaerd and Freitas (2006) technique and currently used in the operations, has a significant accountability for this larger RMSE. Therefore, improving the representation of soil moisture in the model would provide further gain in model skill.
Figure 25 shows model skill in terms of the equitable threat scores (ETS) and the BIAS scores of the $24 \mathrm{~h}$ accumulated rainfall for 36 and $60 \mathrm{~h}$ time integration and averaged over the period of 15 January 2013 to 15 January 2015 . The BIAS score measures the ratio of the frequency of forecast events to the frequency of observed events, binned by certain thresholds. A perfect model would obtain a value of 1 for both ETS and BIAS scores for any threshold. The forecast skills are very reliable and similar to the state-of-the-art NWP models. ETS change from $\sim 0.3$ to $\sim 0.07$ from small to large thresholds. Over the south-southeastern portion of Brazil, which corresponds to the larger number of inhabitants of South America, the forecast has larger skill. Regarding BIAS scores, the model tends to overestimate rain amount 

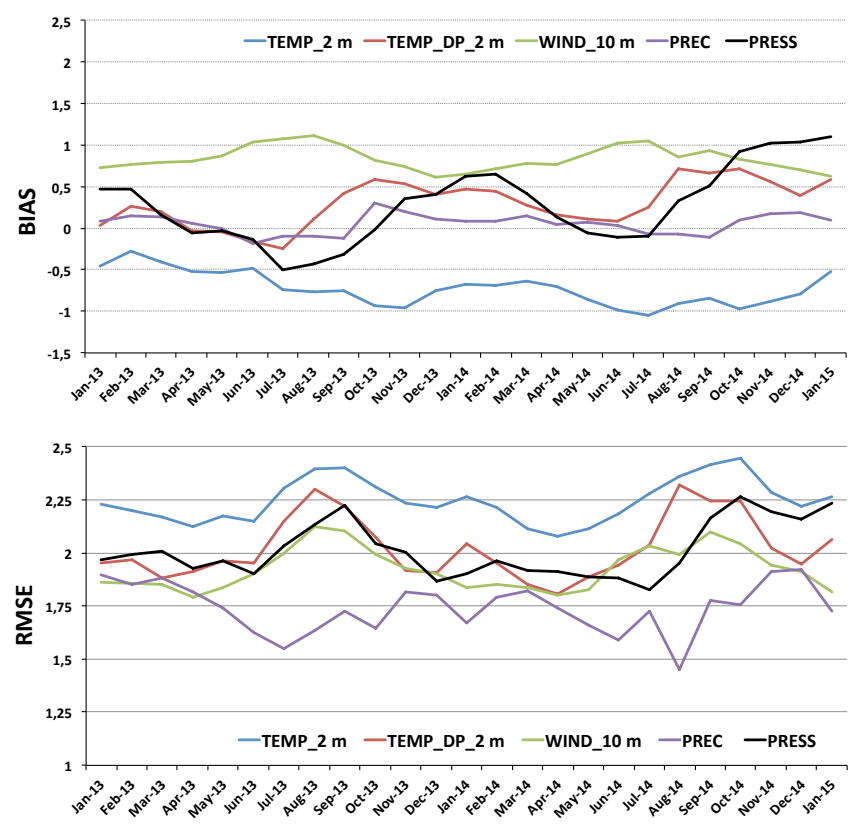

Figure 24. BRAMS $5 \mathrm{~km}$ operational forecast over South America. Model performance evaluation with BIAS (upper panel) and RMSE of five near-surface quantities: $2 \mathrm{~m}$ temperature and dew-point temperature $(\mathrm{K}), 10 \mathrm{~m}$ wind speed $\left(\mathrm{m} \mathrm{a}^{-1}\right), 24 \mathrm{~h}$ accumulated precipitation $(\mathrm{mm})$ and the mean sea level pressure $(\mathrm{hPa})$.

at the lower and higher thresholds, but is pretty close to the optimal value of 1 in between.

\section{Conclusions}

The original RAMS/CSU model was advanced towards a fully integrated regional atmospheric chemistry model, which includes carbon and biogenic VOC cycles, aerosolradiation-cloud interactions, urban surfaces, and other features, giving rise to the Brazilian version named BRAMS. In addition, BRAMS runs on massively parallel supercomputers, clusters, and personal x 86 systems with high efficiency.

Here the main features of the latest version (5.2) are described, which includes a state-of-the-art set of physical and chemical parameterizations for radiation, cloud microphysics, scale aware convective parameterization and turbulence schemes, a land-surface model for urban areas and carbon cycle, and availability of higher-order time integration and advection schemes. BRAMS has been applied for scientific research related to severe weather, urban heat island, urban and remote (e.g. fire emissions) air pollution, aerosolcloud-radiation interactions, and carbon and water cycles over Amazonia, including aerosol effects, volcanic ash dispersion, and many other subjects. For the purposes of operational environmental forecasts, BRAMS is applied in several regional forecast centers and at CPTEC/INPE, providing routinely weather and air quality forecasts for South America.
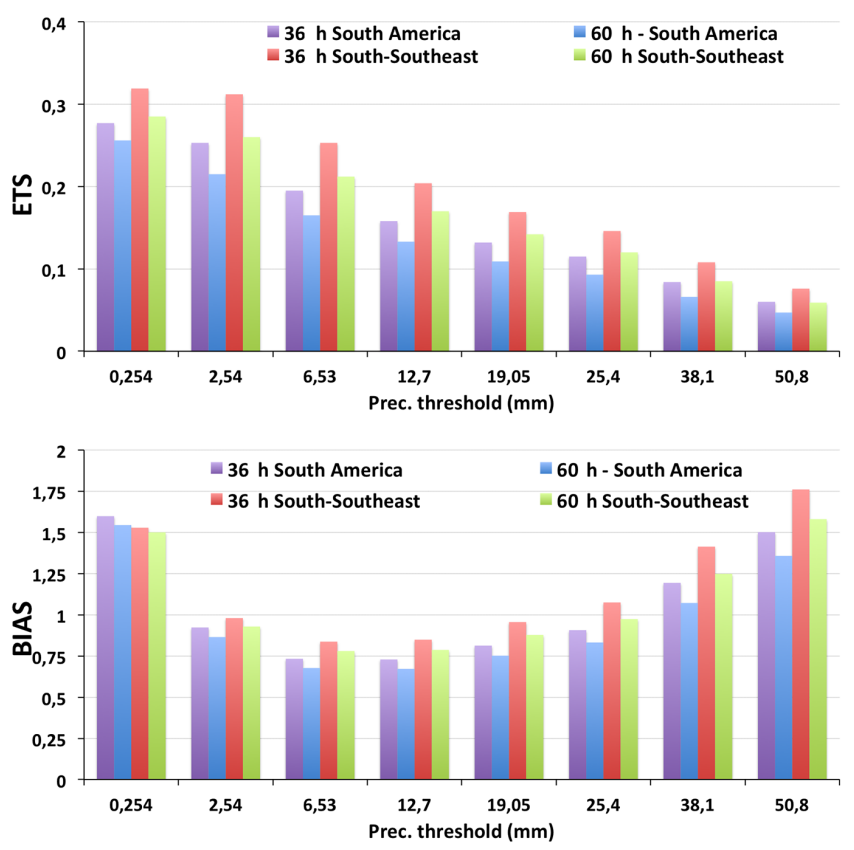

Figure 25. Equitable threat scores (ETS) and BIAS score for the BRAMS $5 \mathrm{~km}$ operational forecast over South America. Results are runs averaged over two model domains (South America and the south-southeastern portion of Brazil) and the time period from 15 January 2013 to 15 January 2015 . The results also show skill for 30 and $60 \mathrm{~h}$ time integration.

Besides its applications in research and operational forecasting, BRAMS has been a platform of joint model development in South America, as such playing a great role in helping to build up a South American community of atmospheric modelers highlighting the participation of young scientists.

Lastly, to maintain and advance its competitiveness in the select team of limited area environmental models in the world, BRAMS needs to keep expanding the community of users and developers, continue being tested and evaluated against observations, and improve the sub-model components. Within the list of the immediately needed improvements is the introduction of a data assimilation procedure that allows BRAMS to have its own initial condition for the integration. This step is essential for a further and significant gain in skill of this modeling system in both, operational and research areas.

\section{Code availability}

BRAMS software is available under the GNU public license. The main code as well as pre- and post-processing software and input data are available on the website http: //brams.cptec.inpe.br/, which is officially maintained by the CPTEC/INPE in Cachoeira Paulista, São Paulo, Brazil. 


\section{The Supplement related to this article is available online at doi:10.5194/gmd-10-189-2017-supplement.}

Competing interests. The authors declare that they have no conflict of interest.

Acknowledgement. S. R. Freitas acknowledges partial support of this work by CNPq (306340/2011-9) and FAPESP (2014/01563-1 and 2015/10206-0) and K. M. Longo acknowledges partial support of this work by FAPESP (2014/01564-8). This work was partially carried out during the sabbatical year of S. R. Freitas and K. M. Longo at the Earth System Research Laboratory at the National Oceanic and Atmospheric Administration (ESRL/NOAA), Boulder, USA. Both authors acknowledge the partial support by this institution. The authors acknowledge Georg Grell from ESRL/NOAA and Michael Baldauf from Deutscher Wetterdienst (DWD), Germany, for their collaboration on key aspects of this modeling system.

Edited by: S. Bekki

Reviewed by: R. Pielke Sr. and one anonymous referee

\section{References}

Abdul-Razzak, H. and Ghan, S. J.: A parameterization of aerosol activation 2. Multiple aerosol types, J. Geophys. Res., 105, 68376844, doi:10.1029/1999JD901161, 2000.

Abdul-Razzak, H. and Ghan, S. J.: A parameterization of aerosol activation 3. Sectional representation, J. Geophys. Res., 107, 4026, doi:10.1029/2001JD000483, 2002.

Albini, F. A.: PROGRAM BURNUP: A simulation model of the burning of large woody natural fuels, final Report on Research Grant INT-92754-GR by U.S.F.S. to Montana State Univ., Mechanical Engineering Dept., 1994.

Albrecht, B. A.: Aerosols, cloud microphysics, and fractional cloudiness, Science, 245, 1227-1230, doi:10.1126/science.245.4923.1227, 1989.

Albrecht, B. A., Ramanathan, V., and Boville, B. A.: The effects of cumulus moisture transports on the simulation of climate with a general circulation model, J. Atmos. Sci., 43, 2443-2462, 1986.

Alonso, M. F., Longo, K., Freitas, S., Fonseca, R., Marécal,V., Pirre, M., and Klenner, L.: An urban emissions inventory for South America and its application in numerical modeling of atmospheric chemical composition at local and regional scales, Atmos. Environ., 44, 5072-5083, doi:10.1016/j.atmosenv.2010.09.013, 2010.

Anderson, H. E.: Aids to determining fuel models for estimating fire behavior, USDA Forest Service, Intermountain Forest and Range Experiment Station, Research Report INT-122, 1982.

Andrade, M. F., Ynoue, R. Y., Harley, R., and Miguel, A. H.: Air quality model simulating photochemical formation of pollutants: the São Paulo Metropolitan Area, Brazil, Int. J. Environ. Pollut., 22, 460-475, 2004.
Arakawa, A. and Schubert, W. H.: Interaction of a cumulus cloud ensemble with the large-scale environment. Part I, J. Atmos. Sci., 31, 674-701, 1974.

Arakawa, A., Jung, J.-H., and Wu, C.-M.: Toward unification of the multiscale modeling of the atmosphere, Atmos. Chem. Phys., 11, 3731-3742, doi:10.5194/acp-11-3731-2011, 2011.

Asselin, R.: Frequency filter for time integrations, Mon. Weather Rev., 100, 487-490, 1972.

Baba, Y. and Takahashi, K.: Weighted essentially non-oscillatory scheme for cloud edge problem, Q. J. Roy. Meteor. Soc., 139, 1374-1388, doi:10.1002/qj.2030, 2013.

Barker, H. W., Cole, J. N. S., Morcrette, J.-J., Pincus, R., Räisänen, P., von Salzen, K., and Vaillancourt, P.: The Monte Carlo Independent Column Approximation: An assessment using several global atmospheric models, Q. J. Roy. Meteor. Soc., 134, 1463-1478, doi:10.1002/qj.303, 2008.

Baldauf, M.: Stability analysis for linear discretisations of the advection equation with Runge-Kutta time integration, J. Comput. Phys., 227, 6638-6659, 2008.

Baldauf, M.: Linear stability analysis of Runge-Kutta based partial time-splitting schemes for the Euler equations, Mon. Weather Rev., 138, 4475-4496, 2010.

Bauer, S. E., Wright, D. L., Koch, D., Lewis, E. R., McGraw, R., Chang, L.-S., Schwartz, S. E., and Ruedy, R.: MATRIX (Multiconfiguration Aerosol TRacker of mIXing state): an aerosol microphysical module for global atmospheric models, Atmos. Chem. Phys., 8, 6003-6035, doi:10.5194/acp-8-60032008, 2008.

Bechtold, P., Chaboureau, J. P., Beljaars, A., Betts, A. K., Köhler, M., Miller, M., and Redelsperger, J. L.: The simulation of the diurnal cycle of convection precipitations over land in a global model, Q. J. Roy. Meteor. Soc., 130, 3119-3137, 2004.

Bechtold, P., Köhler, M., Jung, T., Doblas-Reyes, F., Leutbecher, M., Rodwell, M. J., Vitart, F., and Balsamo, G.: Advances in simulating atmospheric variability with the ECMWF model: From synoptic to decadal time-scales, Q. J. Roy. Meteor. Soc., 134, 1337-1351, 2008.

Bechtold, P., Semane, N., Lopez, P., Chaboureau, J.-P., Beljaars, A., and Bormann, N.: Representing equilibrium and nonequilibrium convection in large-scale models, J. Atmos. Sci., 71, 734-753, doi:10.1175/JAS-D-13-0163.1, 2014.

Bela, M. M., Longo, K. M., Freitas, S. R., Moreira, D. S., Beck, V., Wofsy, S. C., Gerbig, C., Wiedemann, K., Andreae, M. O., and Artaxo, P.: Ozone production and transport over the Amazon Basin during the dry-to-wet and wet-to-dry transition seasons, Atmos. Chem. Phys., 15, 757-782, doi:10.5194/acp-15757-2015, 2015.

Beltran-Przekurat, A., Pielke, R. A., Eastman, J. L., and Coughenour, M. B.: Modeling the effects of land-use/landcover changes on the near-surface atmosphere in southern South America, Int. J. Climatol., 32, 1206-1225, doi:10.1002/joc.2346, 2011.

Best, M. J., Pryor, M., Clark, D. B., Rooney, G. G., Essery, R. L. H., Ménard, C. B., Edwards, J. M., Hendry, M. A., Porson, A., Gedney, N., Mercado, L. M., Sitch, S., Blyth, E., Boucher, O., Cox, P. M., Grimmond, C. S. B., and Harding, R. J.: The Joint UK Land Environment Simulator (JULES), model description Part 1: Energy and water fluxes, Geosci. Model Dev., 4, 677-699, doi:10.5194/gmd-4-677-2011, 2011. 
Brian, H. and Prather, M. J.: Fast-J2: Accurate simulation of stratospheric photolysis in global chemistry models, J. Atmos. Chem., 41, 281-296, 2002.

Carvalho, V. S. B.: O impacto das megacidades sobre a qualidade do ar:os casos das regiões metropolitanas de São Paulo e: do Rio de Janeiro. 234 f. Tese de Doutorado - Instituto de Astronomia, Geofísica e Ciências Atmosféricas, Universidade de São Paulo, São Paulo, 2010.

Clark, D. B., Mercado, L. M., Sitch, S., Jones, C. D., Gedney, N., Best, M. J., Pryor, M., Rooney, G. G., Essery, R. L. H., Blyth, E., Boucher, O., Harding, R. J., Huntingford, C., and Cox, P. M.: The Joint UK Land Environment Simulator (JULES), model description - Part 2: Carbon fluxes and vegetation dynamics, Geosci. Model Dev., 4, 701-722, doi:10.5194/gmd-4-701-2011, 2011.

Clark, T. L., Coen, J. L., and Latham, D.: Description of a coupled atmosphere-fire model, Int. J. Wildland Fire, 13, 49-64, 2004.

Coen, J. L.: Simulation of the Big Elk Fire using coupled atmosphere-fire modeling, Int. J. Wildland Fire, 14, 49-59, 2005.

Costa, S. M. S., Lima, W. F. A., Freitas, S. R., Ceballos, J. C., and Rodrigues, J. V.: Monitoramento dos Traços de Cinzas do Vulcão Chileno Puyehue-Cordón Caulle, in: Congresso Brasileiro De Meteorologia, 17. (CBMET), 2012, Gramado Annals, 1-5, 2012.

Cotton, W. R., Pielke Sr., R. A., Walko, R. L., Liston, G. E., Tremback, C. J., Jiang, H., McAnelly, R. L., Harrington, J. Y., Nicholls, M. E., Carrio, G. G., and McFadden, J. P.: RAMS 2001: Current status and future directions, Meteorol. Atmos. Phys., 82, 5-29, 2003.

Crassier, V., Suhre, K., Tulet, P., and Rosset, R.: Development of a reduced chemical scheme for use in mesoscale meteorological models, Atmos. Environ., 34, 2633-2644, 2000.

Djouad, R., Sportisse, B., and Audiffren, N.: Numerical simulation of aqueous-phase atmospheric models: use of a non-autonomous Rosenbrock method, Atmos. Environ., 36, 873-879, 2002.

Damian, V., Sandu, A., Damian, M., Carmichael, G. R., and Potra, F. A.: KPP - A symbolic preprocessor for chemistry kinetics User's guide, Technical report, The University of Iowa, IowaCity, IA 52246, 1995.

Davies, H. C.: Limitations of some common lateral boundary schemes used in regional NWP models, Mon. Weather Rev., 111, 1002-1012, 1983.

Deardorff, J. W.: Stratocumulus-capped mixed layers derived from a three-dimensional model, Bound.-Lay. Meteorol., 18, 495-527, 1980.

Degrazia, G. A., Anfossi, D., de Campos Velho, H. F., and Ferrero, E.: A Lagrangian Decorrelation Time Scale for Nonhomogeneous Turbulence, Bound.-Lay. Meteorol., 86, 525-534, 1998.

Dos Santos, A. F., Freitas, S. R., de Mattos, J. G. Z., Campos Velho H. F., Gan, M. A., Luz, E. F. P., and Grell, G.: Using the Firefly optimization method to weight the ensemble of rainfall forecasts of the Brazilian developments on the Regional Atmospheric Modeling System (BRAMS), Adv. Geosci., 35, 123-136, doi:10.5194/adgeo-35-123-2013, 2013.

Eastman, J. L., Coughenour, M. B., and Pielke, R. A.: The effects of $\mathrm{CO}_{2}$ and landscape change using a coupled plant and meteorological model, Glob. Change Biol., 7, 797-815, 2001 a.

Eastman, J. L., Coughenour, M. B., and Pielke, R. A.: Does grazing affect regional climate?, J. Hydrometeorol., 2, 243-253, $2001 \mathrm{~b}$.
Ebert, E. E. and Curry, J. A.: A parameterization of ice cloud optical properties for climate models, J. Geophys. Res., 97, 3831-3836, 1992.

Eidhammer, T., DeMott, P. J., and Kreidenweis, S. M.: A comparison of heterogeneous ice nucleation parameterizations using a parcel model framework, J. Geophys. Res., 114, D06202, doi:10.1029/2008JD011095, 2009.

Fazenda, A. L., Panetta, J., Katsurayama, D. M., Rodrigues, L. F., Motta, L. G., and Navaux, P. O. A.: Challenges and solutions to improve the scalability of an operational regional meteorological forecasting model, Int. J. High Perform. S., 3, p. 87, 2011.

Fazenda, A. L., Rodrigues, E. R., Tomita, S. S., Panetta, J., and Mendes, C. L.: Improving the scalability of an operational scientific application on a large multi-core cluster, WSCAD-SSC, 2012.

Feingold, G. and Heymsfield, A. J.: Parameterizations of condensational growth of droplets for use in general circulation models, J. Atmos. Sci., 49, 2325-2342, 1992.

Frank, W. M. and Cohen, C.: Simulation of tropical convective systems, Part I: A cumulus parameterization, J. Atmos. Sci., 44, 3787-3799, 1987.

Freitas, E. D., Martins, L. D., Dias, P. L. D., and Andrade, M. D.: A simple photochemical module implemented in RAMS for tropospheric ozone concentration forecast in the metropolitan area of Sao Paulo, Brazil: Coupling and validation, Atmos. Environ., 39, 6352-6361, 2005.

Freitas, E. D., Rozoff, C. M., Cotton, W. R., and Silva Dias, P. L.: Interactions of an urban heat island and sea breeze circulations during winter over the Metropolitan Area of São Paulo - Brazil, Bound.-Lay. Meteorol., 122, 43-65, 2007.

Freitas, S. R., Longo, K. M., Silva Dias, M. A. F., and Artaxo, P.: Numerical modeling of air mass trajectories from biomass burning areas of the Amazon basin, Anais da Academia Brasileira de Ciências, Brasil, 68, 193-296, 1996.

Freitas, S. R., Dias, M. A. F. S., Dias, P. L. S., Longo, K. M., Artaxo, P., Andreae, M. O., and Fischer, H.: A convective kinematic trajectory technique for low-resolution atmospheric models, J. Geophys. Res., 105, 24375-24386, 2000.

Freitas, S. R., Longo, K. M., Silva Dias, M., Silva Dias, P., Chatfield, R., Prins, E., Artaxo, P., Grell, G., and Recuero, F.: Monitoring the transport of biomass burning emissions in South America, Environ. Fluid Mech., 5, 135-167, doi:10.1007/s10652-0050243-7, 2005.

Freitas, S. R., Longo, K. M., and Andreae, M. O.: Impact of including the plume rise of vegetation fires in numerical simulations of associated atmospheric pollutants, Geophys. Res. Lett., 33, L17808, doi:10.1029/2006GL026608, 2006.

Freitas, S. R., Longo, K. M., Silva Dias, M. A. F., Chatfield, R., Silva Dias, P., Artaxo, P., Andreae, M. O., Grell, G., Rodrigues, L. F., Fazenda, A., and Panetta, J.: The Coupled Aerosol and Tracer Transport model to the Brazilian developments on the Regional Atmospheric Modeling System (CATT-BRAMS) - Part 1: Model description and evaluation, Atmos. Chem. Phys., 9, 28432861, doi:10.5194/acp-9-2843-2009, 2009.

Freitas, S. R., Longo, K. M., Trentmann, J., and Latham, D.: Technical Note: Sensitivity of 1-D smoke plume rise models to the inclusion of environmental wind drag, Atmos. Chem. Phys., 10, 585-594, doi:10.5194/acp-10-585-2010, 2010. 
Freitas, S. R., Longo, K. M., Alonso, M. F., Pirre, M., Marecal, V., Grell, G., Stockler, R., Mello, R. F., and Sánchez Gácita, M.: PREP-CHEM-SRC - 1.0: a preprocessor of trace gas and aerosol emission fields for regional and global atmospheric chemistry models, Geosci. Model Dev., 4, 419-433, doi:10.5194/gmd-4419-2011, 2011.

Freitas, S. R., Rodrigues, L. F., Longo, K. M., and Panetta, J.: Impact of a monotonic advection scheme with low numerical diffusion on transport modeling of emissions from biomass burning, J. Adv. Model. Earth Syst., 4, M01001, doi:10.1029/2011MS000084, 2012.

Gerbig, C., Lin, J. C., Wofsy, S. C., Daube, B. C., Andrews, A. E., Stephens, B. B., Bakwin, P. S., and Grainger, C. A.: Toward constraining regional-scale fluxes of $\mathrm{CO}_{2}$ with atmospheric observations over a continent: 1 . Observed spatial variability from airborne platforms, J. Geophys. Res.-Atmos., 108, 4756, doi:10.1029/2002JD003018, 2003.

Gevaerd, R. and Freitas, S. R.: Estimativa operacional da umidade do solo para inicialização de modelos de previsão numérica da atmosfera. Parte I: Descrição da metodologia e validação, Rev. Bras. Meteorol., 21, 1-15, 2006.

Grell, G. A.: Prognostic evaluation of assumptions used by cumulus parameterizations within a generalized framework, Mon. Weather Rev., 121, 764-787, 1993.

Grell, G. A. and Devenyi, D.: A generalized approach to parameterizing convection combining ensemble and data assimilation techniques, Geophys. Res. Lett., 29, 38-1, doi:10.1029/2002GL015311, 2002.

Grell, G. A. and Freitas, S. R.: A scale and aerosol aware stochastic convective parameterization for weather and air quality modeling, Atmos. Chem. Phys., 14, 5233-5250, doi:10.5194/acp-145233-2014, 2014.

Grell, G. A., Peckham, S., McKeen, S., Schmitz, R., Frost, G., Skamarock, W. C., and Eder, B.: Fully coupled "online" chemistry within the WRF model, Atmos. Environ., 39, 6957-6975, 2005.

Hack, J. J., Boville, B. A., Briegleb, B. P., Kiehl, J. T., Rasch, P. J., and Williamson, D. L.: Description of the NCAR Community Climate Model (CCM2), NCAR Technical Note, NCAR/TN382+STR, 1993 .

Hamill, T. M.: Hypothesis Tests for Evaluating Numerical Precipitation Forecasts, Weather Forecast., 14, 155-167, 1999.

Hanna, S.: Applications in Air Pollution Modeling, in: Atmospheric Turbulence and Air Pollution Modelling, edited by: Nieuwstadt, F. and van Dop, H., vol. 1 of Atmospheric Sciences Library, chap. 7 275-310, Springer Netherlands, doi:10.1007/978-94010-9112-1_7, 1982.

Helfand, H. M. and Labraga, J. C.: Design of a Nonsingular Level 2.5 Second-Order Closure Model for the Prediction of Atmospheric Turbulence, J. Atmos. Sci., 45, 113-132, 1988.

Hill, G. E.: Factors Controlling the Size and Spacing of Cumulus Clouds as Revealed by Numerical Experiments, J. Atmos. Sci., 31, 646-673, 1974.

Holben, B. N., Eck, T. F., Slutsker, I., Tanreé, D., Buis, J. P., Setzer, A., Vermote, E., Reagan, J. A., Kaufman, Y. J., Nakajima, T., Lavenu, F., Jankowiak, I., and Smirnov, A.: AERONET - a federated instrument network and data archive for aerosol characterization, Remote Sens. Environ., 66, 1-16, doi:10.1016/s00344257(98)00031-5, 1998
Hu, Y. X. and Stamnes, K.: An accurate parameterization of the radiative properties of water clouds suitable for use in climate models, J. Climate, 6, 728-742, 1993.

Huffman, G. J., Adler, R. F., Bolvin, D. T., Gu, G. J., Nelkin, E. J., Bowman, K. P., Hong, Y., Stocker, E. F., and Wolff, D. B.: The TRMM multi-satellite precipitation analysis (TMPA): Quasiglobal, multiyear, combined-sensor precipitation estimates at fine scales, J. Hydrometeorol., 8, 38-55, 2007.

Iacono, M. J., Delamere, J. S., Mlawer, E. J., Shephard, M. W., Clough, S. A., and Collins, W. D.: Radiative forcing by long-lived greenhouse gases: Calculations with the AER radiative transfer models, J. Geophys. Res., 113, D13103, doi:10.1029/2008JD009944, 2008.

Jakob, C. and Siebesma, A. P.: A new subcloud model for mass-flux convection schemes: influence on triggering, updrafts properties, and model climate, Mon. Weather Rev., 131, 2765-2778, 2003.

Janjić, Z.: Nonsingular implementation of the Mellor-Yamada Level 2.5 Scheme in the NCEP Meso model, Office note 437, National Center for Environmental Prediction, Boulder, CO, available at: http://www.lib.ncep.noaa.gov/ncepofficenotes/2000s/ (last access: 10 January 2017), 2001.

Johansson, E., Spangenberg, J., Gouvêa, M. L., and Freitas, E. D.: Scale-integrated atmospheric simulations to assess thermal comfort in different urban tissues in the warm humid summer of São Paulo, Brazil, Urban Climate, 6, 24-43, 2013.

Kain, J. S. and Fritsch, J. M.: The role of the convective "trigger function" in numerical forecasts of mesoscale convective systems, Meteorol. Atmos. Phys., 49, 93-106, 1992.

Khan, S. and Simpson, R.: Effect of a heat island on the meteorology of a complex urban airshed, Bound.-Lay. Meteorol., 100, 487-506, 2001.

Kiehl, J. T., Hack, J. J., Bonan, G. B., Boville, B. A., Williamson, D. L., and Rasch, P. L.: The National Center for Atmospheric Research Community Climate Model: CCM3, J. Climate, 11, 11311149, 1998.

Klein, S. A. and Hartmann, D. L.: The seasonal cycle of low stratiform clouds, J. Climate, 6, 1588-1606, 1993.

Klemp, J. B. and Wilhelmson, R. B.: The Simulation of ThreeDimensional Convective Storm Dynamics, J. Atmos. Sci., 35, 1070-1096, 1978.

Krishnamurti, T. N., Low-Nam, S., and Pasch, R.: Cumulus parameterizations and rainfall rates II, Mon. Weather Rev., 111, 815828, 1983.

Krol, M., Houweling, S., Bregman, B., van den Broek, M., Segers, A., van Velthoven, P., Peters, W., Dentener, F., and Bergamaschi, P.: The two-way nested global chemistry-transport zoom model TM5: algorithm and applications, Atmos. Chem. Phys., 5, 417 432, doi:10.5194/acp-5-417-2005, 2005.

Lin, J. C., Gerbig, C., Wofsy, S. C., Andrews, A. E., Daube, B. C., Davis, K. J., and Grainger, C. A.: A near-field tool for simulating the upstream influence of atmospheric observations: The Stochastic Time-Inverted Lagrangian Transport (STILT) model, J. Geophys. Res.-Atmos., 108, 4493 , doi:10.1029/2002JD003161, 2003.

Liu, Y., Daum, P. H., Guo, H., and Peng, Y.: Dispersion bias, dispersion effect, and the aerosol-cloud conundrum. Environ. Res. Lett., 3, 045021, doi:10.1088/1748-9326/3/4/045021, 2008. 
Lilly, D. K.: On the numerical simulation of buoyant convection, Tellus, 14, 148-172, doi:10.1111/j.2153-3490.1962.tb00128.x, 1962.

Longo, K. M., Freitas, S. R., Andreae, M. O., Setzer, A., Prins, E., and Artaxo, P.: The Coupled Aerosol and Tracer Transport model to the Brazilian developments on the Regional Atmospheric Modeling System (CATT-BRAMS) - Part 2: Model sensitivity to the biomass burning inventories, Atmos. Chem. Phys., 10, 5785-5795, doi:10.5194/acp-10-5785-2010, 2010.

Longo, K. M., Freitas, S. R., Pirre, M., Marécal, V., Rodrigues, L. F., Panetta, J., Alonso, M. F., Rosário, N. E., Moreira, D. S., Gácita, M. S., Arteta, J., Fonseca, R., Stockler, R., Katsurayama, D. M., Fazenda, A., and Bela, M.: The Chemistry CATT-BRAMS model (CCATT-BRAMS 4.5): a regional atmospheric model system for integrated air quality and weather forecasting and research, Geosci. Model Dev., 6, 1389-1405, doi:10.5194/gmd-61389-2013, 2013.

Lu, L., Pielke, R. A., Liston, G. E., Parton, W. J., Ojima, D., and Hartman, M.: Implementation of a two-way interactive atmospheric and ecological model and its application to the central United States, J. Climate, 14, 900-919, 2001.

Lyons, W. A., Pielke, R. A., Tremback, C. J., Walko, R. L., Moon, D. A., and Keen, C. S.: Modeling the impacts of mesoscale vertical motions upon coastal zone air pollution dispersion, Atmos. Environ., 29, 283-301, 1995.

Madronich, S.: Photodissociation in the atmosphere: 1. Actinic flux and the effect of ground reflections and clouds, J. Geophys. Res., 92, 9740-9752, doi:10.1029/JD092iD08p09740, 1989.

Mandel, J., Beezley, J. D., Coen, J. L., and Kim, M.: Data assimilation for wildland fires: Ensemble Kalman filters in coupled atmosphere-surface models, IEEE Contr. Syst. Mag., 29, 47-65, doi:10.1109/MCS.2009.932224, 2009.

Mandel, J., Beezley, J. D., and Kochanski, A. K.: Coupled atmosphere-wildland fire modeling with WRF 3.3 and SFIRE 2011, Geosci. Model Dev., 4, 591-610, doi:10.5194/gmd-4-5912011, 2011.

Masson, V.: A physically-based scheme for the urban energy budget in atmospheric models, Bound.-Lay. Meteorol., 94, 357-397, 2000.

Mastin, L., Guffanti, M., Servranckx, R., Webley, P., Barsotti, S., Dean, K., Durant, A., Ewert, J., Neri, A., and Rose, W.: A multidisciplinary effort to assign realistic source parameters to models of volcanic ash-cloud transport and dispersion during eruptions, J. Volcanol. Geoth. Res., 186, 10-21, 2009.

McKain, K., Down, A., Raciti, S. M., Budney, J., Hutyra, L. R., Floerchinger, C., Herndon, S. C., Nehrkorn, T., Zahniser, M. S., Jackson, R. B., Phillips, N., and Wofsy, S. C.: Methane emissions from natural gas infrastructure and use in the urban region of Boston, Massachusetts, P. Natl. Acad. Sci. USA, 112, 19411946, doi:10.1073/pnas.1416261112, 2015.

Medvigy, D., Moorcroft, P. R., Avissar, R., and Walko, R. L.: Mass conservation and atmospheric dynamics in the Regional Atmospheric Modeling System (RAMS), Environ. Fluid Mech., 5, 109-134, doi:10.1007/s10652-005-5275-5, 2005.

Mellor, G. L. and Yamada, T.: Development of a turbulence closure model for geophysical fluid problems, Rev. Geophys. Space Phys., 20, 851-875, doi:10.1029/RG020i004p00851, 1982.

Menezes, I. C.: Construção de um modelo de interacção atmosfera/fogo aplicado à gestão florestal e avaliação de risco de fogos florestais no Alentejo, PhD thesis, University of Évora, Portugal, 2015.

Meyers, M. P., Walko, R. L., Harrington, J. Y., and Cotton, W. R.: New RAMS cloud microphysics parameterization: Part II. The two-moment scheme, Atmos. Res., 45, 3-39, 1997.

Miller, S. M., Matross, D. M., Andrews, A. E., Millet, D. B., Longo, M., Gottlieb, E. W., Hirsch, A. I., Gerbig, C., Lin, J. C., Daube, B. C., Hudman, R. C., Dias, P. L. S., Chow, V. Y., and Wofsy, S. C.: Sources of carbon monoxide and formaldehyde in North America determined from high-resolution atmospheric data, Atmos. Chem. Phys., 8, 7673-7696, doi:10.5194/acp-8-7673-2008, 2008.

Miller, S. M., Wofsy, S. C., Michalak, A. M., Kort, E. A., Andrews, A. E., Biraud, S. C., Dlugokencky, E. J., Eluszkiewicz, J., Fischer, M. L., Janssens-Maenhout, G., Miller, B. R., Miller, J. B., Montzka, S. A., Nehrkorn, T., and Sweeney, C.: Anthropogenic emissions of methane in the United States, P. Natl. Acad. Sci USA, 110, 20018-20022, doi:10.1073/pnas.1314392110, 2013.

Mlawer, E. J., Taubman, S. J., Brown, P. D., Iacono, M. J., and Clough, S. A.: Radiative transfer for inhomogeneous atmosphere: RRTM a validated correlated-k model for the longwave, J. Geophys. Res., 102, 16663-16682, 1997.

Moreira, D. S., Freitas, S. R., Bonatti, J. P., Mercado, L. M., Rosário, N. M. É., Longo, K. M., Miller, J. B., Gloor, M., and Gatti, L. V.: Coupling between the JULES land-surface scheme and the CCATT-BRAMS atmospheric chemistry model (JULESCCATT-BRAMS1.0): applications to numerical weather forecasting and the $\mathrm{CO}_{2}$ budget in South America, Geosci. Model Dev., 6, 1243-1259, doi:10.5194/gmd-6-1243-2013, 2013.

Nair, K. N., Freitas, E. D., Sánchez-Ccoyllo, O. R., Silva Dias M. A. F., Silva Dias, P. L., Andrade, M. F., and Massambani, O.: Dynamics of urban boundary layer over Sao Paulo associated with mesoscale processes, Meteorol. Atmos. Phys., 86, 87-98, 2004.

Nakanishi, M. and Niino, H.: An Improved Mellor-Yamada Level-3 Model with Condensation Physics: Its Design and Verification, Bound.-Lay. Meteorol., 112, 1-31, doi:10.1023/B:BOUN.0000020164.04146.98, 2004.

Nakanishi, M. and Niino, H.: An Improved Mellor-Yamada Level3 Model: Its Numerical Stability and Application to a Regional Prediction of Advection Fog, Bound.-Lay. Meteorol., 119, 397407, doi:10.1007/s10546-005-9030-8, 2006.

Nehrkorn, T., Eluszkiewicz, J., Wofsy, S. C., Lin, J. C., Gerbig, C., Longo, M., and Freitas, S.: Coupled weather research and forecasting-stochastic time-inverted lagrangian transport (WRF-STILT) model, Meteorol. Atmos. Phys., 107, 51-64, doi:10.1007/s00703-010-0068-x, 2010.

Pavani, C. A. B.: Modelagem numérica do transporte de emissões vulcânicas: caso do vulcão Puyehue, 184 pp., (sid.inpe.br/mtcm18/2014/01.20.11.25-TDI), Dissertation (Master in Meteorology) - Instituto Nacional de Pesquisas Espaciais (INPE), São José dos Campos, 2014, available at: http://urlib.net/ 8JMKD3MGP8W/3FJUGQ8, last access: 27 May 2014.

Pavanni, C., Freitas, S. R., Lima, W. F. A., Costa, S. M. S., Rosario, N. M., Moreira, D. S., and Yoshida, M. C.: Incluindo funcionalidades no modelo BRAMS para simular o transporte de cinzas vulcânicas: descrição e análise de sensibilidade aplicada ao evento eruptivo do Puyehue em 2011, Revista 
Brasileira de Meteorologia, 31(4), 377-393, doi:10.1590/0102$778631231420150035,2016$.

Petters, M. D. and Kreidenweis, S. M.: A single parameter representation of hygroscopic growth and cloud condensation nucleus activity, Atmos. Chem. Phys., 7, 1961-1971, doi:10.5194/acp-71961-2007, 2007.

Pielke, R. A.: Mesoscale meteorological modeling, 3rd Edn., Academic Press, San Diego, CA, 2013.

Pielke, R. A. and Uliasz, M.: Use of meteorological models as input to regional and mesoscale air quality models - Limitations and strengths. Atmos. Environ., 32, 1455-1466, 1998.

Pielke, R. A., Cotton, W. R., Walko, R. L., Tremback, C. J., Lyons, W. A., Grasso, L. D., Nicholls, M. E., Moran, M. D., Wesley, D. A., Lee, T. J., and Copeland, J. H.: A comprehensive meteorological modeling system - RAMS, Meteorol. Atmos. Phys., 49, 69-91, 1992.

Pincus, R. and Baker, M. B.: Effect of precipitation on the albedo susceptibility of clouds in the marine boundary layer, Nature, 372, 250-252, 1994.

Pincus, R., Barker, H. R., and Morcrette, J.-J.: A fast, flexible, approximate technique for computing radiative transfer in inhomogeneous cloud fields, J. Geophys. Res., 108, 4376, doi:10.1029/2002JD003322, 2003.

Procopio, A. S., Remer, L. A., Artaxo, P., Kaufman, Y. J., and Holben, B. N.: Modeled spectral optical properties for smoke aerosols in Amazonia, Geophys. Res. Lett., 30, 2265, doi:10.1029/2003g1018063, 2003.

RAMS: The Regional Atmospheric Modeling System: Technical Description (Draft), Technical report, ATMET, Fort Collins, CO, USA, available at: http://www.atmet.com/html/ docs/documentation.shtml (last access: 10 January 2017), 2003.

Rasch, P. J. and Kristjansson, J. E.: A comparison of the CCM3 model climate using diagnosed and predicted condensate parameterizations, J. Climate, 11, 1587-1614, 1998.

Rennó, N. O. and Ingersoll, A. P.: Natural convection as a heat engine: A theory for CAPE, J. Atmos. Sci., 53, 572-585, 1996.

Reynolds, R. W., Rayner, N. A., Smith, T. M., Stokes, D. C., and Wang, W.: An Improved In Situ and Satellite SST Analysis for Climate, J. Climate, 15, 1609-1625, 2002.

Rosário, N. E., Longo, K. M., Freitas, S. R., Yamasoe, M. A., and Fonseca, R. M.: Modeling the South American regional smoke plume: aerosol optical depth variability and surface shortwave flux perturbation, Atmos. Chem. Phys., 13, 2923-2938, doi:10.5194/acp-13-2923-2013, 2013.

Saleeby, S. M. and Cotton, W. R.: A large-droplet mode and prognostic number concentration of cloud droplets in the Colorado State University Regional Atmospheric Modeling System (RAMS). Part I: Module descriptions and supercell test simulations, J. Appl. Meteorol., 43, 182-195, 2004.

Saleeby, S. M. and Cotton, W. R.: A Binned Approach to CloudDroplet Riming Implemented in a Bulk Microphysics Model, J. Appl. Meteorol., 47, 694-703, 2008.

Sánchez Gácita, M., Longo, K. M., Freire, J. L. M., Freitas, S. R., and Martin, S. T.: Impact of mixing state and hygroscopicity on CCN activity of biomass burning aerosol in Amazonia, Atmos. Chem. Phys. Discuss., doi:10.5194/acp-2016-248, in review, 2016.

Santos, A. F.: Inverse problems using the optimization method firefly applied in the precipitation parameterization of the model brams over South America. PhD thesis- National Institute for Space Research (INPE), São José dos Campos, 2014 (in Portuguese).

Santos e Silva, C. M., Gielow, R., and Freitas, S. R.: Diurnal and semidiurnal rainfall cycles during the rain season in SW Amazonia, observed via rain gauges and estimated using S-band radar, Atmos. Sci. Lett., 10, 87-93, doi:10.1002/as1.214, 2009.

Santos e Silva, C. M., Freitas, S. R., and Gielow, R.: Numerical simulation of the diurnal cycle of rainfall in SW Amazon basin during the 1999 rainy season: the role of convective trigger function, Theor. Appl. Climatol., 109, 473-483, 2012.

Savijärvi, H.: Shortwave optical properties of rain, Tellus, 49a, 177$181,1997$.

Savijärvi, H. and Raisanen, P.: Long-wave optical properties of water clouds and rain, Tellus, 50A, 1-11, 1998.

Savijärvi, H., Arola, A., and Räisänen, P.: Short-wave optical properties of precipitating water clouds, Q. J. Roy. Meteor. Soc., 123, 883-899, doi:10.1002/qj.49712354005, 1997.

Sestini, M. F., Reimer, E. S., Valeriano, D. M., Alvalá, R. C. S., Mello, E. M. K., Chan, C. S., and Nobre, C. A.: Mapa de cobertura da terra da Amazônia legal para uso em modelos meteorológicos, in: Anais do Simpósio Brasileiro de Sensoriamento Remoto, 11, Belo Horizonte, 2901-2906, 2003 (in Portuguese).

Skamarock, W. C.: Positive-definite and monotonic limiters for unrestricted-time-step transport schemes, Mon. Weather Rev., 134, 2241-2250, 2006.

Skamarock, W. C. and Klemp, J. B.: A time-split nonhydrostatic atmospheric model for weather research and forecasting applications, J. Comput. Phys., 227, 3465-3485, doi:10.1016/j.jcp.2007.01.037, 2008.

Skamarock, W. C., Klemp, J. B., Duda, M. G., Fowler, L. D., Park, S. H., and Ringler, T. D.: A multi-scale non-hydrostatic atmospheric model using centroidal Voronoi tesselations and C-grid staggering, Mon. Weather Rev., 240, 3090-3105, 2012.

Slingo, J. M.: The development and verifcation of a cloud prediction scheme for the ECMWF model, Q. J. Roy. Meteor. Soc., 113, 899-927, 1987.

Smagorinsky, J.: General circulation experiments with the primitive equations, Mon. Weather Rev., 91, 99-164, doi:10.1175/15200493(1963)091<0099:GCEWTP>2.3.CO,2, 1963.

Souto, R. P., Silva Dias, P. L., and Vigilant, F.: Parallel Performance Analysis of a Regional Numerical Weather Prediction Model in a Petascale Machine, in: High Performance Computing, Communications in Computer and Information Science, 565, 146-150, 2015.

Souza, E. P.: Theoretical and numerical study of the relationship between convection and heterogeneous surfaces in the Amazon region, 121 pp., PhD Dissertation - University of São Paulo, São Paulo, 1999 (in Portuguese).

Stockwell, W. R., Kirchner, F., and Kuhn, M.: A new mechanism for regional chemistry modeling, J. Geophys. Res., 102, 25847 25879, 1997.

Stuefer, M., Freitas, S. R., Grell, G., Webley, P., Peckham, S., McKeen, S. A., and Egan, S. D.: Inclusion of ash and $\mathrm{SO}_{2}$ emissions from volcanic eruptions in WRF-Chem: development and some applications, Geosci. Model Dev., 6, 457-468, doi:10.5194/gmd6-457-2013, 2013.

Stull, R. B.: An introduction to boundary layer meteorology, Kluwer Academic Publishers, Dordrecht, Netherlands, 1988. 
Sun, Z. and Shine, K. P.: Studies of the radiative properties of ice and mixed-phase clouds, Q. J. Roy. Meteor. Soc., 120, 111-137, doi:10.1002/qj.49712051508, 1994.

Thompson, G. and Eidhammer, T.: A study of aerosol impacts on clouds and precipitation development in a large winter cyclone, J. Atmos. Sci., 71, 3636-3658, doi:10.1175/JAS-D-13-0305, 2014.

Thompson, G., Field, P. R., Rasmussen, R. M., and Hall, W. D.: Explicit forecasts of winter precipitation using an improved bulk microphysics scheme. Part II: Implementation of a new snow parameterization, Mon. Weather Rev., 136, 5095-5115, doi:10.1175/2008MWR2387.1, 2008.

Tie, X., Madronich, S., Walters, S., Zhang, R., Rasch, P., and Collins, W.: Effects of clouds on photolysis and oxydants in the troposphere, J. Geophys. Res., 108, 1-25, 2003.

Toon, O. B., McKay, C. P., Ackerman, T. P., and Santhanam, K.: Rapid Calculation of Radiative Heating Rates and Photodissociation Rates in Inhomogeneous Multiple Scattering Atmospheres, J. Geophys. Res., 94, 16287-16301, doi:10.1029/JD094iD13p16287, 1989.

Tremback, C., Powell, J., Cotton, W., and Pielke, R.: The forwardin-time upstream advection scheme: Extension to higher orders, Mon. Weather Rev., 115, 540-555, 1987.

Tremback, C. J.: Numerical simulation of a mesoscale convective complex: model development and numerical results. Ph.D. dissertation, Atmos. Sci. Paper No. 465, Department of Atmospheric Science, Colorado State University, Fort Collins, CO 80523, 247 pp., 1990.

Tripoli, G. J. and Cotton, W. R.: The Colorado State University three-dimensional cloud/mesoscale model. Part I: General theoretical framework and sensitivity experiments, J. Rech. Atmos., 16, 185-220, 1982.

Twomey, S.: Pollution and the planetary albedo, Atmos. Environ., 8, 1251-1256, doi:10.1016/0004-6981(74)90004-3, 1974.

Vogel, B., Vogel, H., Bäumer, D., Bangert, M., Lundgren, K., Rinke, R., and Stanelle, T.: The comprehensive model system COSMOART - Radiative impact of aerosol on the state of the atmosphere on the regional scale, Atmos. Chem. Phys., 9, 8661-8680, doi:10.5194/acp-9-8661-2009, 2009.

Vogelezang, D. and Holtslag, A.: Evaluation and model impacts of alternative boundary-layer height formulations, Bound.-Lay. Meteorol., 81, 245-269, doi:10.1007/BF02430331, 1996.

Walcek, C. J.: Minor flux adjustment near mixing ratio extremes for simplified yet highly accurate monotonic calculation of tracer advection, J. Geophys. Res., 105, 9335-9348, doi:10.1029/1999JD901142, 2000.

Walko, R. L., Cotton, W. R., Harrington, J. L., and Meyers, M. P.: New RAMS cloud microphysics parameterization. Part I: The single-moment scheme, Atmos. Res., 38, 29-62, 1995a.
Walko, R. L., Tremback, C. J., Pielke, R. A., and Cotton, W. R.: An interactive nesting algorithm for stretched grids and variable nesting ratios, J. Appl. Meteor., 34, 994-999, 1995b.

Walko, R., Band, L., Baron, J., Kittel, F., Lammers, R., Lee, T., Ojima, D., Pielke, R., Taylor, C., Tague, C., Tremback, C., and Vidale, P.: Coupled atmosphere-biophysics- hydrology models for environmental modeling, J. Appl. Meteorol., 39, 931-944, 2000.

Wicker, L. J. and Skamarock, W. C.: A time-splitting scheme for the elastic equations incorporating second-order Runge-Kutta time differencing, Mon. Weather Rev., 126, 1992-1999, 1998.

Wicker, L. J.: A two-step Adams-Bashforth-Moulton split-explicit integrator for compressible atmospheric models, Mon. Weather Rev., 137, 3588-3595, 2009.

Wicker, L. J. and Skamarock, W. C.: Time-splitting methods for elastic models using forward time schemes, Mon. Weather Rev., 130, 2088-2097, 2002.

Wild, O., Zhu, X., and Prather, M. J.: Fast-J: accurate simulation of in and below cloud photolysis in tropospheric chemical models, J. Atmos. Chem., 37, 245-282, 2000.

Wilde, N. P., Stull, R. B., and Eloranta, E. W.: The LCL zone and cumulus onset, J. Clim. Appl. Meteor., 24, 640-657, 1985.

Williams, P. D.: A proposed modification to the Robert-Asselin time filter, Mon. Weather Rev., 137, 2538-2546, 2009.

Wyser, K. and Yang, P.: Average ice crystal size and bulk singlescattering properties of cirrus clouds, Atmos. Res., 49, 315-335, 1989.

Xiang, B., Miller, S. M., Kort, E. A., Santoni, G. W., Daube, B. C., Commane, R., Angevine, W. M., Ryerson, T. B., Trainer, M. K., Andrews, A. E., Nehrkorn, T., Tian, H., and Wofsy, S. C.: Nitrous oxide $\left(\mathrm{N}_{2} \mathrm{O}\right)$ emissions from California based on 2010 CalNex airborne measurements, J. Geophys. Res.-Atmos., 118, 2809-2820, doi:10.1002/jgrd.50189, 2013.

Xu, K.-M. and Krueger, S. K.: Evaluation of cloudiness parameterizations using a cumulus ensemble model, Mon. Weather Rev., 119, 342-367, 1991.

Xu, K.-M. and Randall, D.A.: A semiempirical cloudiness parameterization for use in climate models, J. Atmos. Sci., 53, 3084 3102, 1996.

Yang, X.-S.: Nature-Inspired Metaheuristic Algorithms, Luviner Press, 2008.

Yarwood, G., Rao, S., Yocke, M., and Whitten, G. Z.: Updates to the Carbon Bond chemical mechanism: CB05, Final Report to the US EPA, RT-0400675, Novato, CA, available at: http://www. camx.com/publ/pdfs/cb05_final_report_120805.pdf (last access: 10 January 2017), 2005. 